\title{
Collections d'échantillons biologiques autochtones et cryopolitique de la vie congelée
}

Emma Kowal et Joanna Radin

\section{(2) OpenEdition}

Édition électronique

URL : http://journals.openedition.org/actesbranly/660

ISSN : $2105-2735$

Éditeur

Musée du quai Branly Jacques Chirac

Référence électronique

Emma Kowal et Joanna Radin, «Collections d'échantillons biologiques autochtones et cryopolitique de la vie congelée », Les actes de colloques du musée du quai Branly Jacques Chirac [En ligne], 6 | 2016, mis en ligne le 20 janvier 2016, consulté le 08 septembre 2020. URL : http://journals.openedition.org/ actesbranly/660

Ce document a été généré automatiquement le 8 septembre 2020

(c) Tous droits réservés 


\title{
Collections d'échantillons biologiques autochtones et cryopolitique de la vie congelée
}

\author{
Emma Kowal et Joanna Radin
}

\section{Introduction}

Le ronronnement des réfrigérateurs et congélateurs est une sonorité habituelle dans les laboratoires scientifiques du monde entier. Tout laboratoire contient d'ordinaire bon nombre d'appareils de refroidissement: des chambres froides maintenues à quatre degrés Celsius, des chambres de congélation à moins vingt degrés, des réfrigérateurs de laboratoire permettant de garder à portée de main les échantillons en décongélation, et des congélateurs à azote liquide pouvant aller jusqu'à $-196^{\circ}$ et nécessitant le port d'équipements de protection. Ces variations de température permettent de ralentir le processus vital des substances biologiques et de prévenir leur décomposition. Des échantillons de sang, de salive, de tissus chirurgicalement excisés, de placenta, et de bien d'autres composants d'organismes humains et non-humains sont aujourd'hui recueillis et congelés pour permettre aux scientifiques de les analyser dans un futur dont l'horizon est sans cesse repoussé. L'existence de ces échantillons biologiques se situe entre celle de l'être vivant et celle de l'artefact ; leur statut d'éléments vivants est à la fois renforcé et amoindri par leur présence à l'état d'artefacts dans un congélateur.

Cette présentation examine les questions que soulève la pratique de la congélation scientifique en considérant le cas d'échantillons congelés qui, de plus en plus souvent, font l'objet de controverses: des échantillons recueillis auprès de populations qui se désignent elles-mêmes, ou sont désignées, comme autochtones, aborigènes ou indigènes. Nous nous intéressons à des échantillons de sang recueillis, en Australie, auprès de communautés aborigènes et insulaires du détroit de Torres $^{1}$ et, plus précisément, à une collection d'échantillons récoltés dans les années 1960, et actuellement conservés dans plusieurs chambres de congélation de l'une des plus 
grandes universités australiennes. Le vif intérêt que ces échantillons biologiques suscitent auprès d'acteurs très différents les uns des autres rend intensément visible l'ambigüité de leur statut, entre vie et artefact. L'étude de ce cas nous permet d'illustrer deux formes différentes de "cryopolitique», perspective théorique que nous proposons pour analyser les variations concernant le statut de la vie congelée.

3 En 1949, la technique permettant de congeler des cellules sans qu'elles ne soient endommagées lors de leur décongélation fut mise au point quand il fut découvert que l'ajout de glycérol prévenait la survenue de dégâts irréversibles sur les cellules (Parry 2004 ; Landecker 2005 ; 2007 ; Radin 2013). Dans les années 1960, de nouveaux procédés (des congélateurs de laboratoire mécaniques et des techniques de congélation en chambres froides mobiles utilisant de la neige carbonique) permirent de récolter des échantillons de sang dans des lieux reculés. Les chercheurs partirent alors recueillir des échantillons à travers le monde, les transportant vers les laboratoires pour les analyser ou les stocker en vue d'analyses futures. En biologie humaine, l'International Biological Program (IBP) permit de consolider les efforts globaux de collecte en assurant leur coordination internationale de 1964 à 1974 (Radin 2012).

4 Les chercheurs de l'IBP souhaitaient que l'étude de l'être humain soit envisagée sous l'angle de la biosphère, tâche jugée urgente face aux bouleversements en marche (Worthington 1975). Les scientifiques étaient particulièrement intéressés par des "sociétés simples vivant encore dans des conditions 'naturelles' difficiles ». Certains groupes, que l'on qualifie aujourd'hui d'«autochtones", "pourraient illustrer la capacité d'adaptation de l'homme lorsqu'il dépend très fortement de son capital biologique » (Collins et Weiner 1977). Ces scientifiques croyaient que les populations aborigènes d'Australie, entre autres groupes autochtones, cesseraient sous peu de vivre comme des chasseurs-cueilleurs "traditionnels ", ne laissant à la science que peu de temps pour recueillir des données biologiques et génétiques d'importance capitale, qui pourraient contribuer à résoudre certains problèmes de santé, présents et futurs, auxquels toutes les populations humaines se confrontent (Radin 2013). Les chercheurs impliqués dans les projets de sauvetage de l'IBP voulaient assurer la préservation de ce savoir biologique, et du matériau corporel dont il dérivait, avant qu'il ne soit trop tard.

5 L'Australie participa à l'IBP avec deux études basées sur des populations autochtones, menées par Robert (Bob) Louis Kirk, un biologiste anglais qui s'installa en Australie dans les années 1950. Il recueillit des échantillons de sang auprès d'un certain nombre de communautés autochtones réparties dans le nord de l'Australie, dans le but de cartographier les variations régionales dans les protéines plasmatiques, espérant ainsi recueillir des informations sur l'histoire des migrations humaines dans la longue durée. Mais, après le départ à la retraite de Kirk en 1987, et au cours de la décennie suivante, certains scientifiques se mirent à craindre que l'usage de ces échantillons, pour des finalités génomiques notamment, ne soulève des problèmes éthiques. Le directeur de l'institut concerné prit en fin de compte la décision de mettre un terme à l'utilisation scientifique de la collection : c'est à cette dernière période que nous nous intéressons ici. Nous étudions par ailleurs, dans nos travaux de recherches actuels, les réactions des acteurs autochtones lorsqu'ils sont informés de l'existence de la collection et consultés sur son devenir².

6 Nous nous appuyons dans cette présentation sur des entretiens réalisés auprès de scientifiques et de techniciens de laboratoire australiens pour illustrer brièvement le 
cadre de réflexion cryopolitique que nous serons amenées à élargir dans nos travaux ultérieurs.

7 On peut mettre en relation la fermeture de la collection de Bob Kirk avec le contexte plus étendu des transformations intervenues dans l'éthique de la recherche scientifique, en réponse notamment aux critiques autochtones. À partir des années 1980 , les critiques autochtones de la recherche « occidentale » ont en effet commencé à se faire entendre dans le monde entier, menaçant la continuité, dans les années 1990, des projets scientifiques impliquant l'usage de parties de corps humains autochtones (Smith 2012). Ces critiques se déployèrent parallèlement aux efforts émergents pour demander le rapatriement des restes humains autochtones conservés à travers le monde dans des musées et instituts de recherche (Fforde, Hubert et al. 2002; Kakaliouras 2012). Les revendications autochtones faisaient valoir le fait que les restes humains (ou " ancestraux ») devaient être appréhendés comme un patrimoine culturel et que leurs propriétaires légitimes, les communautés ou les familles concernées, avaient elles-mêmes pour responsabilité de les inhumer convenablement ${ }^{3}$.

8 Dans les années 1990, les scientifiques travaillant sur la collection de Kirk commencèrent à craindre que les échantillons de sang congelé en leur possession ne fassent également l'objet de demandes de rapatriement. Ces craintes se sont depuis concrétisées : au cours des dix dernières années, des groupes autochtones du continent américain se sont appuyés sur le modèle du rapatriement de restes humains pour demander que leur soient retournés des échantillons de sang originellement recueillis pour servir à la recherche scientifique ${ }^{4}$.

9 Des échantillons de sang collectés dans les années 1960 et 1970 et conservés en divers laboratoires des États-Unis firent ainsi l'objet de revendications de la part des Yanomami sur des bases culturelles, dans le contexte d'une violente controverse sur les pratiques des chercheurs concernés, que certains voyaient comme contraires à l'éthique (Tierney 2001 ; American Anthropological Association 2002; Borofsky 2005). Les Yanomami et leurs partisans soulignèrent que le maintien des échantillons de sang dans une chambre froide aux États-Unis empêchait leurs donneurs décédés de parvenir à quitter complètement le monde. Comme le magazine Science le rapporta, les Yanomami demandaient que les échantillons leur soient remis; les Chamans et les Anciens procèderaient alors à leur destruction rituelle pour s'assurer que la séparation entre le monde des vivants et celui des morts s'opère (Couzin-Frankel 2010). Les principes spirituels des Yanomami sont bien plus complexes et hétérogènes que ne le laisse entrevoir leur description dans les médias internationaux, mais cette brève évocation permet néanmoins de penser que pour eux, l'imbrication de la vie et de l'artefact (Coupaye 2016; Pitrou 2016) constituée par les échantillons de sang congelé crée un état liminal, entre la vie et la mort.

\section{Cryopolitique}

10 De nombreux experts en cryopolitique, dans des domaines allant de la bioéthique et du droit à la philosophie et l'histoire en passant par l'anthropologie et la sociologie, ont cherché à déterminer les problèmes soulevés par le fait de maintenir à travers le temps des échantillons corporels congelés, qu'il s'agisse d'échantillons de sangs autochtones ou de gamètes et d'embryons cosmopolites. Parmi les questions les plus épineuses que posent les cryotechnologies (dont les questions éthiques de propriété, de bienfait, de 
justice, et de statut de la personne), il y a celle de la vie elle-même. Quel est le statut de tissus vivants, jadis à l'intérieur d'un corps et pouvant être ramenés à la vie, au moins in vitro?

Les travaux d'Hannah Landecker jouent sur ce point un rôle fondateur. Elle met en avant l'idée que la technologie somme toute banale du congélateur a le pouvoir de rendre le matériau biologique mobile à travers l'espace et le temps. Cette mobilité est fondatrice de la science biologique moderne, rendant possibles, entre autres, les technologies de reproduction assistée, la science des cellules souches ou le clonage. La capacité d'arrêter et de faire repartir le temps, de conserver et ranimer des cellules à volonté, a transformé la définition même du biologique. "Être biologique, vivant, cellulaire ", signifie à présent pouvoir être "suspendu dans le temps, interrompu, conservé et congelé en morceaux » (Landecker 2005).

Arrêtons-nous un instant sur la manière dont se mêlent les concepts de "biologique ", de "vivant" et de "cellulaire» dans la formule de Landecker. Depuis que les techniques de culture cellulaire ont été développées, les cellules qui se métabolisent, croissent et se reproduisent sous forme de culture sont communément considérées comme de la matière vivante. Bien que Landecker utilise "matière vivante " et "matière biologique » de façon interchangeable, la catégorie de "matière biologique humaine » est plus étendue que celle de cellules vivantes. Par exemple, à la catégorie "matière biologique" pourraient correspondre des tissus ne comportant pas de cellules (comme le plasma) ou n'étant pas vivants (comme des sections de tissus sur lames).

Sur un plan pratique, la distinction entre des cellules vivantes (ou des cellules congelées pouvant être ramenées à la vie) et de la matière biologique qui, à aucun moment, n'est considérée comme vivante est importante. Le fait d'étendre l'appellation « vivant » à de la matière biologique qui ne peut se métaboliser, croître et se reproduire pourrait donner à penser qu'il est possible, en décongelant des échantillons de sang congelé, de produire des cellules vivantes, ou même de cloner un organisme à partir de l'ADN des échantillons. Par mesure de clarté, précisons que la collection d'échantillons à laquelle nous nous intéressons dans cette présentation ne fut pas recueillie dans l'intention de produire des cultures de cellules immortelles, et qu'elle ne pourrait à ce jour être utilisée à ces fins.

14 Ceci met en lumière les divergences de vues possibles entre les sciences et les sciences sociales. Les scientifiques lisant par exemple la formule de Rose selon laquelle la vie a été «molécularisée » à partir des années 1930 (Rose 2001 : 13), pourraient en conclure que les tenants des sciences sociales qui s'intéressent aux sciences de la vie font un usage très élargi du terme "vie ». Si les cellules vivantes sont faites de molécules, les molécules elles-mêmes peuvent difficilement être individuellement conçues comme vivantes.

Mais, partant d'une autre perspective, les chercheurs en sciences sociales soutiennent précisément l'idée que, depuis le développement des biotechnologies au $\mathrm{XX}^{\mathrm{e}}$ siècle, les définitions du vivant ont fluctué (Waldby et Squier 2003; Fischer 2003; Franklin et Lock 2003 ; Helmreich 2011). Le terme de « vie » lui-même est mis entre guillemets par beaucoup de chercheurs en sciences sociales (et de scientifiques), et ses limites définitionnelles sont considérées comme un objet d'étude plutôt que comme un fait scientifique dépourvu d'ambiguïté. Les historiens ont ainsi observé, par exemple, que la notion de vie comme code génétique (et plus largement comme information) avait 
progressé dans les champs de la science, des sciences sociales et de la culture populaire au cours du XXe siècle (Fox Keller 2000 ; Kay 2000 ; Nelkin et Lindee 2004). L'ADN est sous cet angle envisagé comme contenant l'essence de la vie, ce qui constitue en soi un exemple de "forme de vie " selon la définition de l'anthropologue Stefan Helmreich, pour qui les formes de vie (forms of life) sont des "manières de penser et d'agir culturelles, sociales, symboliques et pragmatiques qui organisent les communautés humaines » (Helmreich 2009). Les formes de vie façonnent la façon dont «la vie» est comprise et vécue, et les formes de vie comme les formes vivantes (life forms) mutent, exposées à de nouvelles technologies et de nouveaux champs du savoir scientifique (Helmreich 2011 ; Kowal, Radin et al. 2013).

Les questions que nous souhaitons soulever dans cette présentation au sujet de la « vie latente » des échantillons de sang congelé font écho aux débats des $\mathrm{XX}^{\mathrm{e}}$ et XXI $\mathrm{XIècles}^{\mathrm{e}}$ sur les limites de la vie. La vie latente, comme nous l'expliquerons, constitue une " forme de vie " plutôt qu'une forme de la vie. La congélation du sang à partir du milieu $\mathrm{du} \mathrm{XX}^{\mathrm{e}}$ siècle a fait apparaître de nouvelles formes de vie qui reconfigurèrent la biologie humaine du $\mathrm{XX}^{\mathrm{e}}$ siècle, et qui pourraient reconfigurer les communautés autochtones du XXI ${ }^{\mathrm{e}}$ siècle.

Nous souhaitons centrer notre attention sur un aspect particulier de cette forme de vie, qu'évoque l'humain suspendu, interrompu, conservé, congelé: la mise en différé perpétuel de la mort. Nous proposons le concept de «cryopolitique» comme cadre théorique pour analyser la forme de vie que créé la pratique de la congélation. Notre conception de la cryopolitique est issue de la biopolitique de Foucault sur le gouvernement des vies des individus et des populations à partir du début du XIX ${ }^{\mathrm{e}}$ siècle. Dans sa célèbre expression, Foucault faisait la distinction entre le pouvoir du Souverain qui vise à «laisser vivre et faire mourir » et le biopouvoir qui cherche à "faire vivre et laisser mourir» (Foucault 2003). Le développement au XIX ${ }^{\mathrm{e}}$ siècle de mesures de santé publique visant à améliorer la santé des populations (dont la démographie, la vaccination, la sécurité sociale) sont des stratégies biopolitiques paradigmatiques. De même, les chercheurs qui défendent l'idée que la vie s'est "molécularisée " au XXI siècle reconnaissent l'existence de nouvelles formes de "biopolitique moléculaire ", avec de nouvelles mesures visant à optimiser la santé des individus et des populations par l'identification de prédispositions et l'amélioration des formes vivantes aux niveaux cellulaire et génomique (Rose 2007).

La congélation est un outil crucial pour la biopolitique du XXI siècle, et nous proposons d'envisager la cryoconservation comme productrice d'une forme spécifique de biopolitique moléculaire. Si les assemblages biopolitiques font vivre et laissent mourir, les assemblages cryopolitiques révèlent les conséquences inattendues d'efforts ordinaires pour faire vivre et ne pas laisser mourir. Les scientifiques se sont mis à s'intéresser de près à la cryoconservation d'une variété de tissus humains et nonhumains (des gamètes, du sang, voire des organismes entiers) parce qu'elle promettait de différer perpétuellement la mort des individus, des populations ou des espèces, transformant par la même occasion la vie elle-même. L'usage du froid artificiel comme moyen de mise en différé opère comme une prothèse temporelle, telle la promesse qu'il ne sera jamais trop tard pour raviver un individu, une race, ou une espèce. Les chercheurs du XXe siècle en biologie humaine réagirent quant à eux au risque supposé de disparition des populations autochtones en congelant leurs composants génétiques, créant une forme de vie sans mort, au moins pour ce qui est des gènes. 


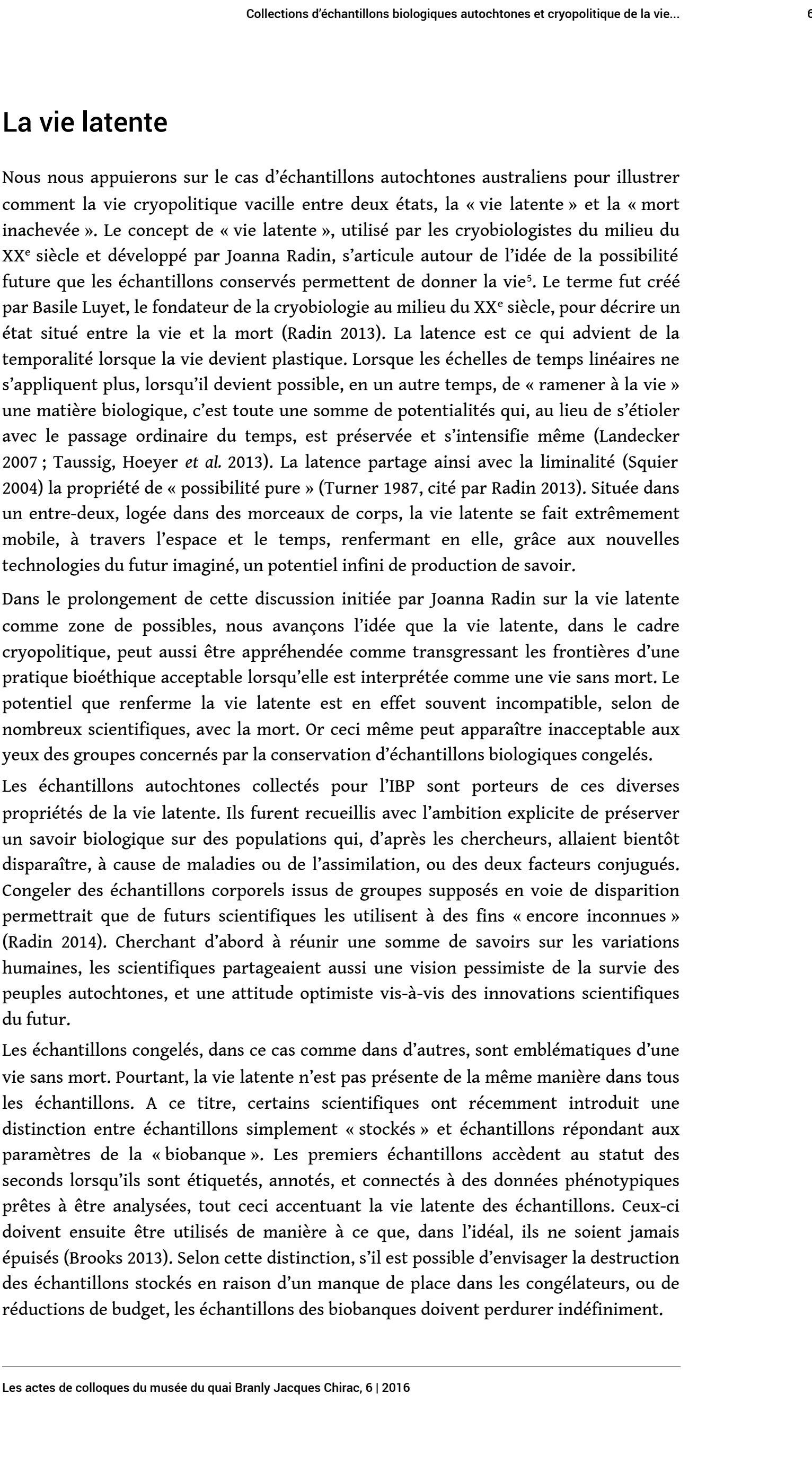

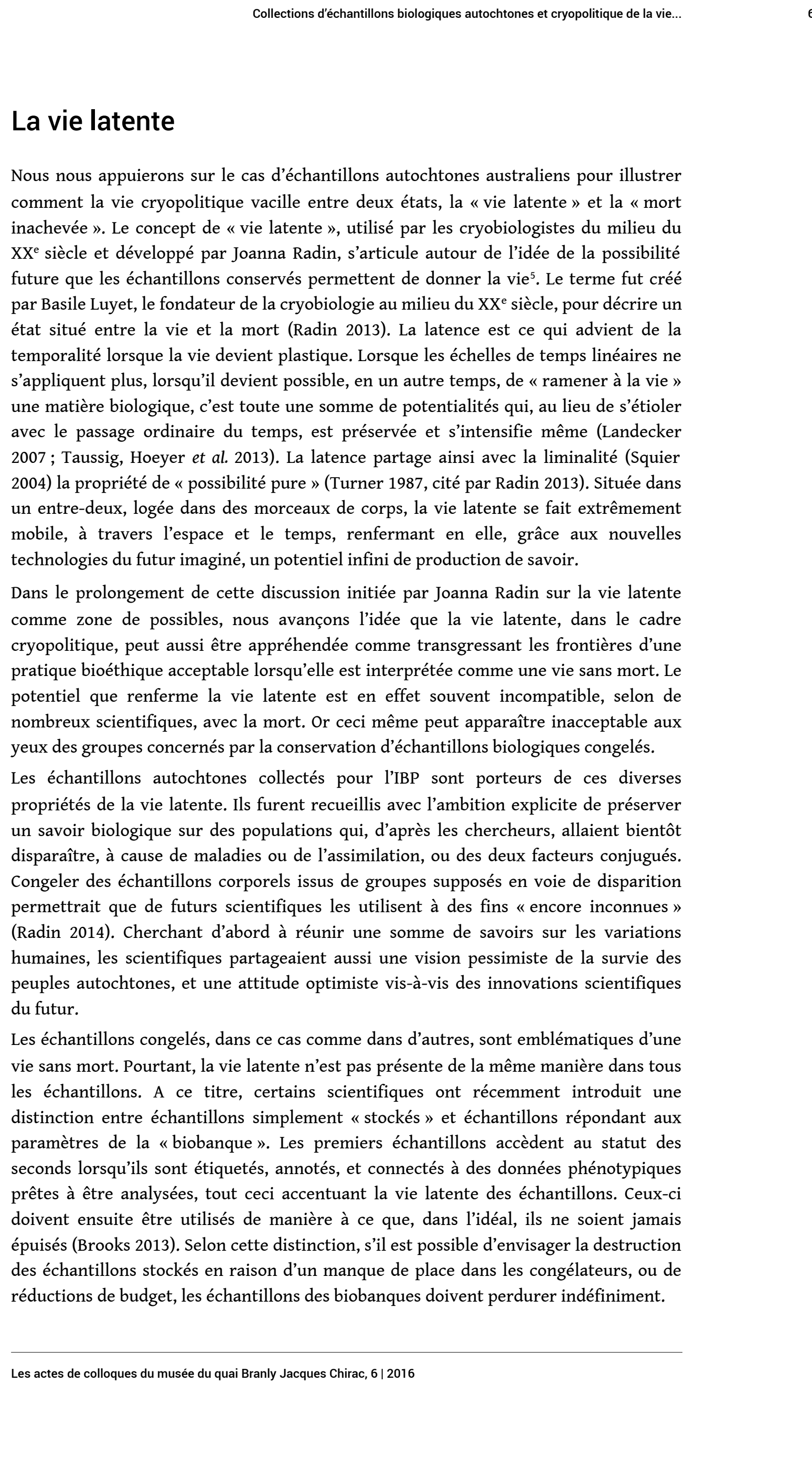

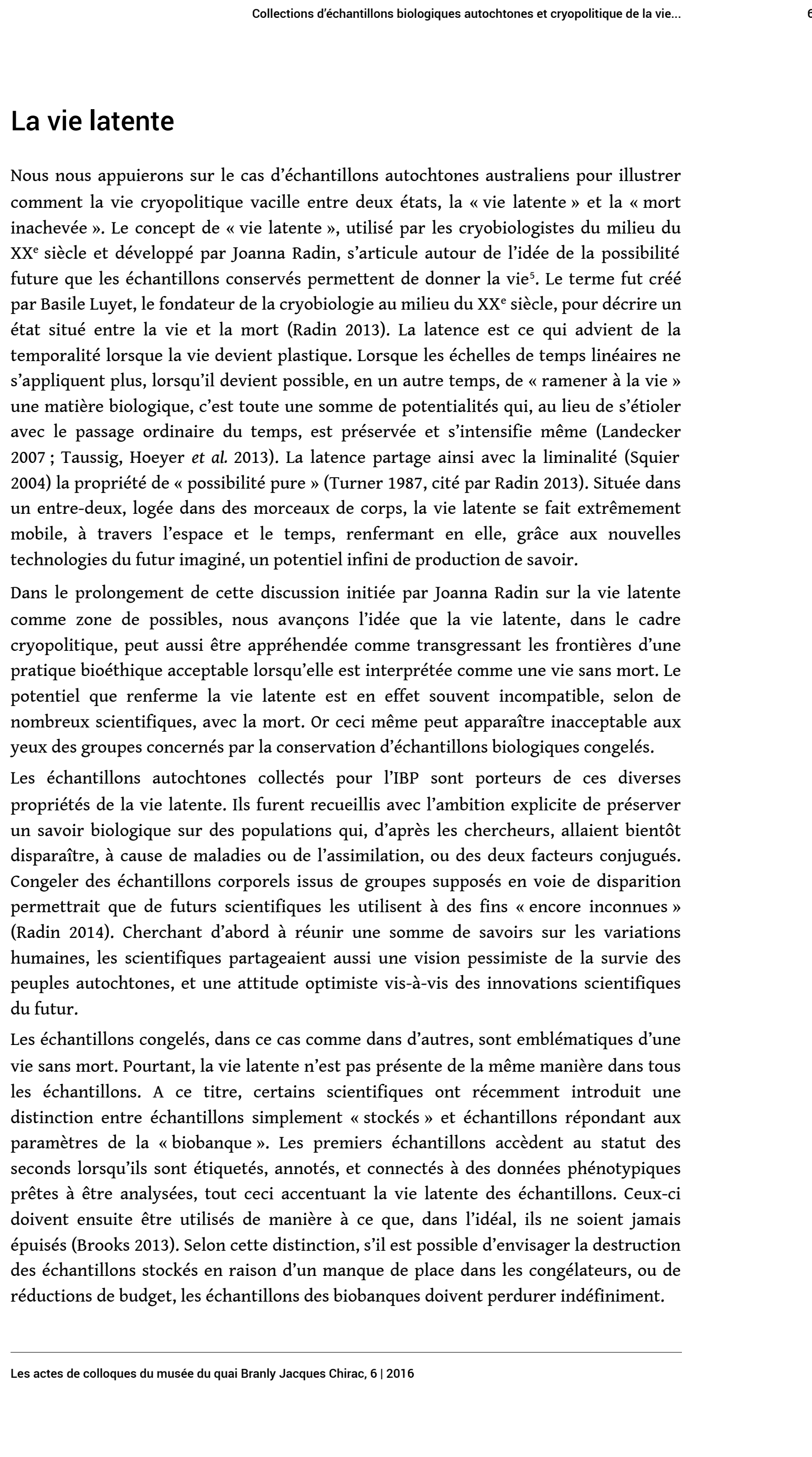

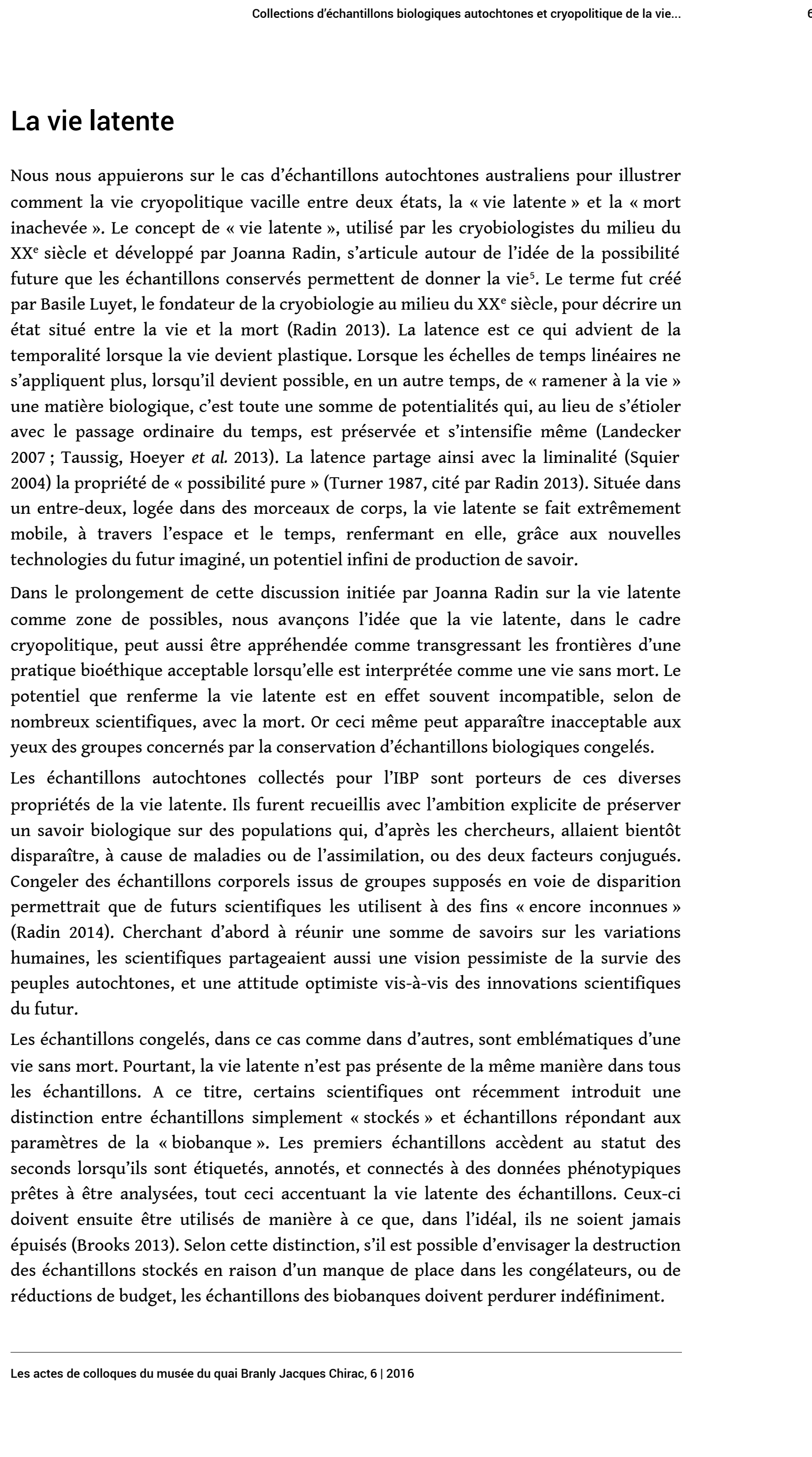

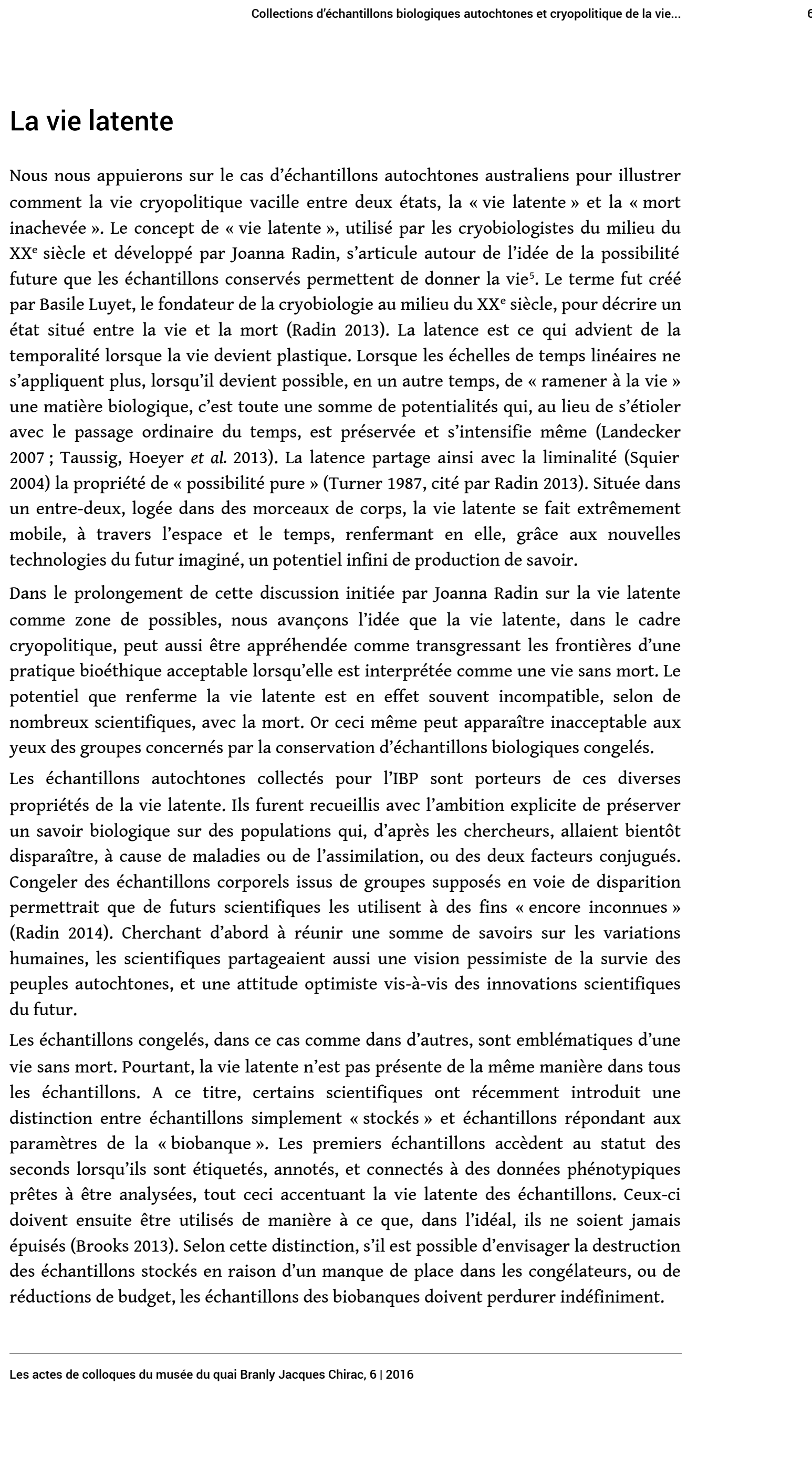

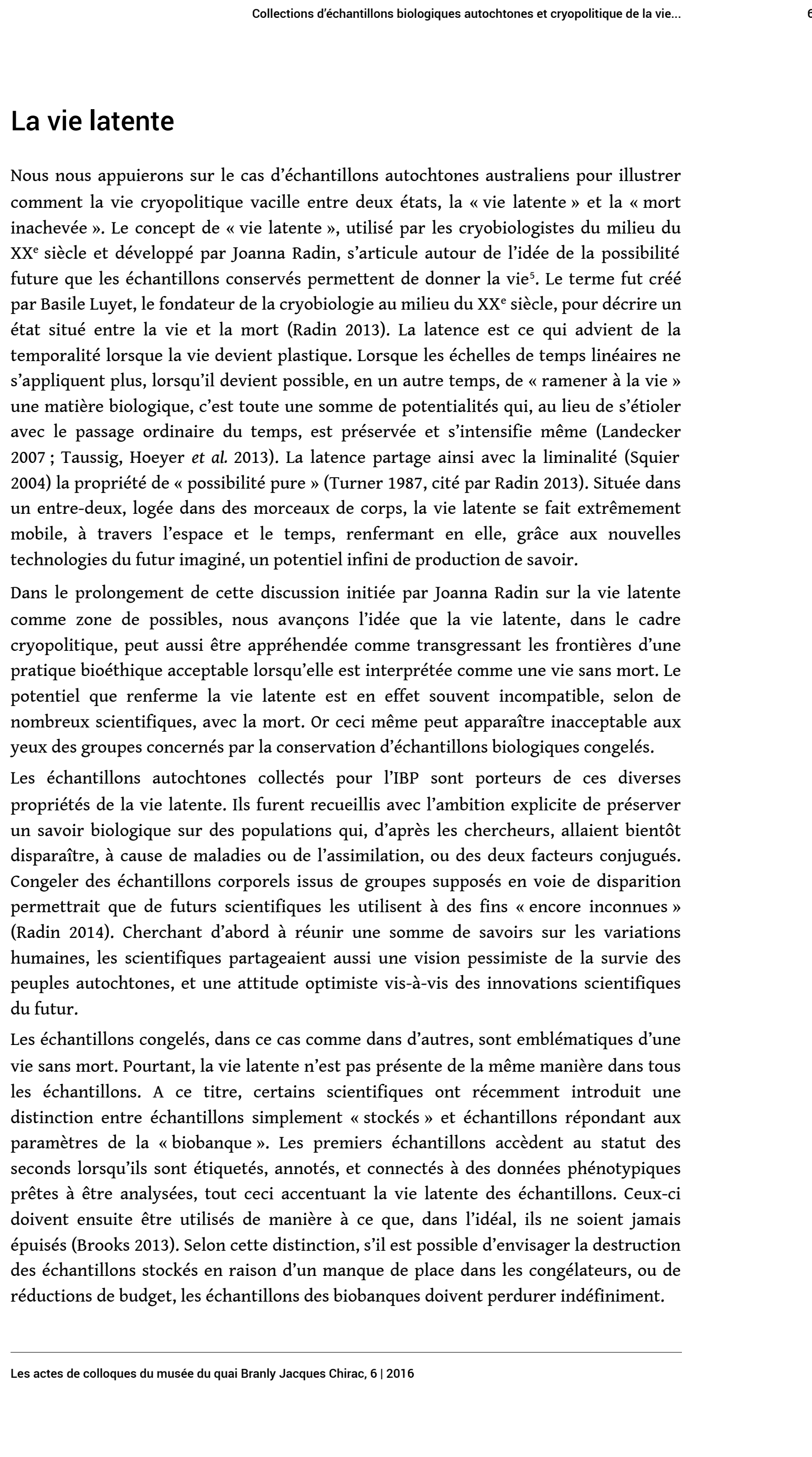

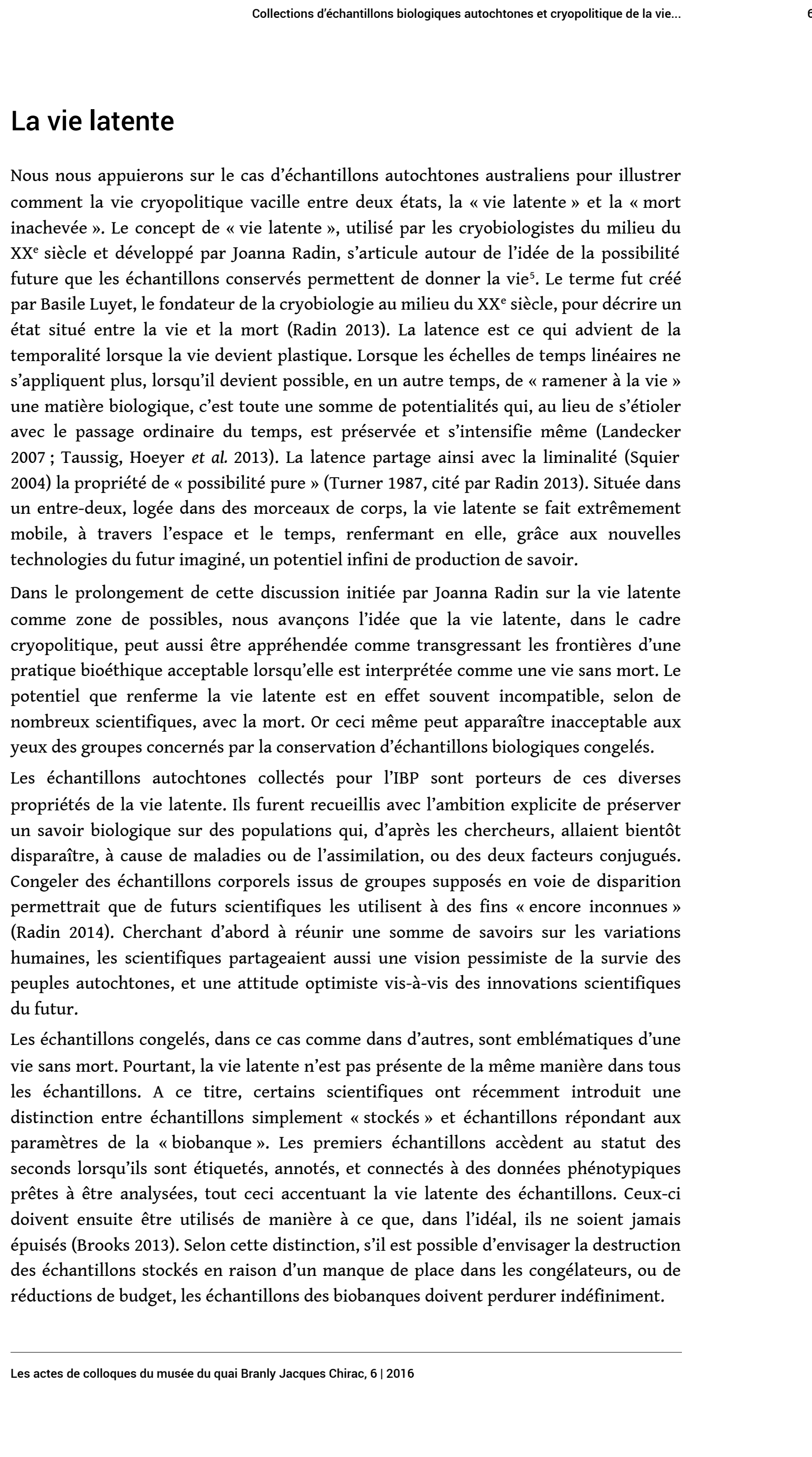

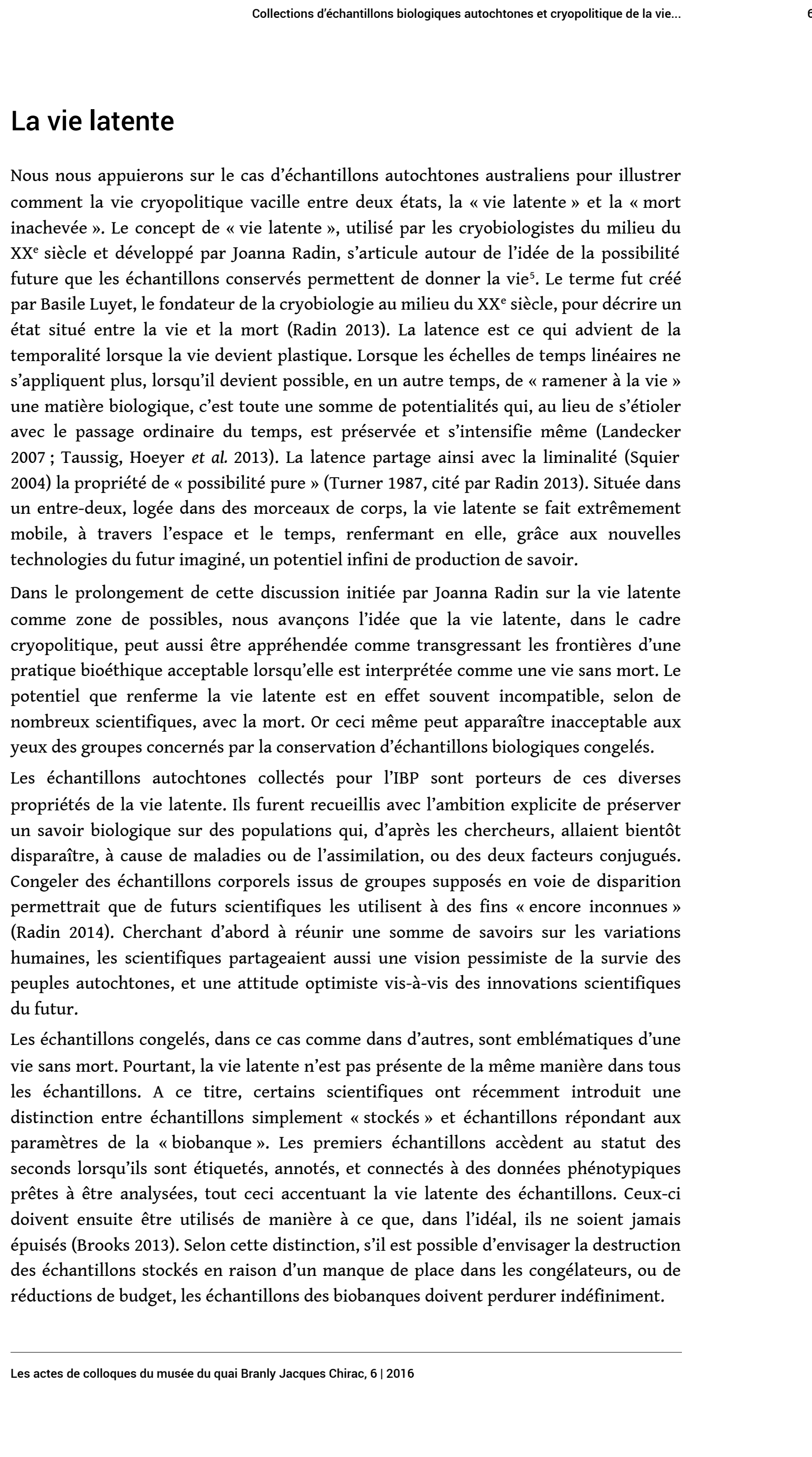

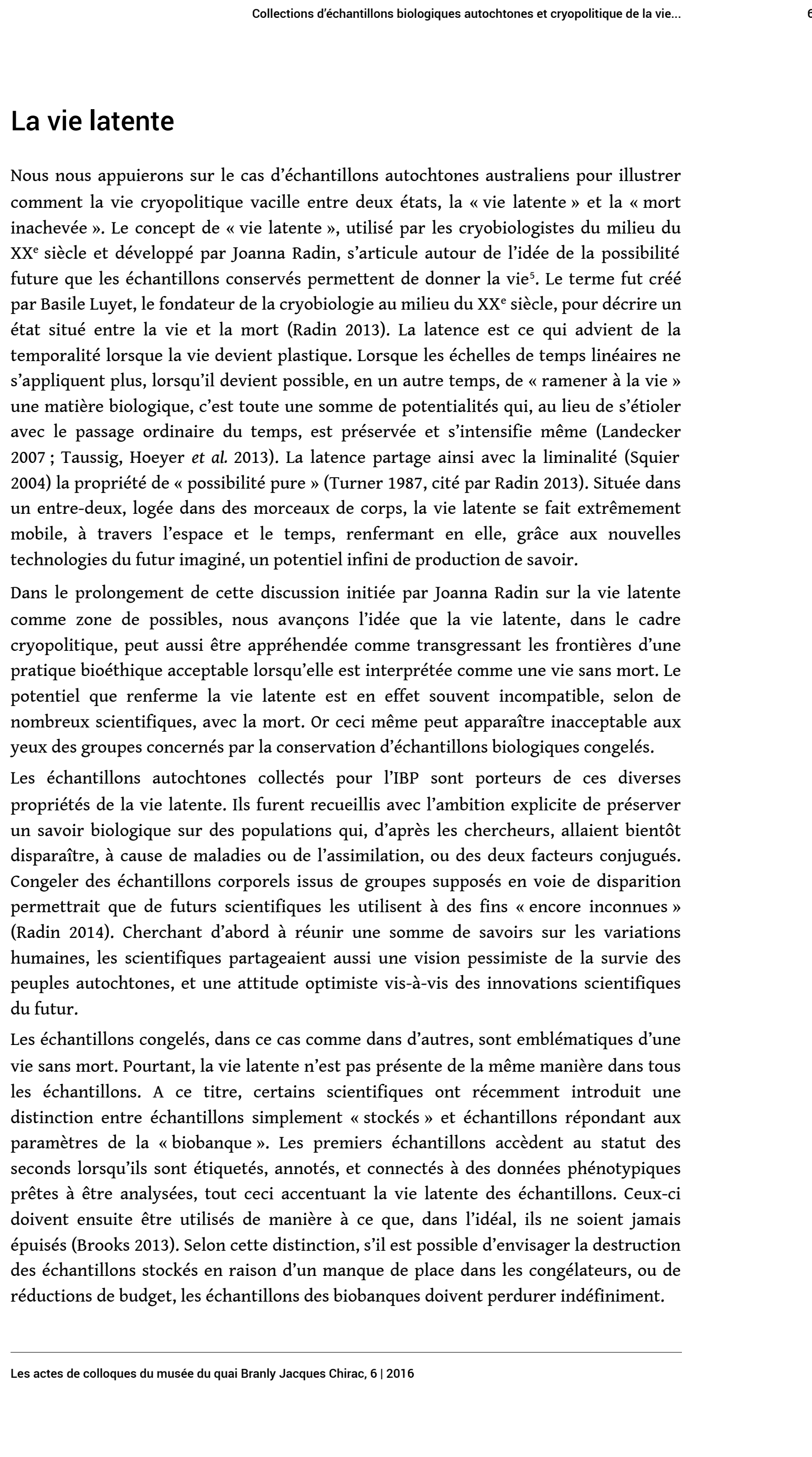

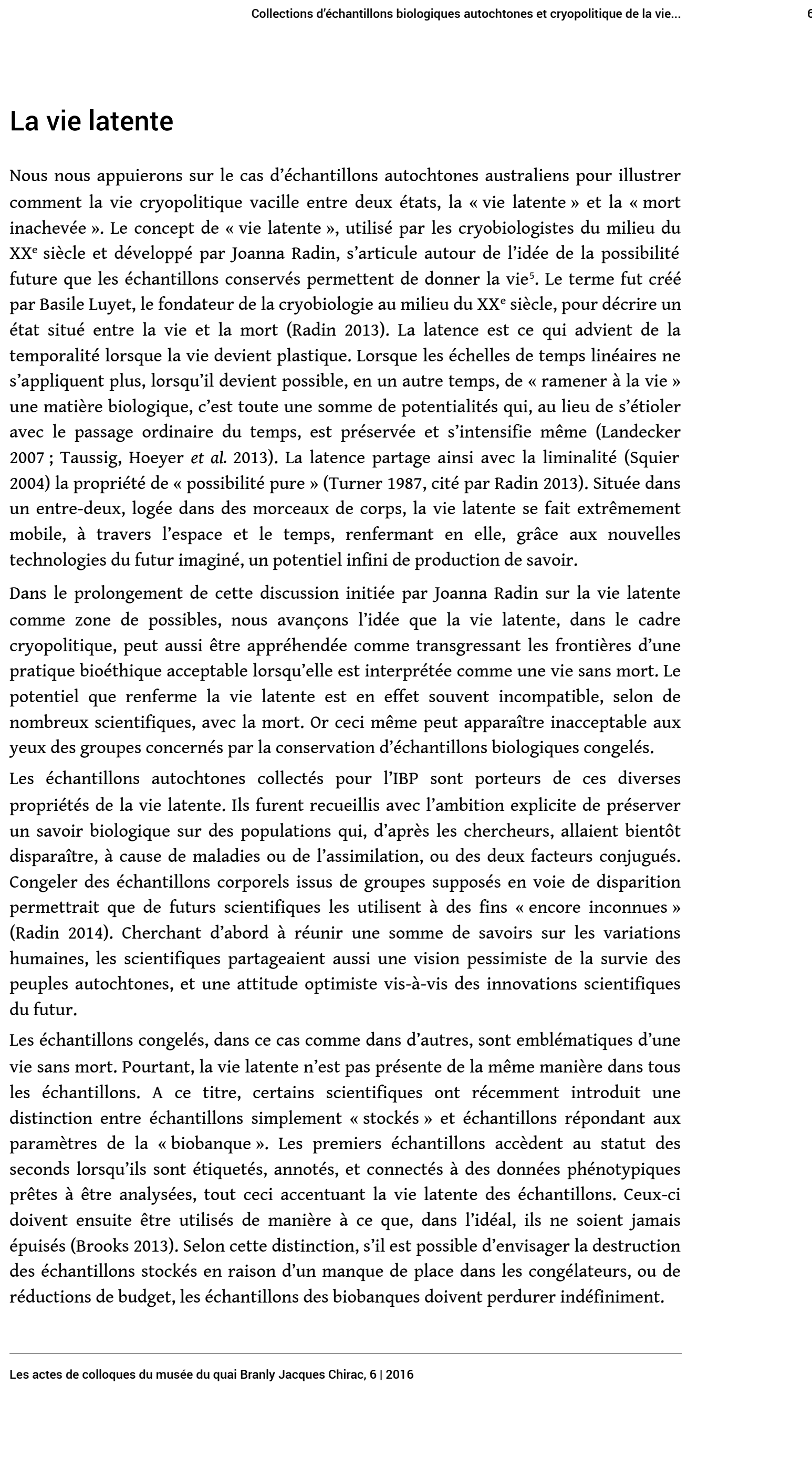

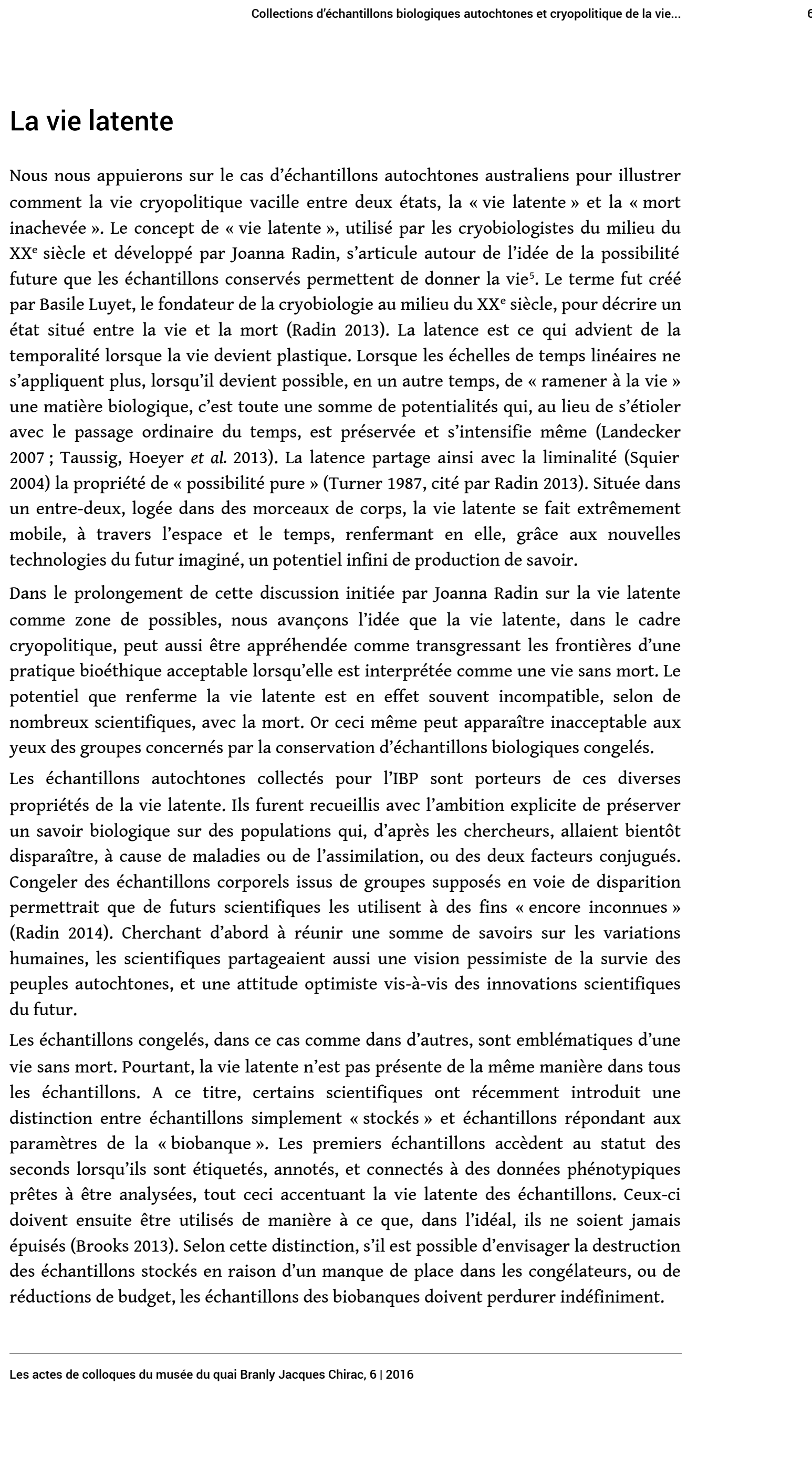

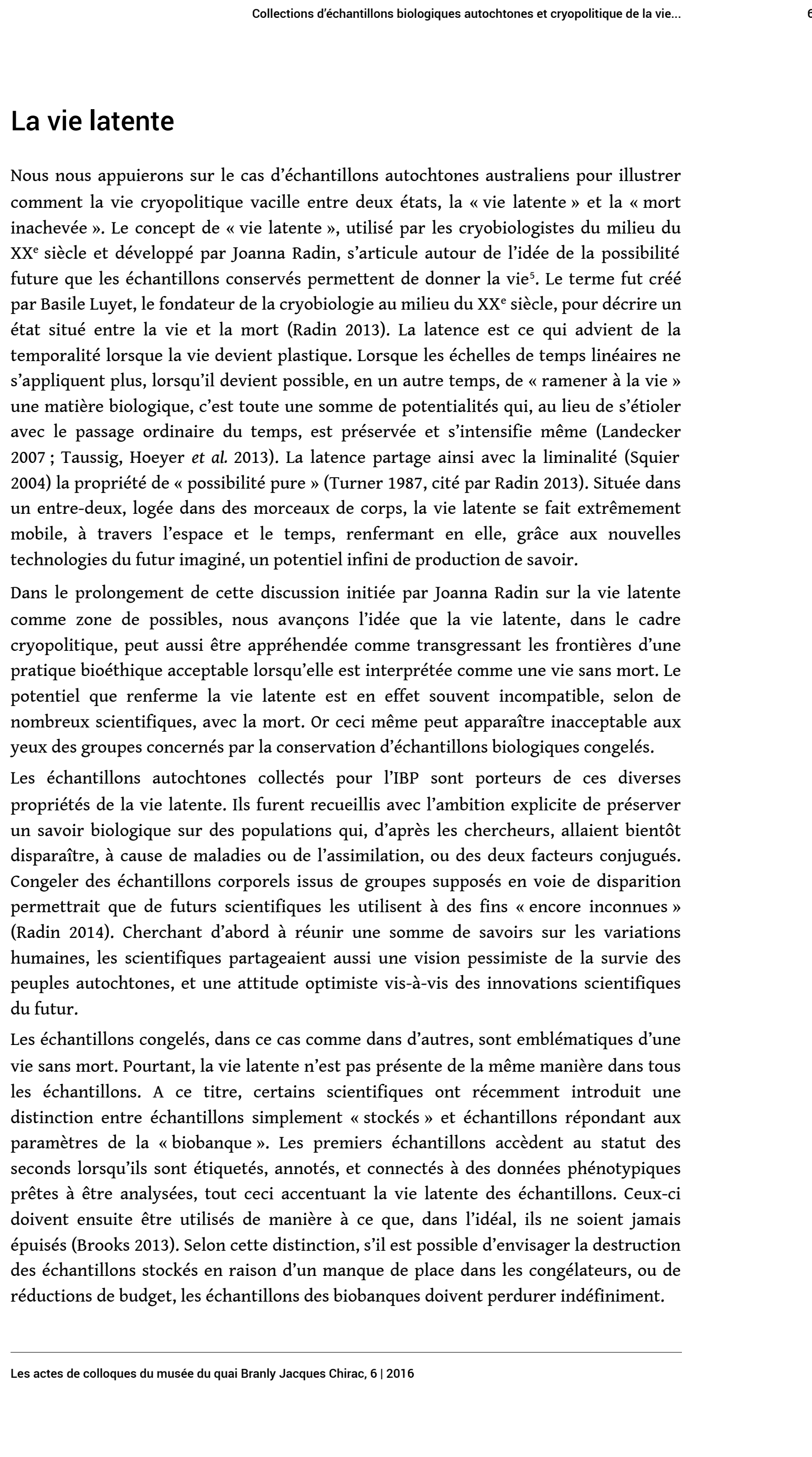

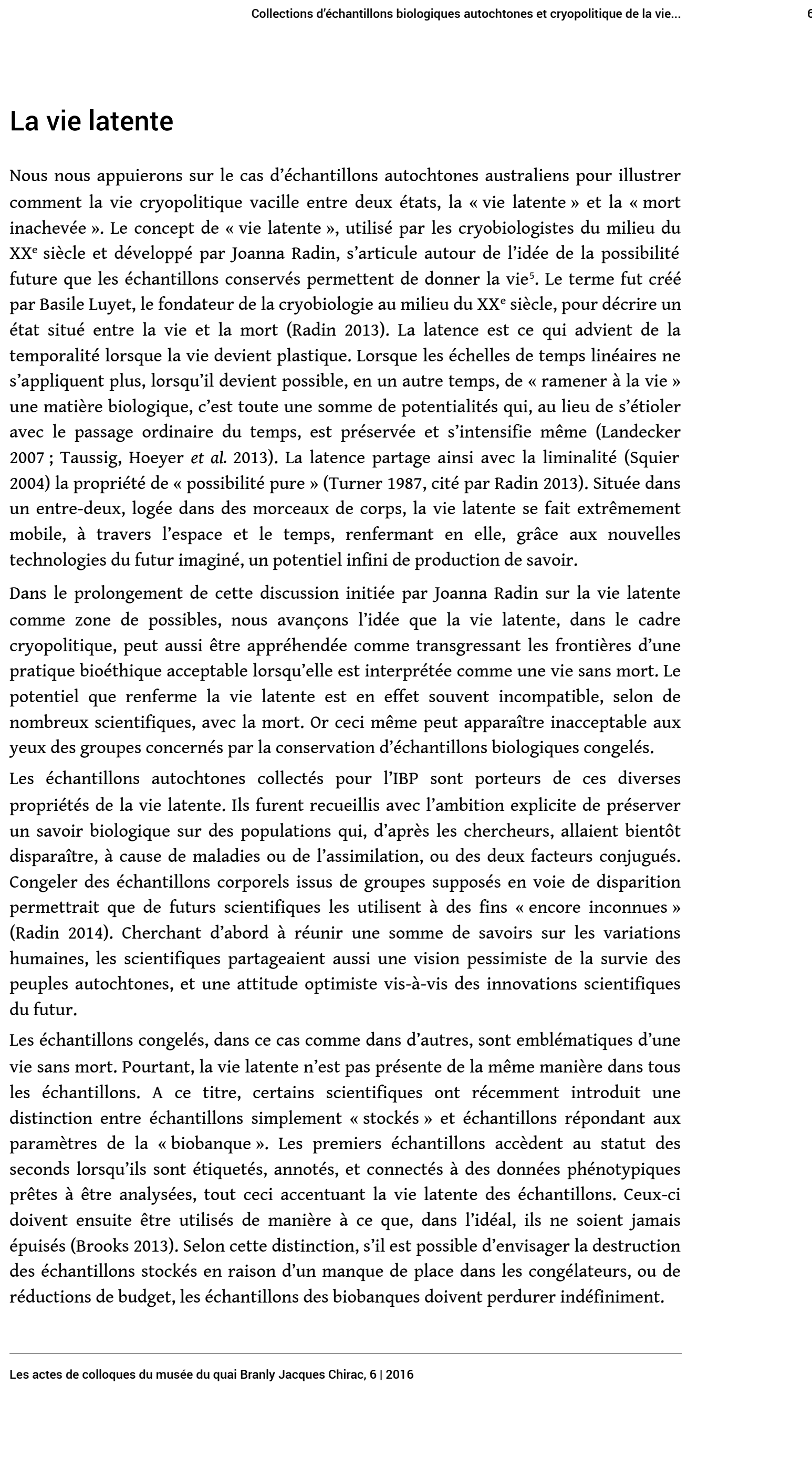

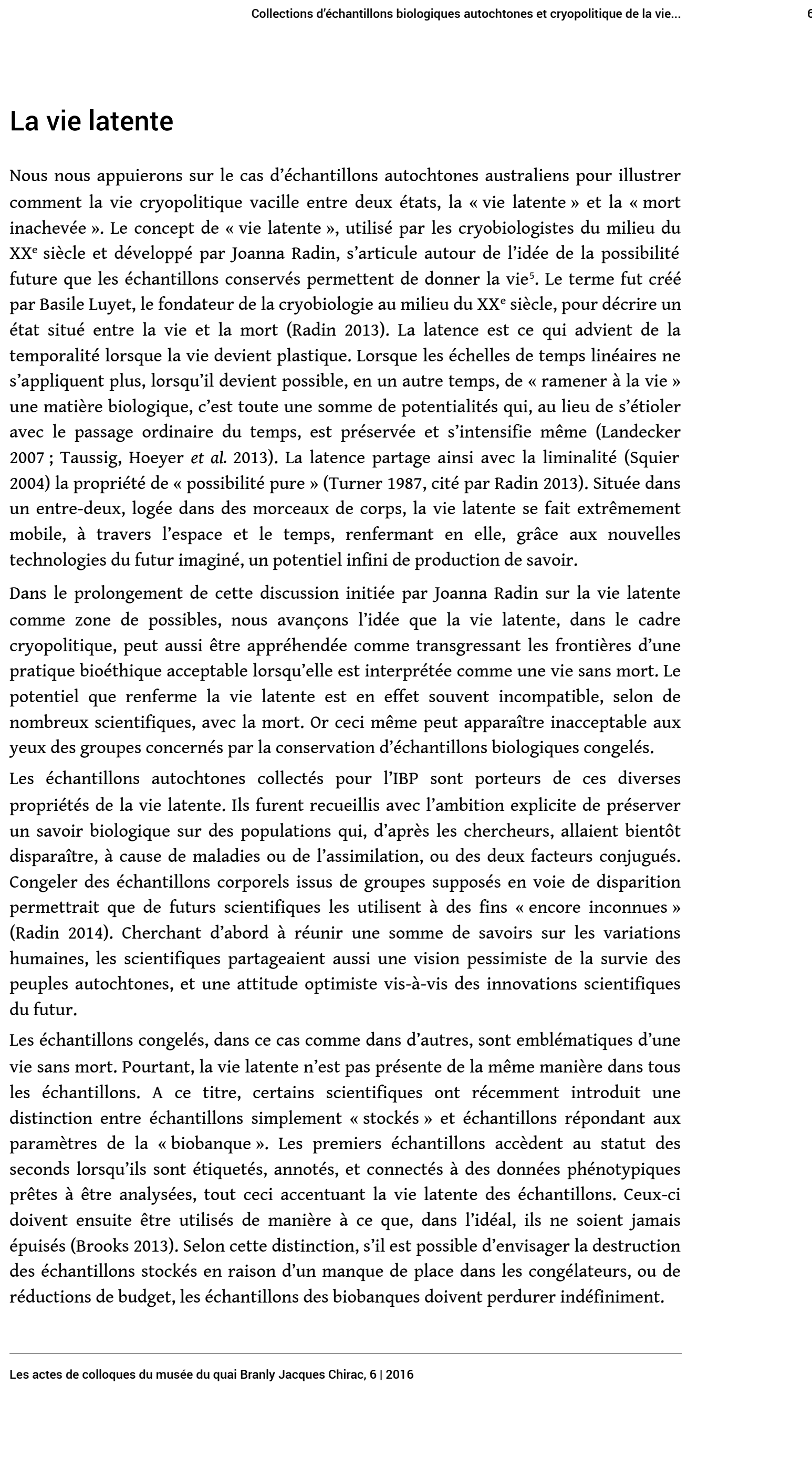

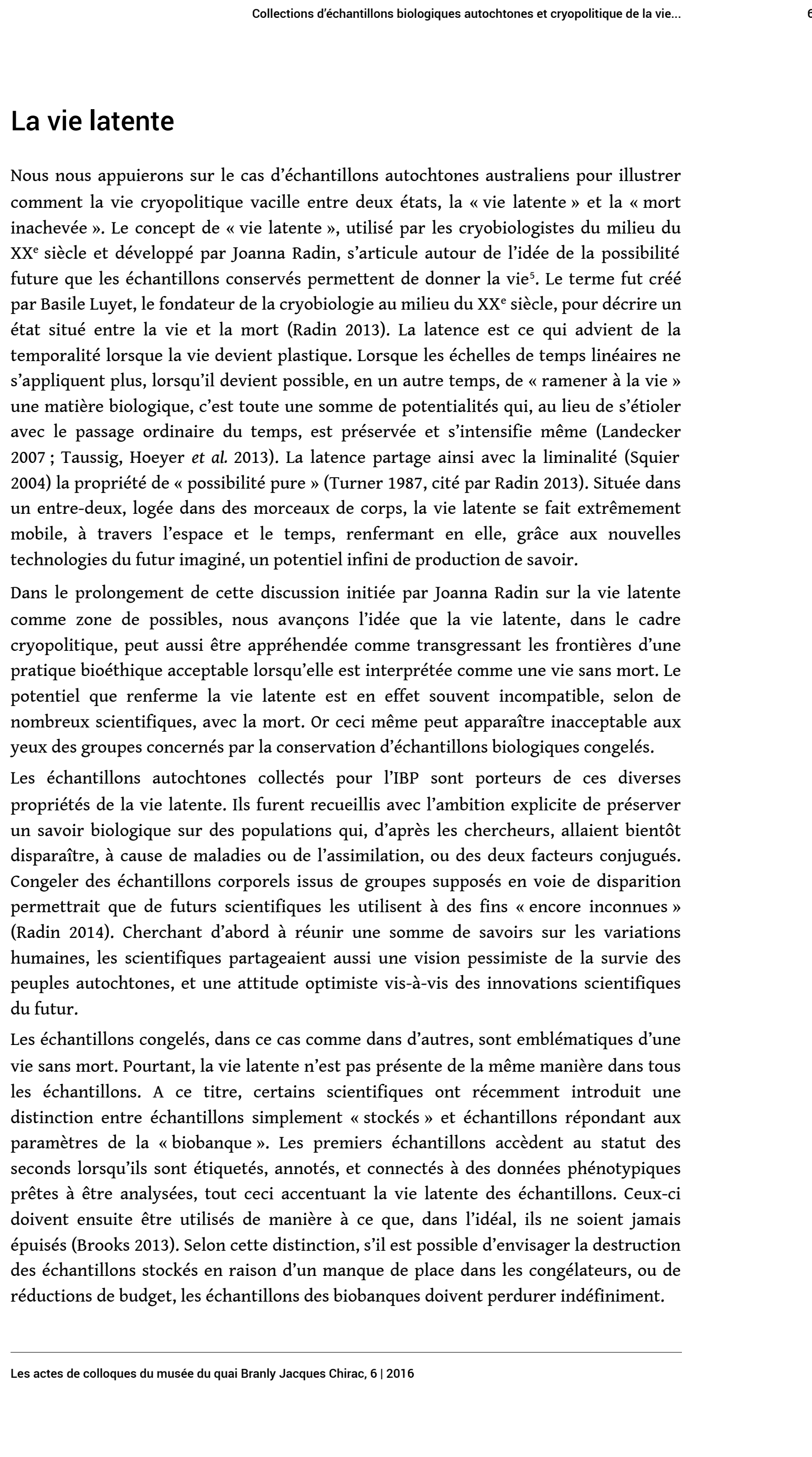

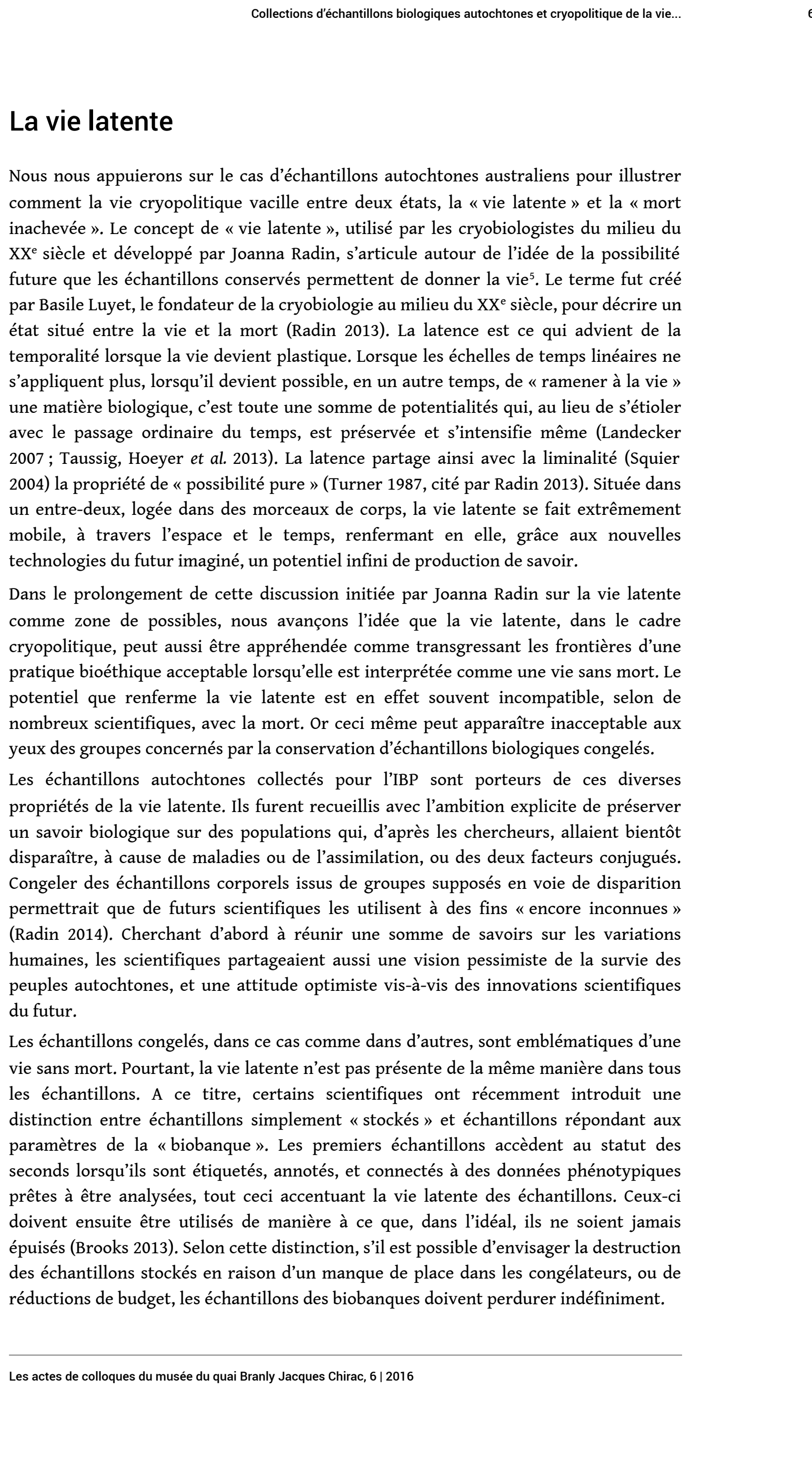

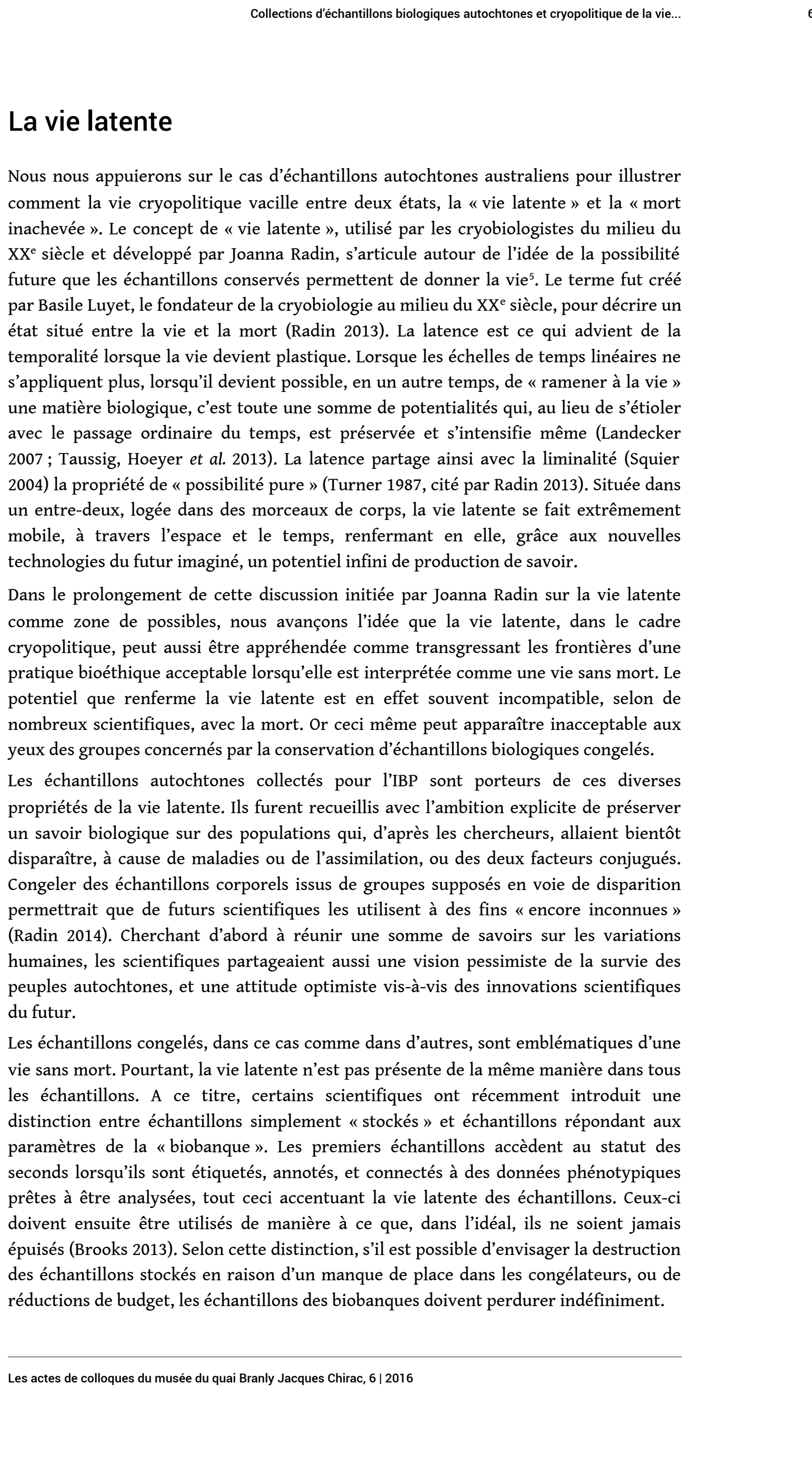

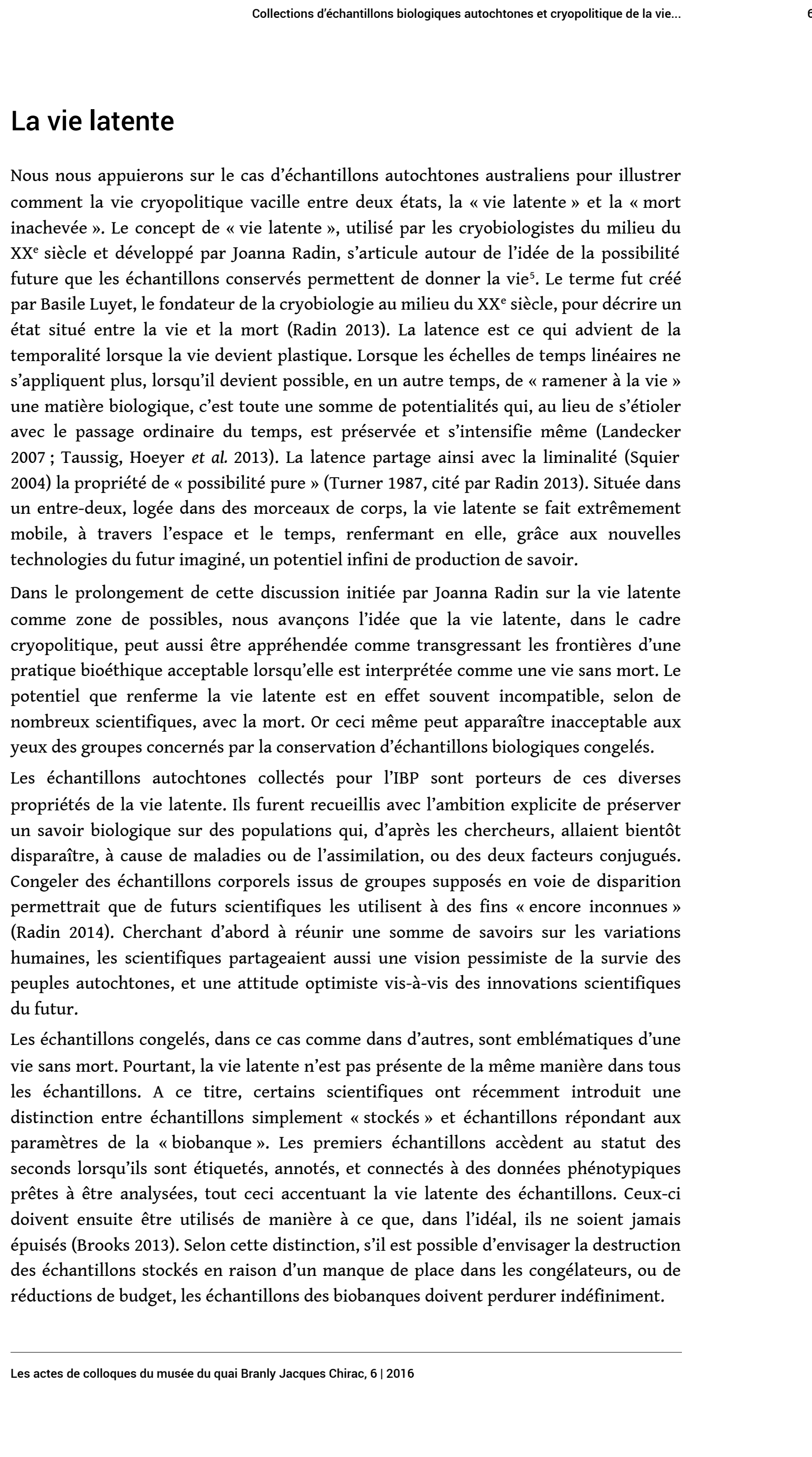

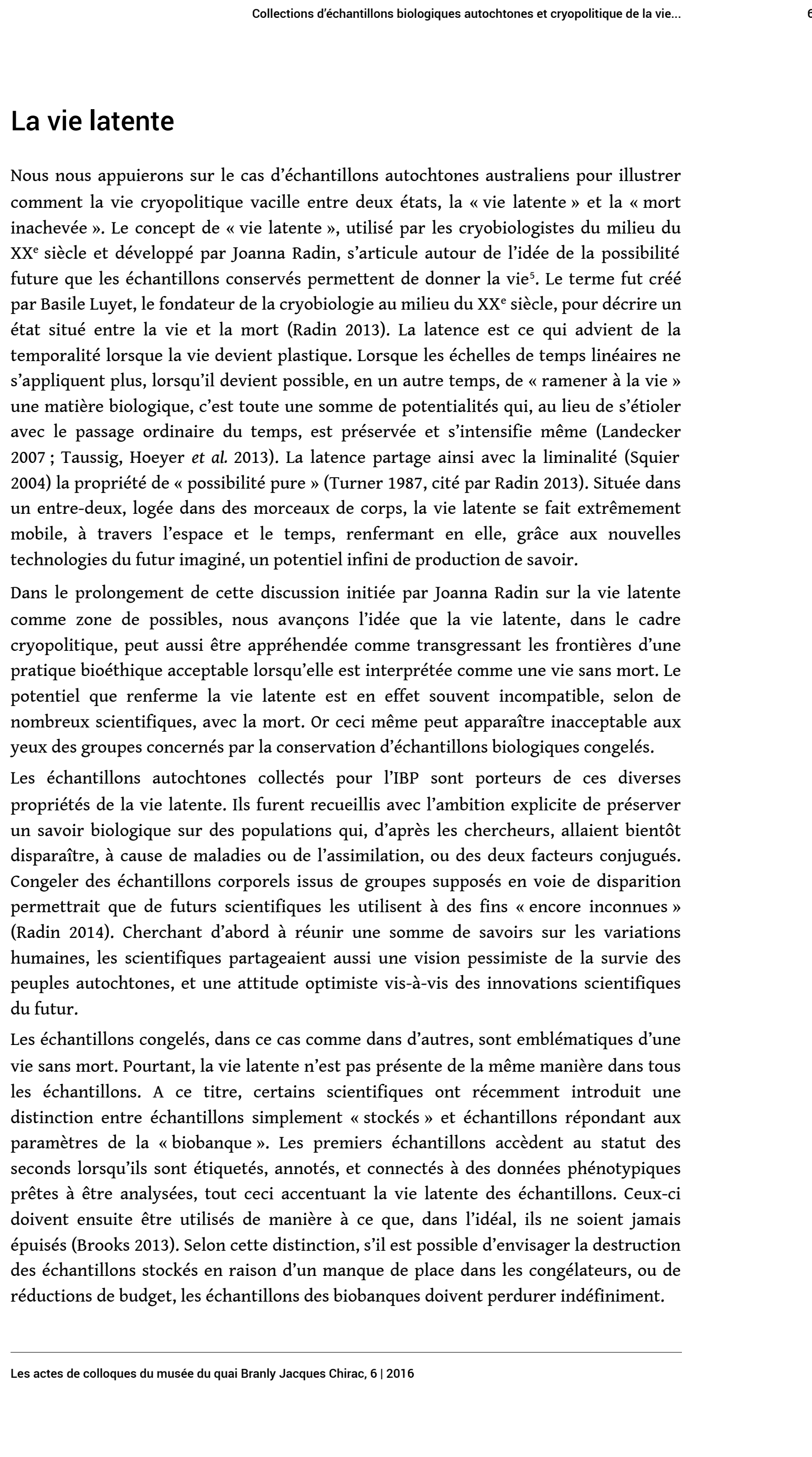

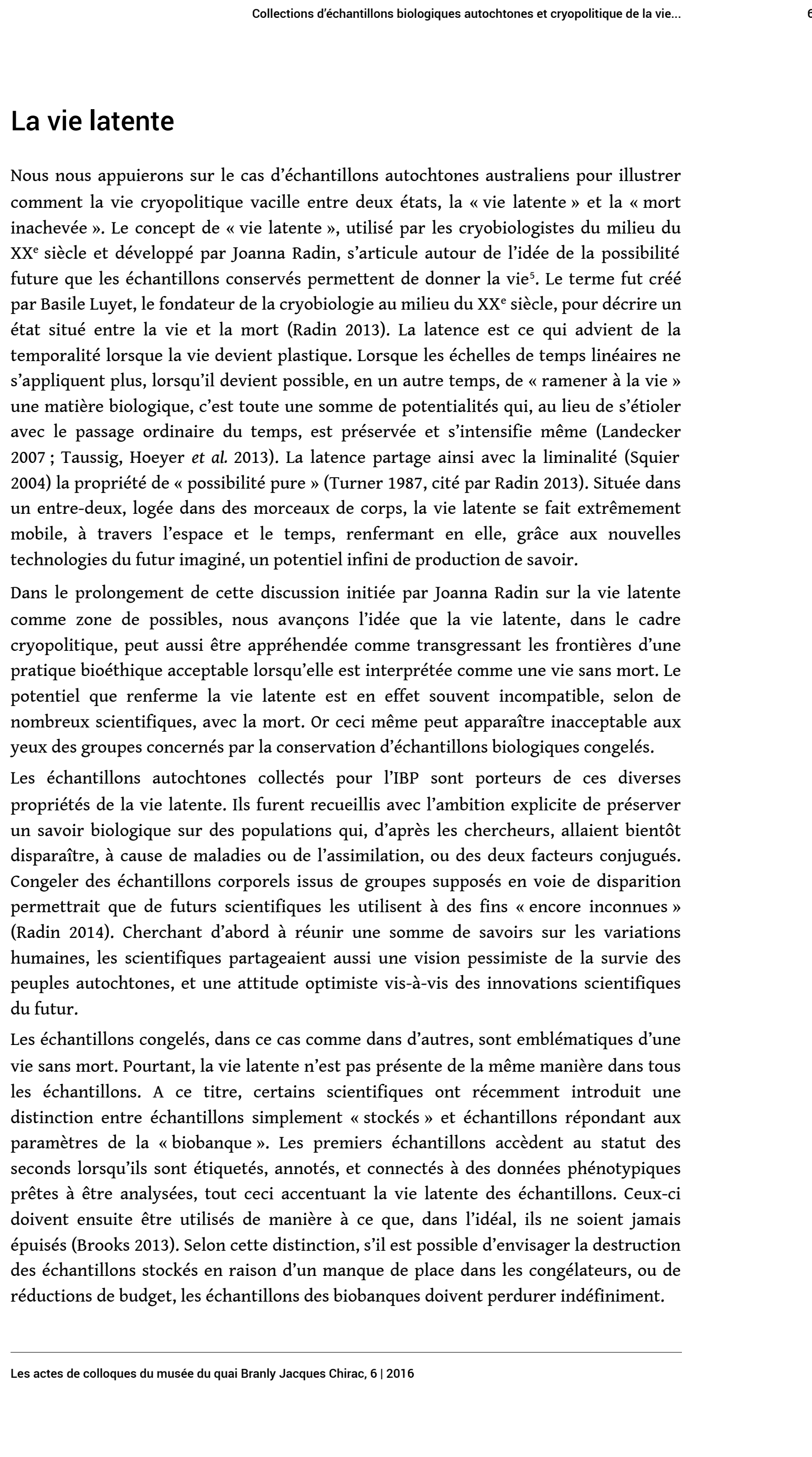

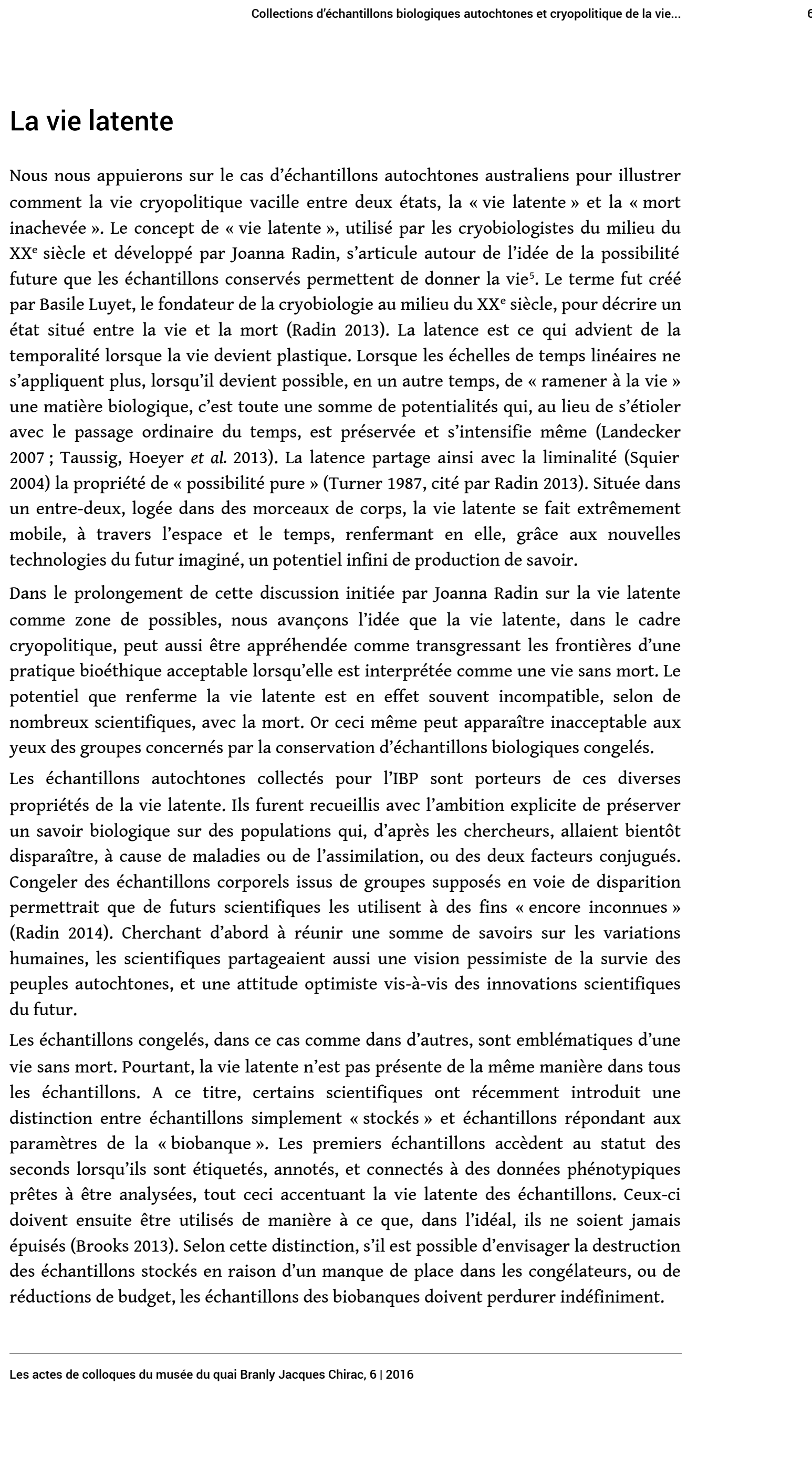

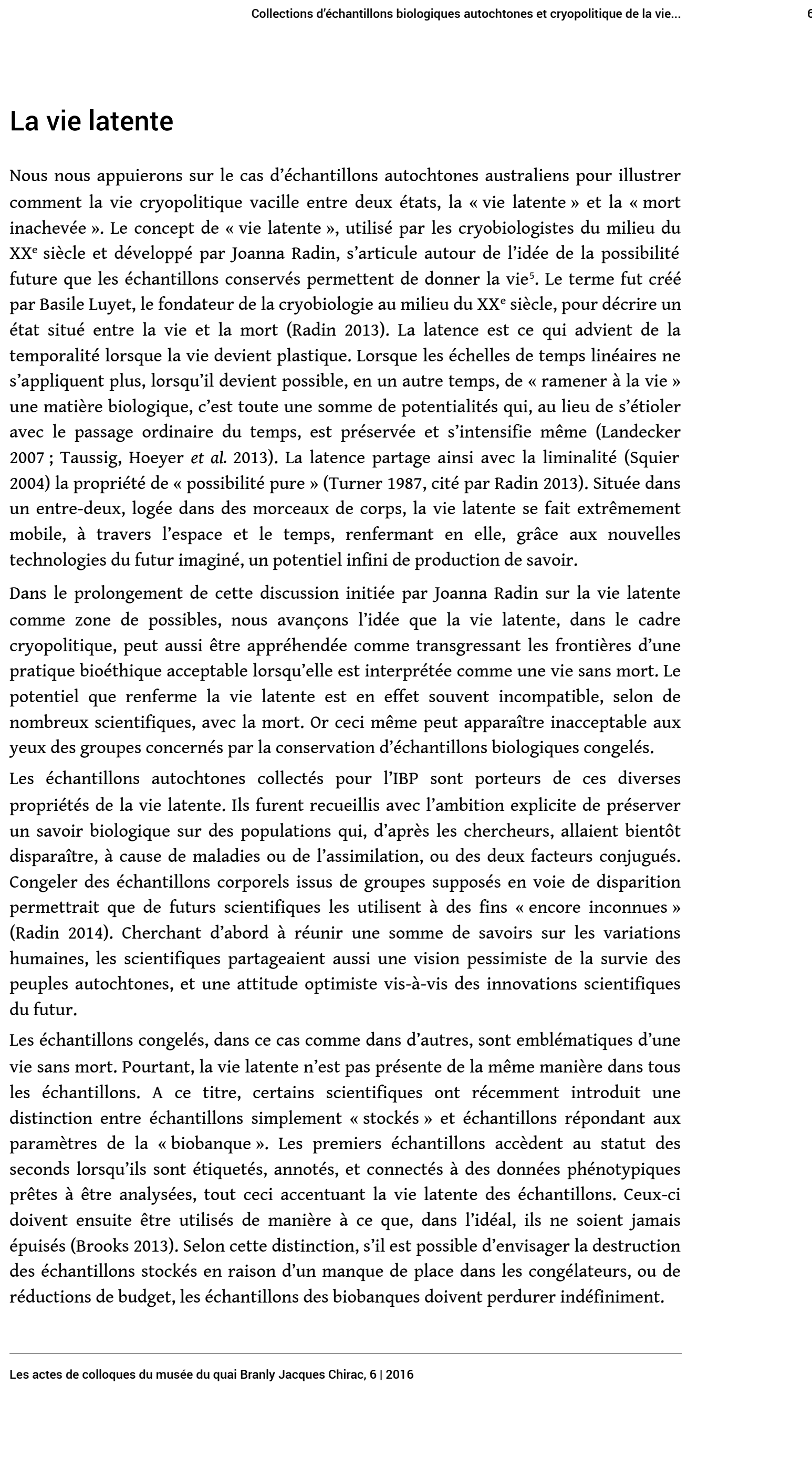

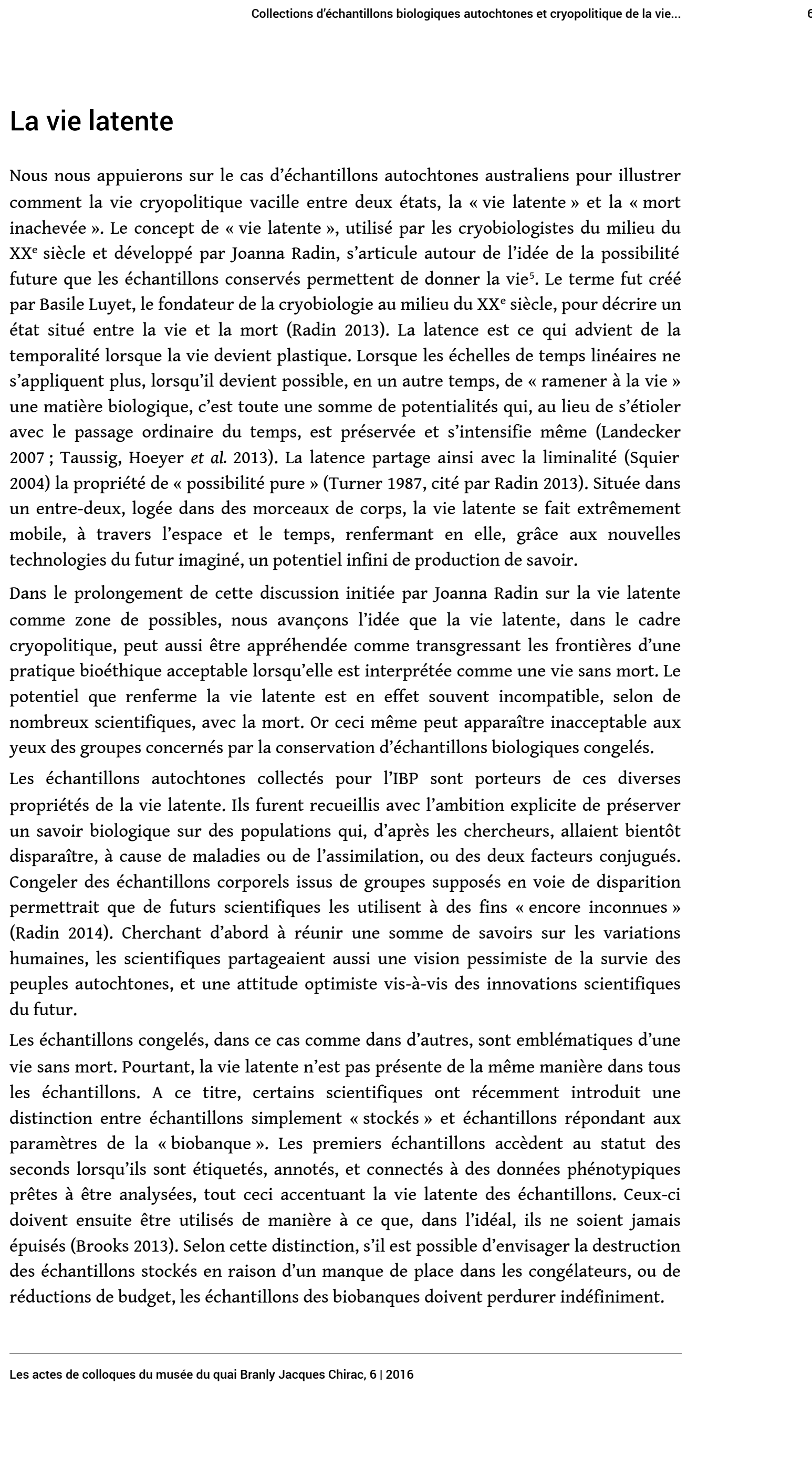

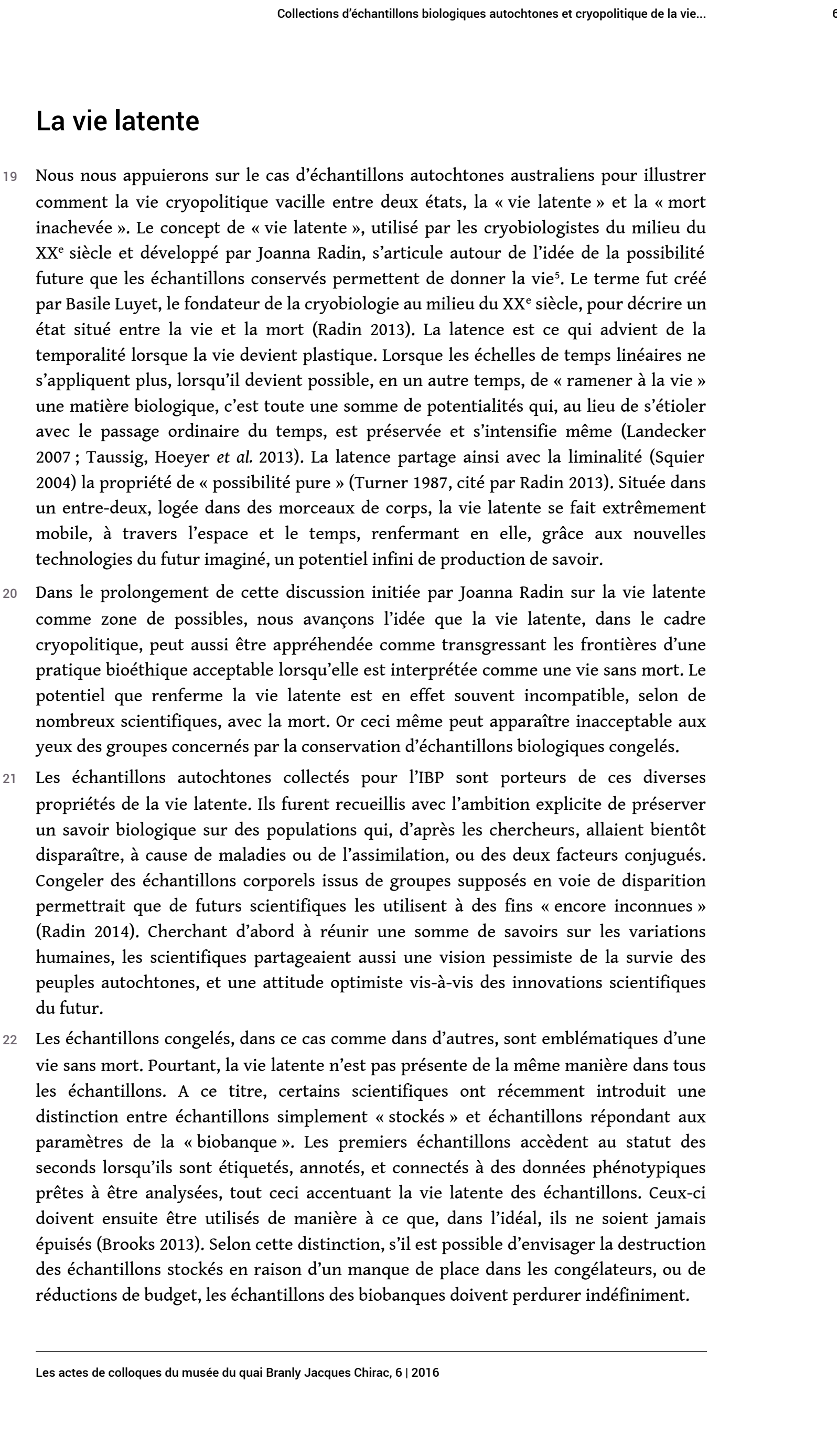

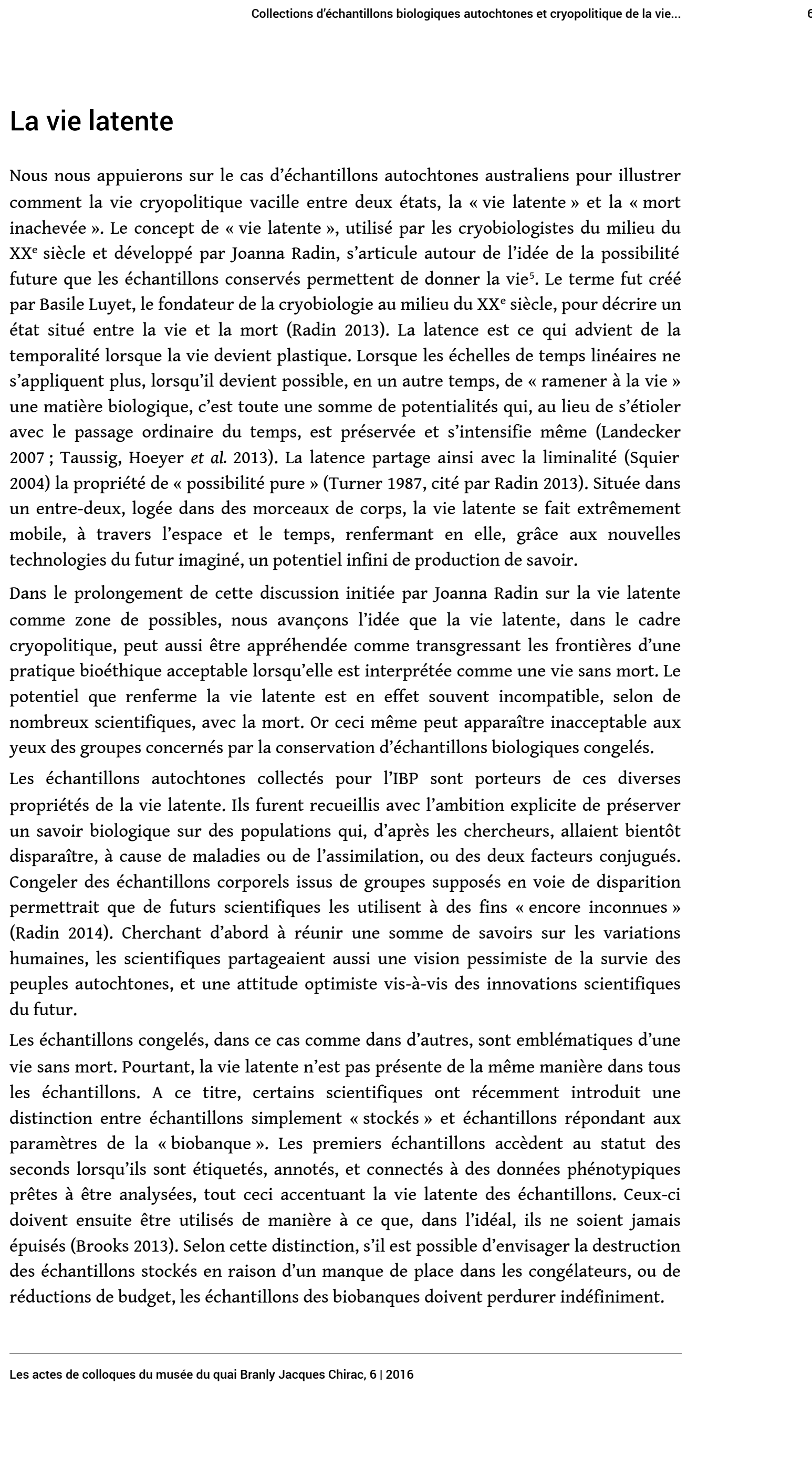

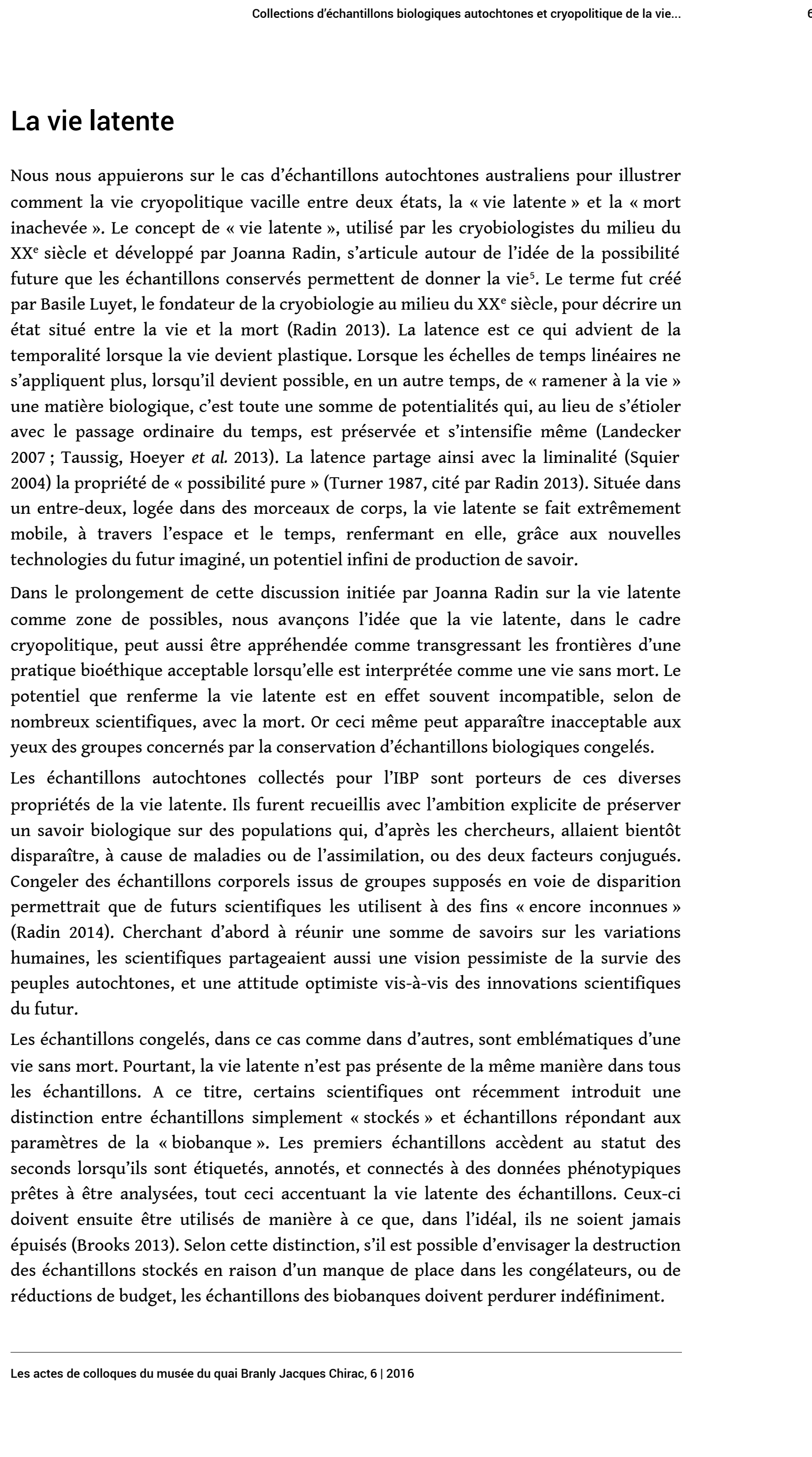

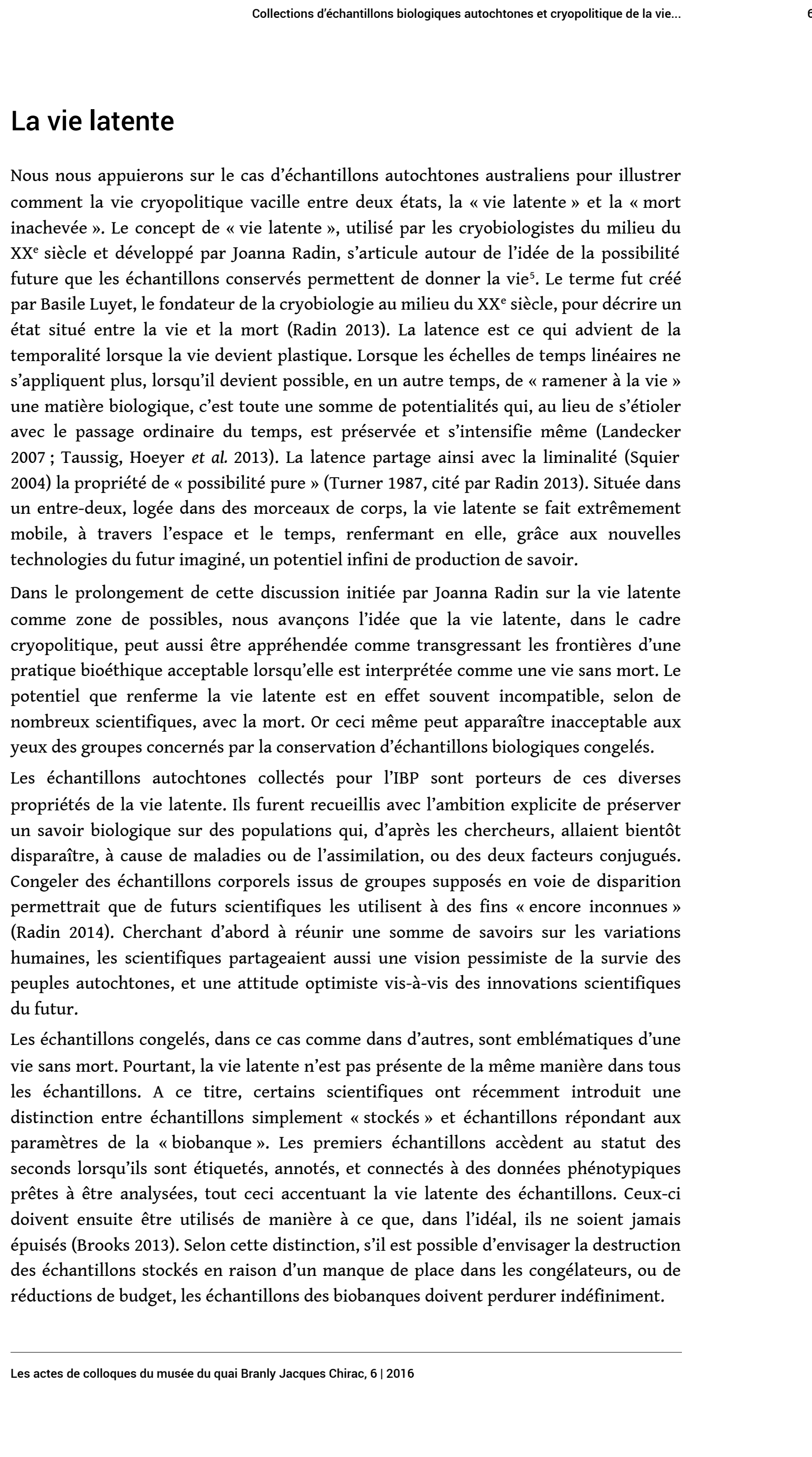

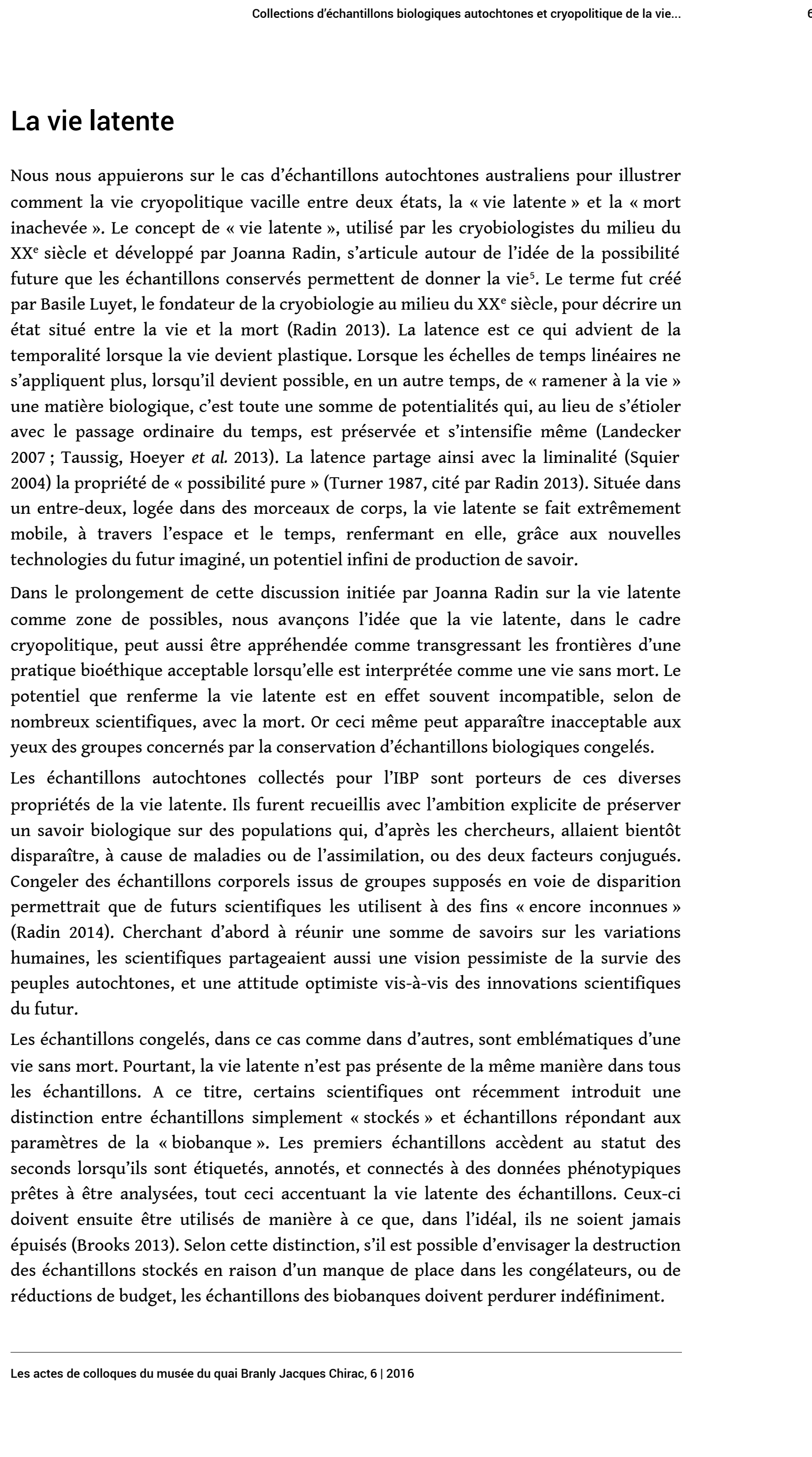

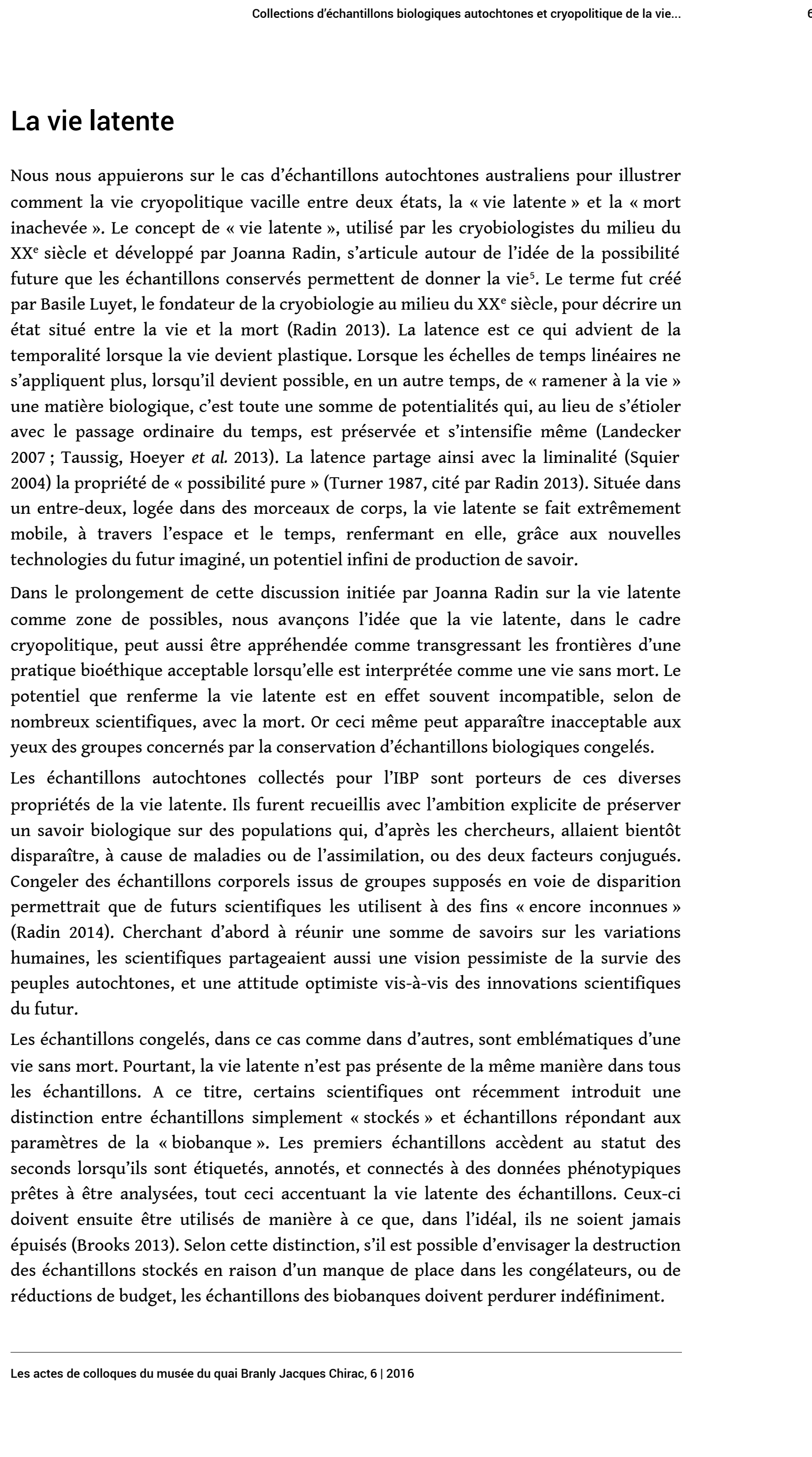

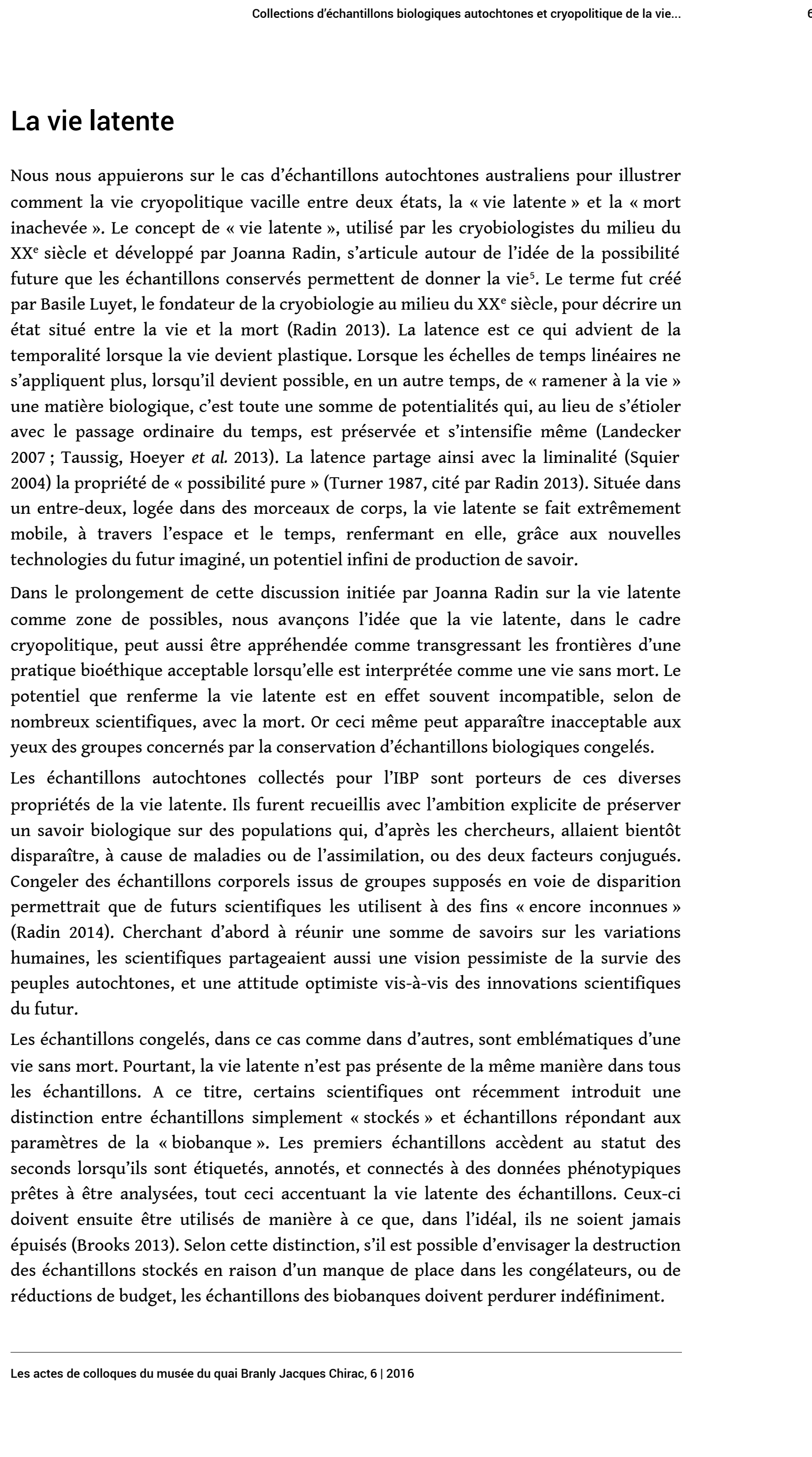

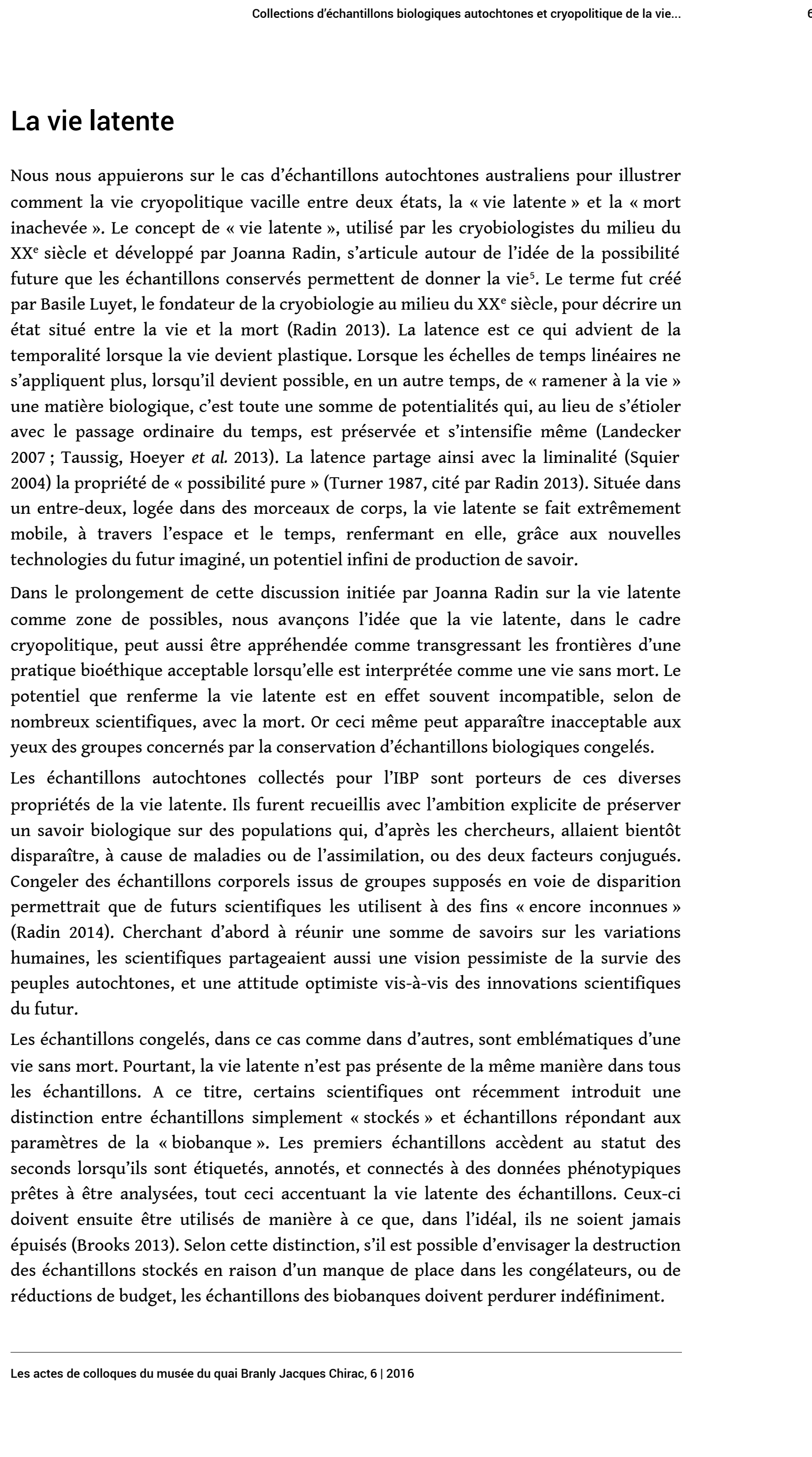

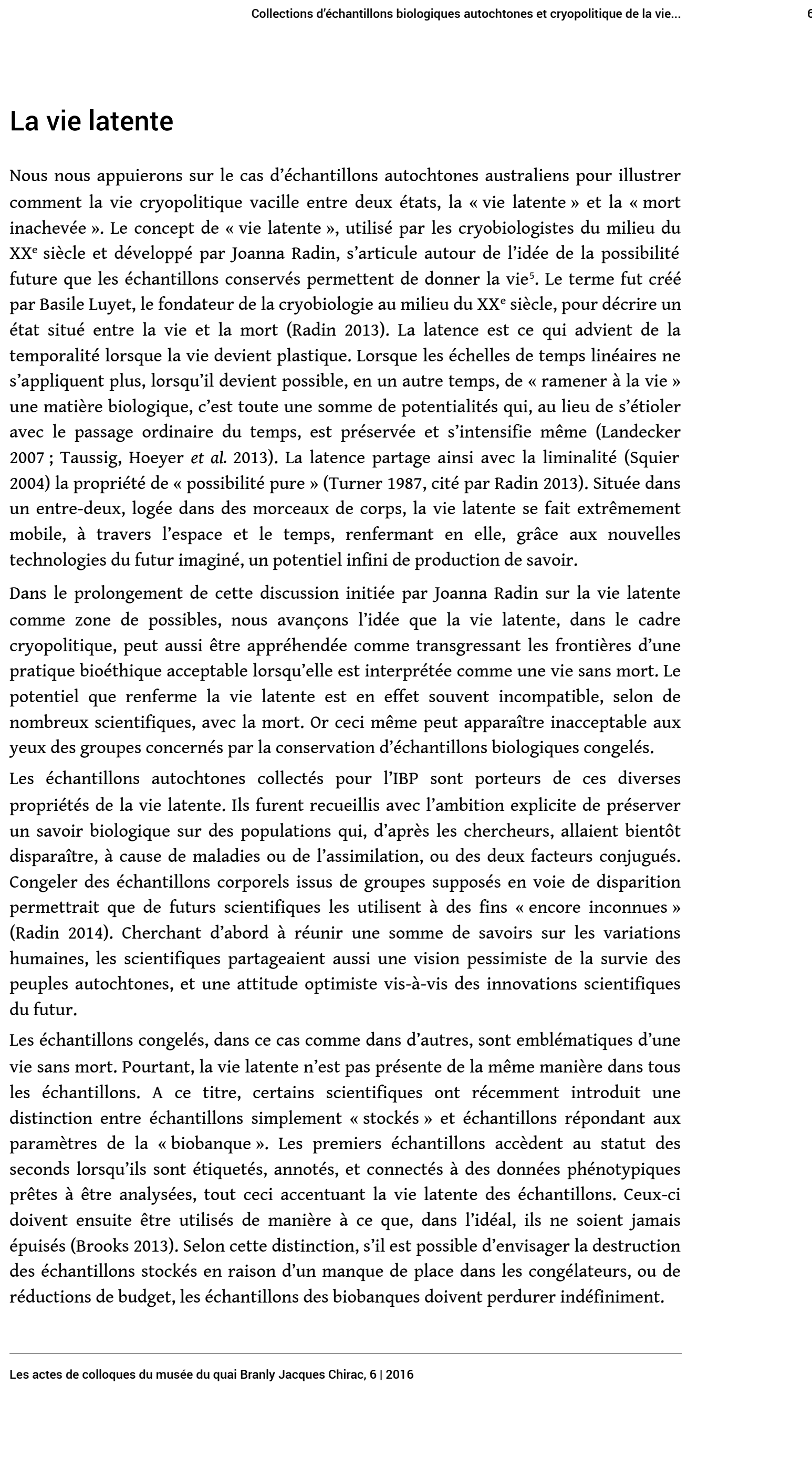

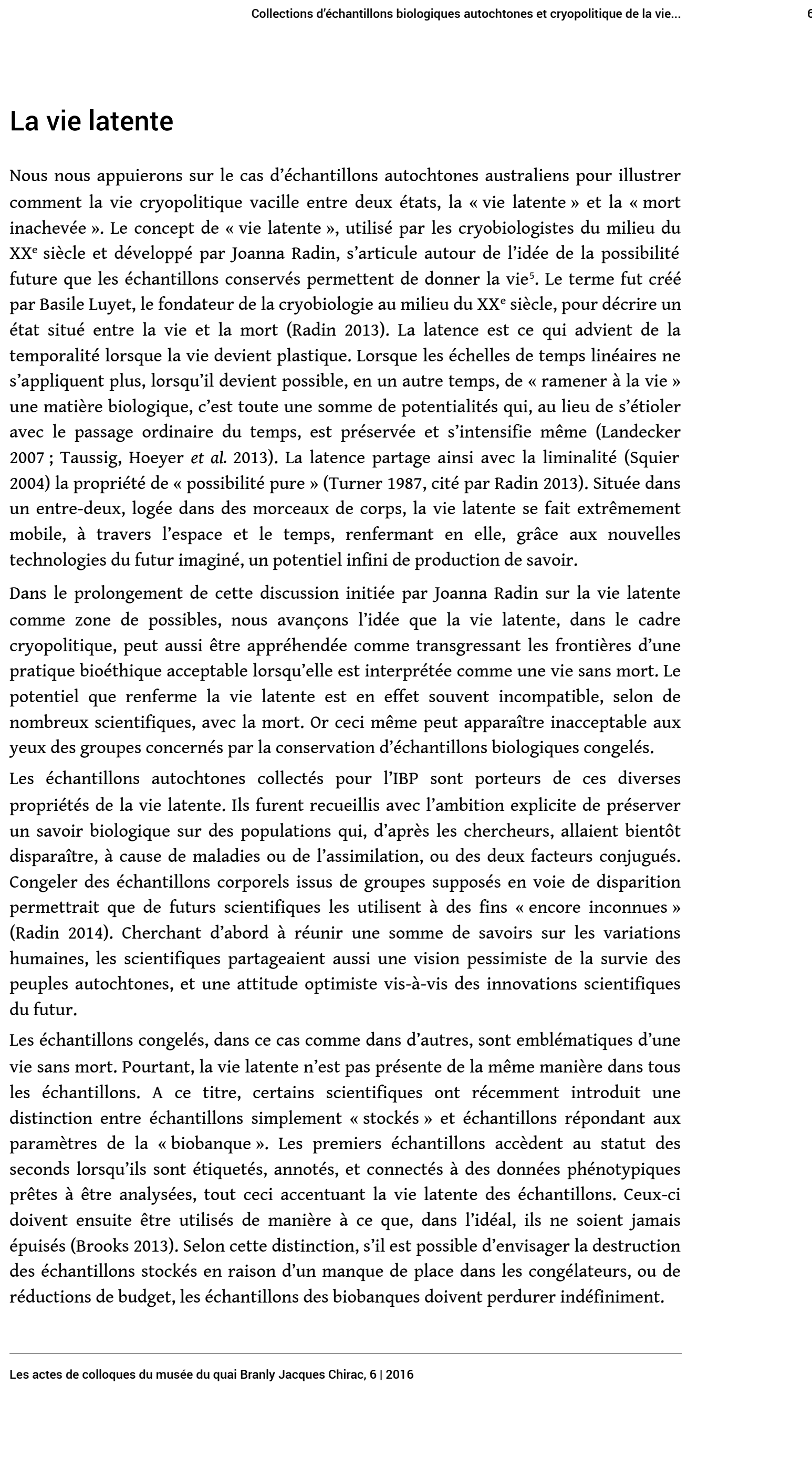

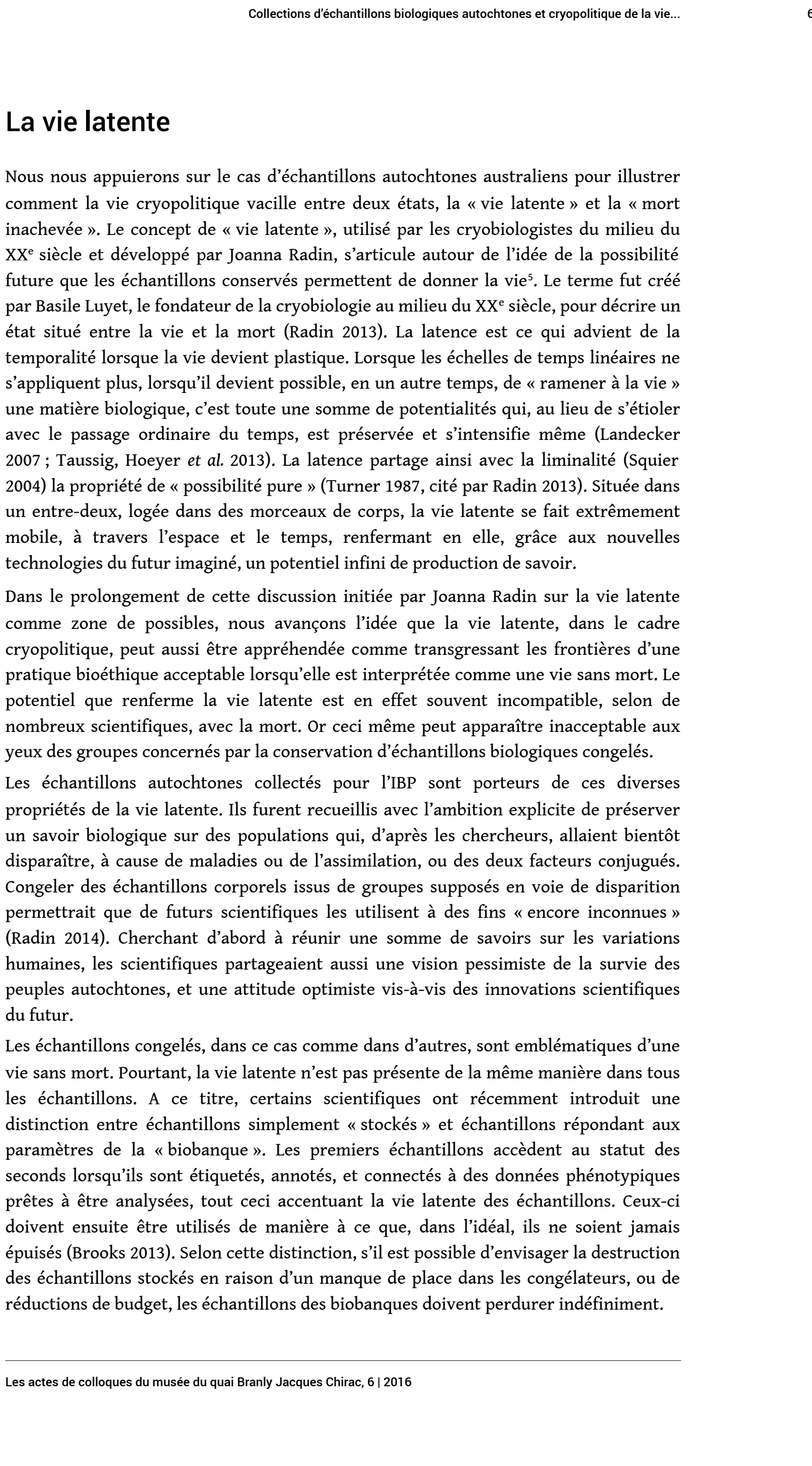

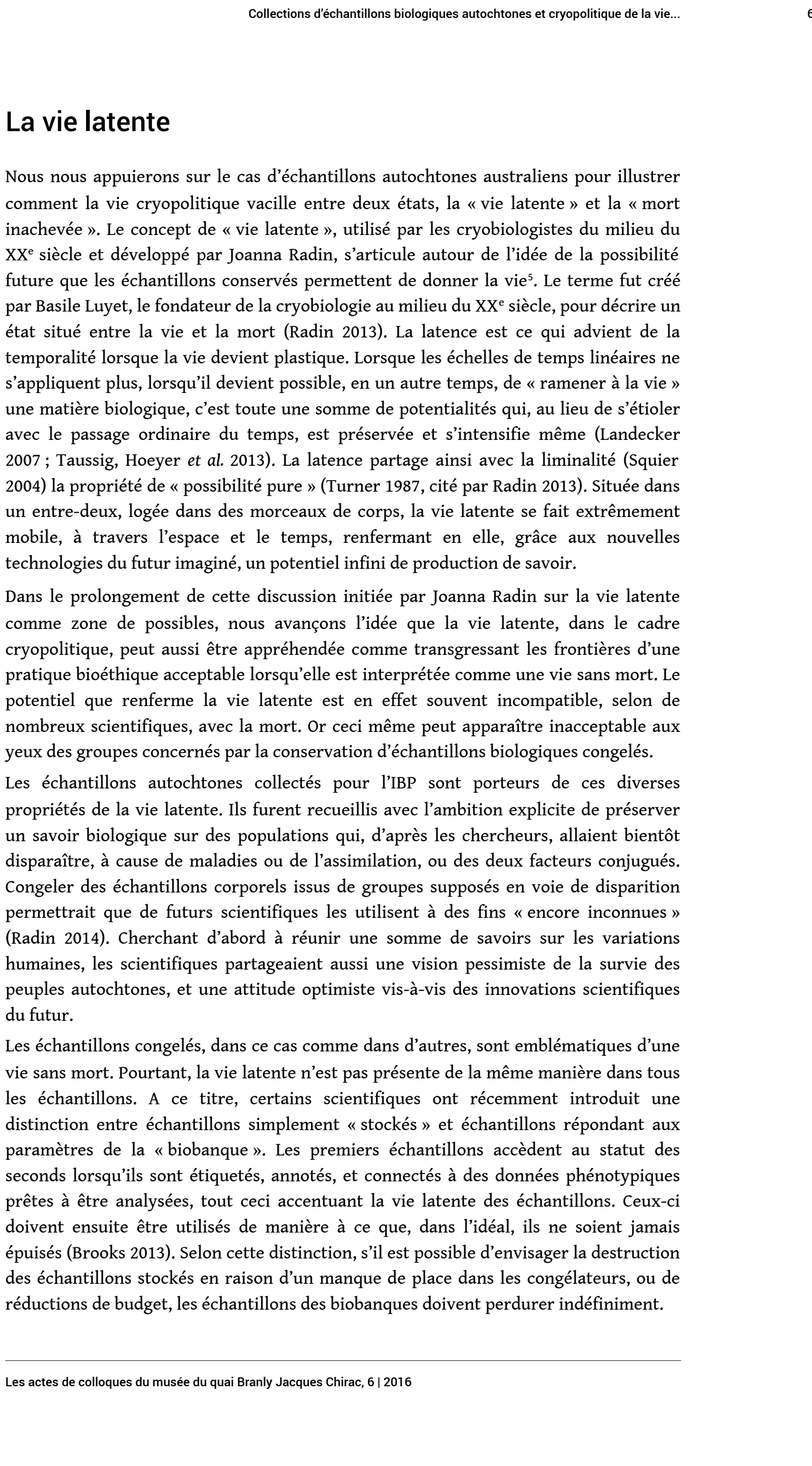

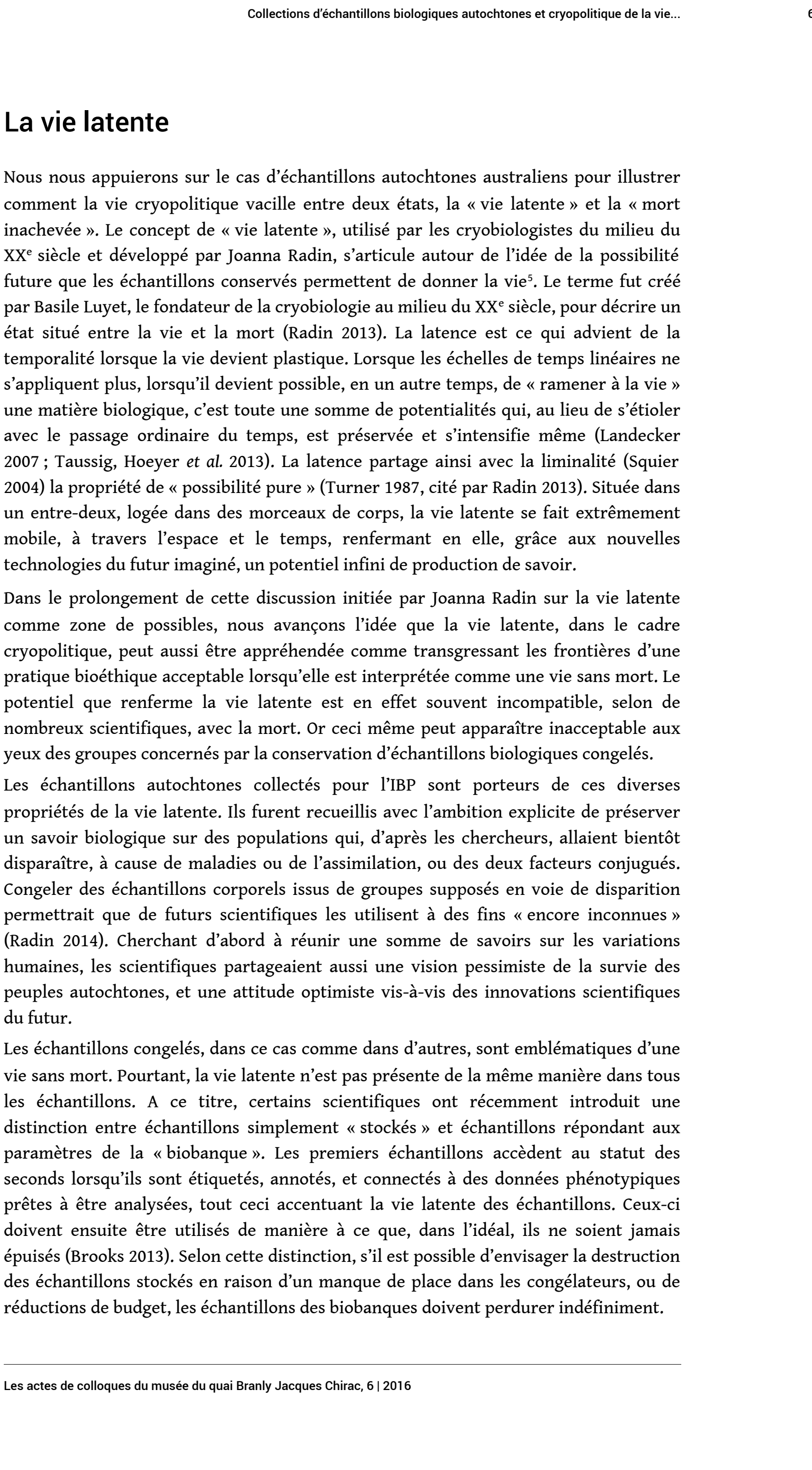

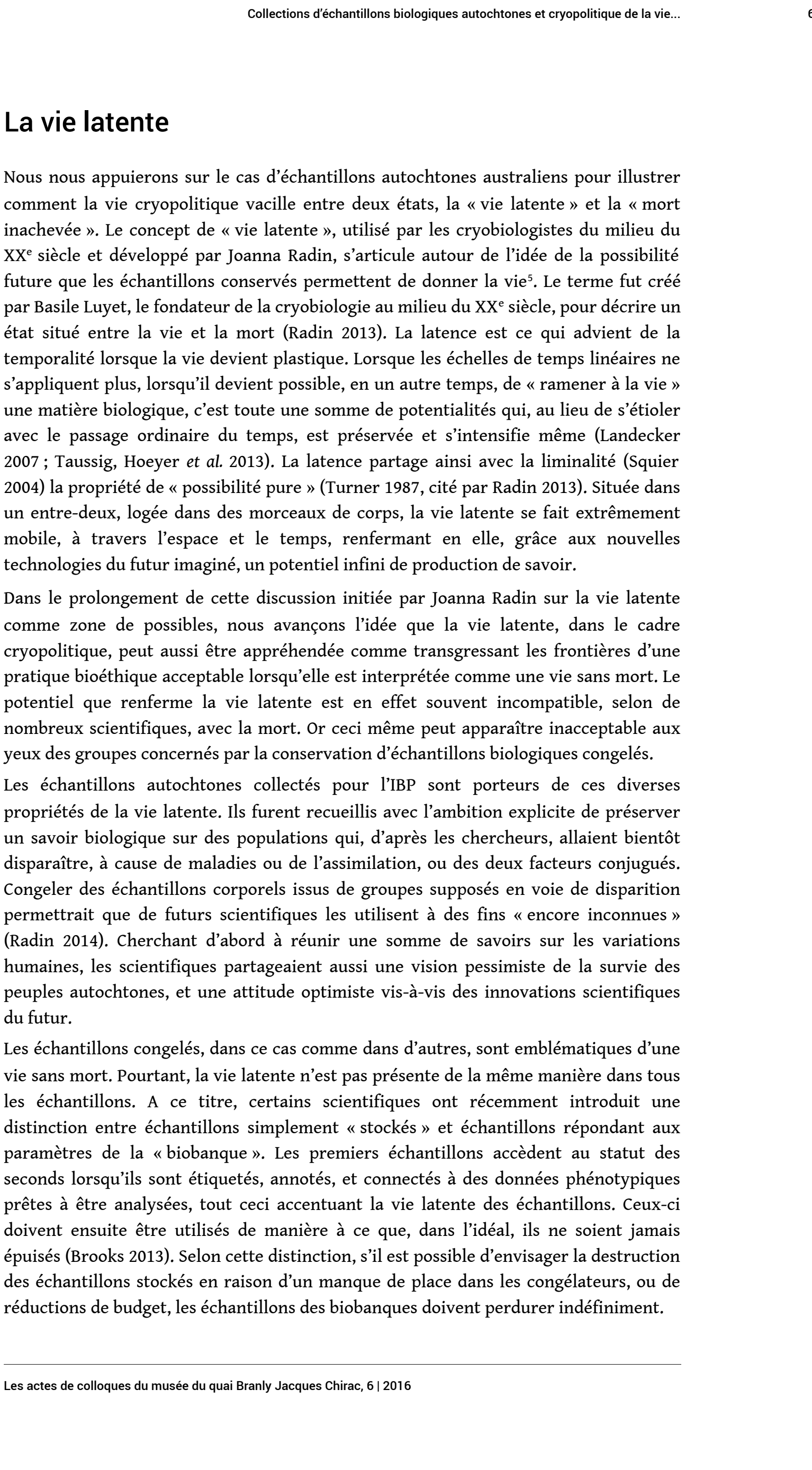

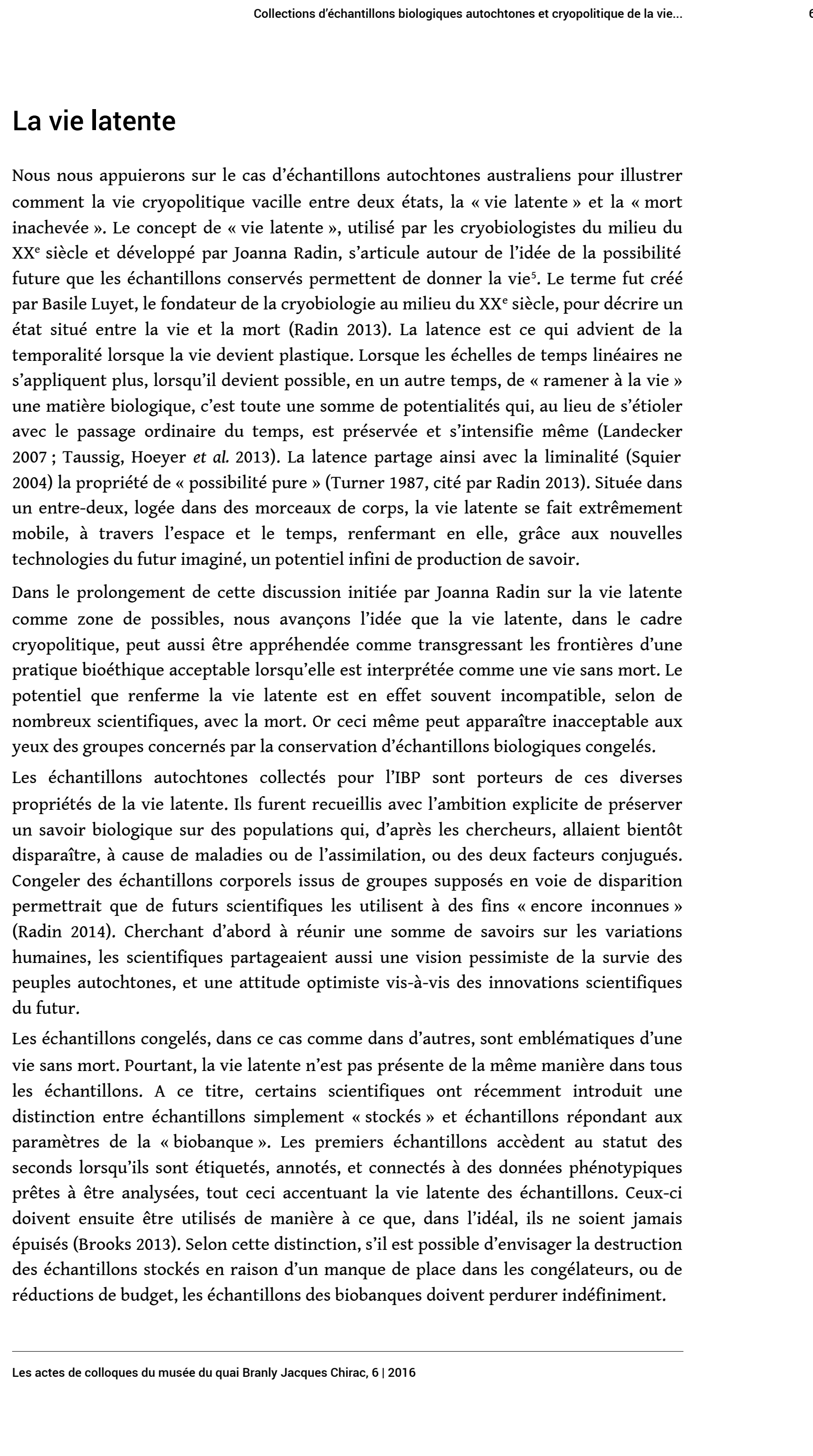

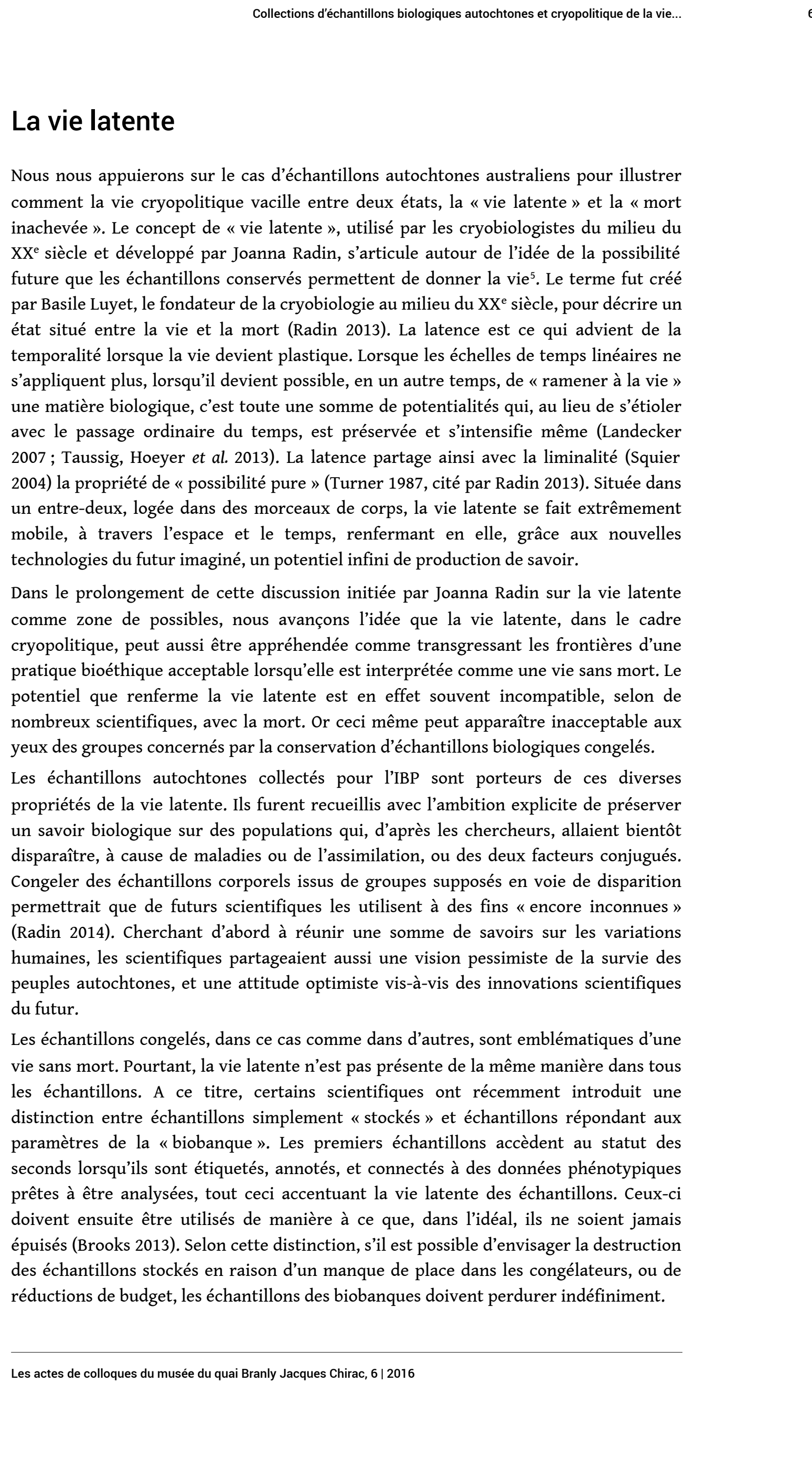

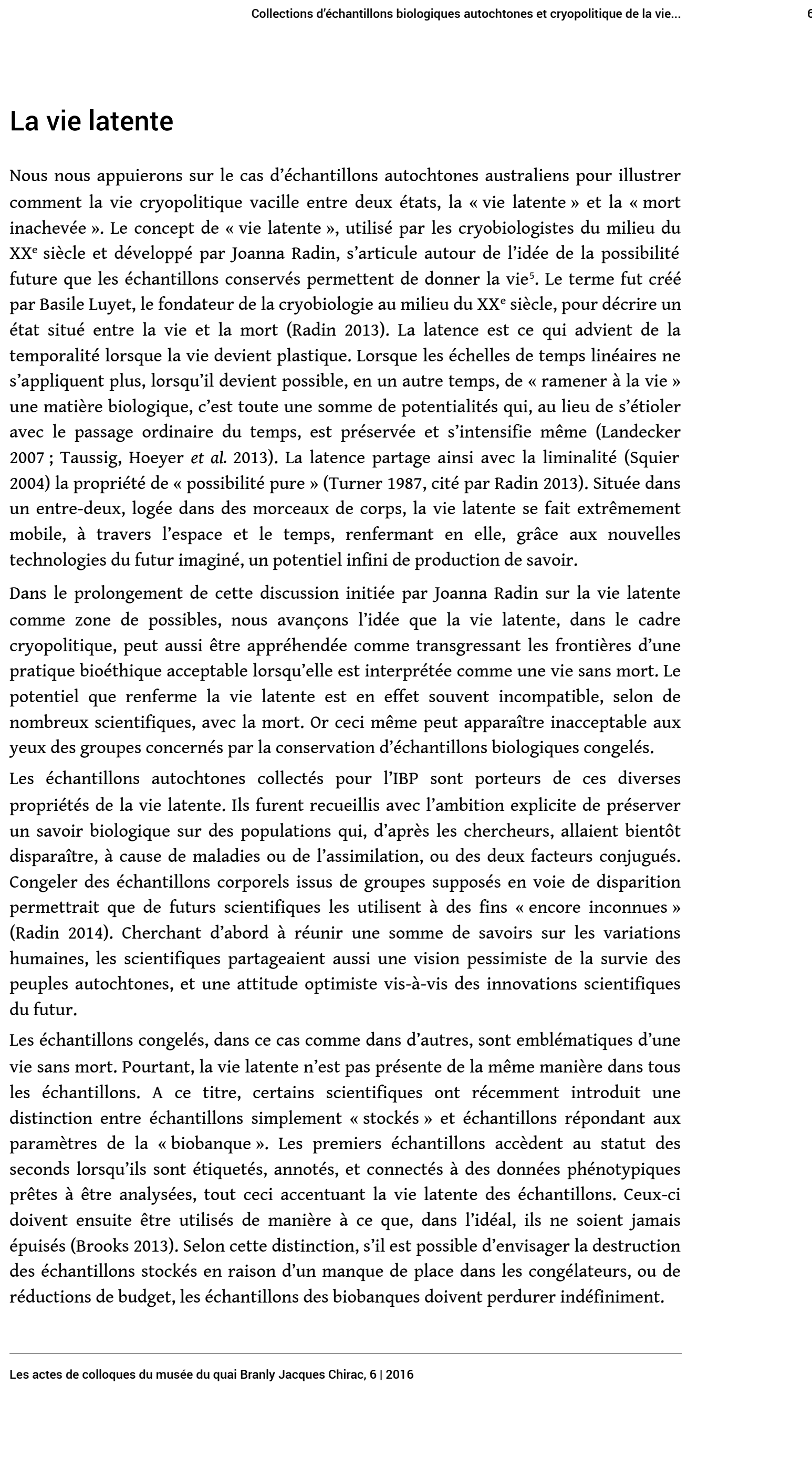

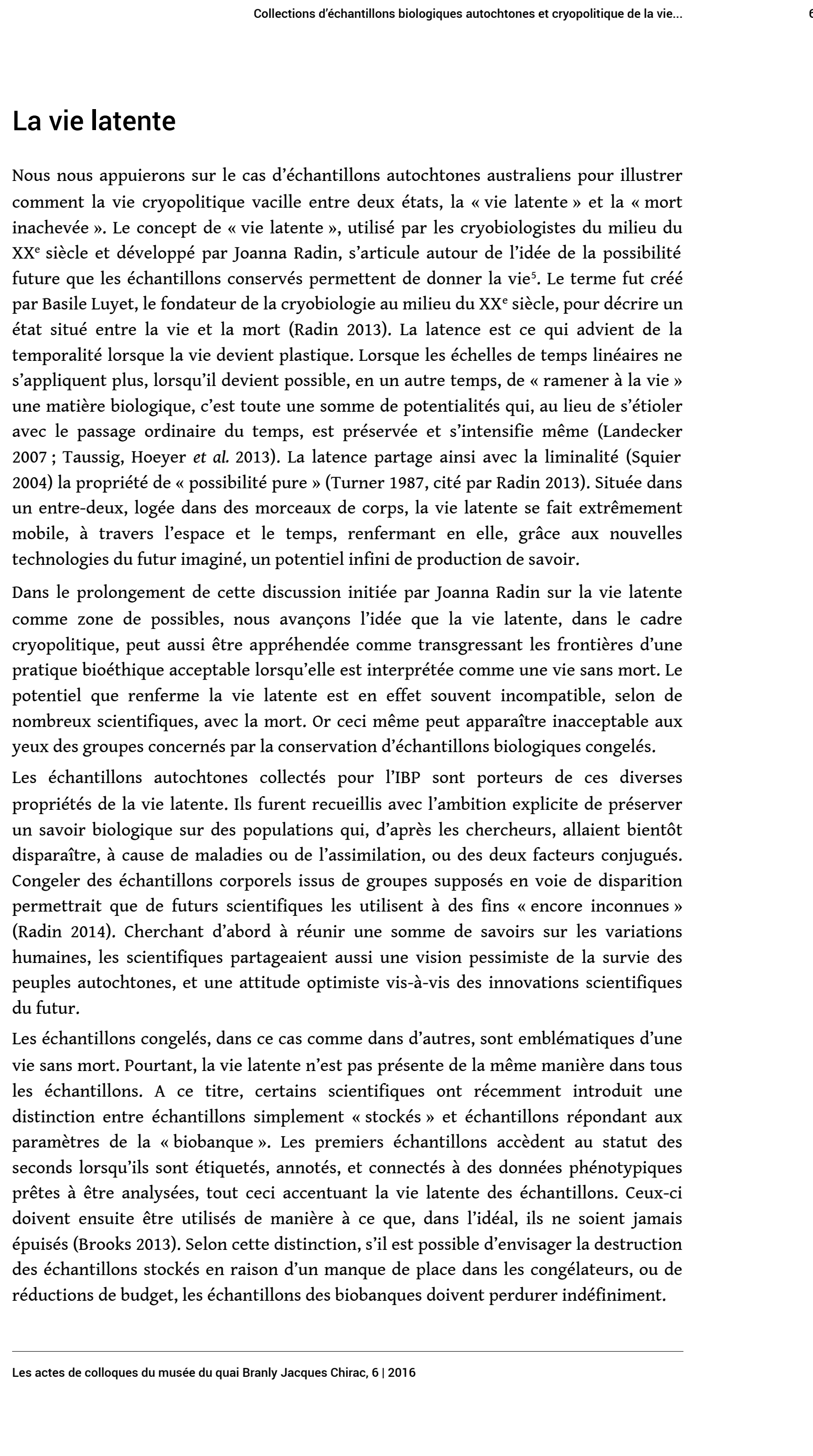

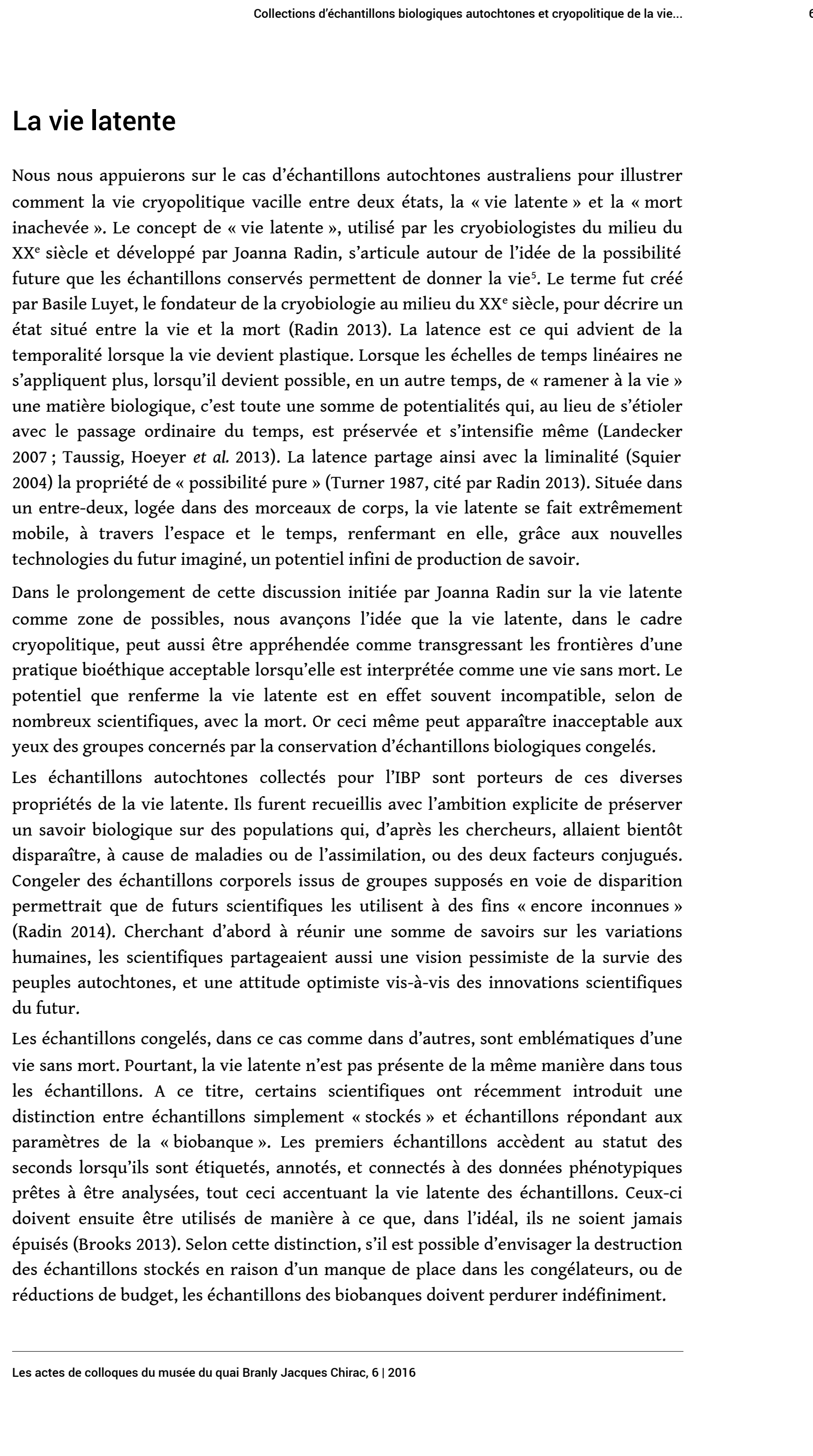

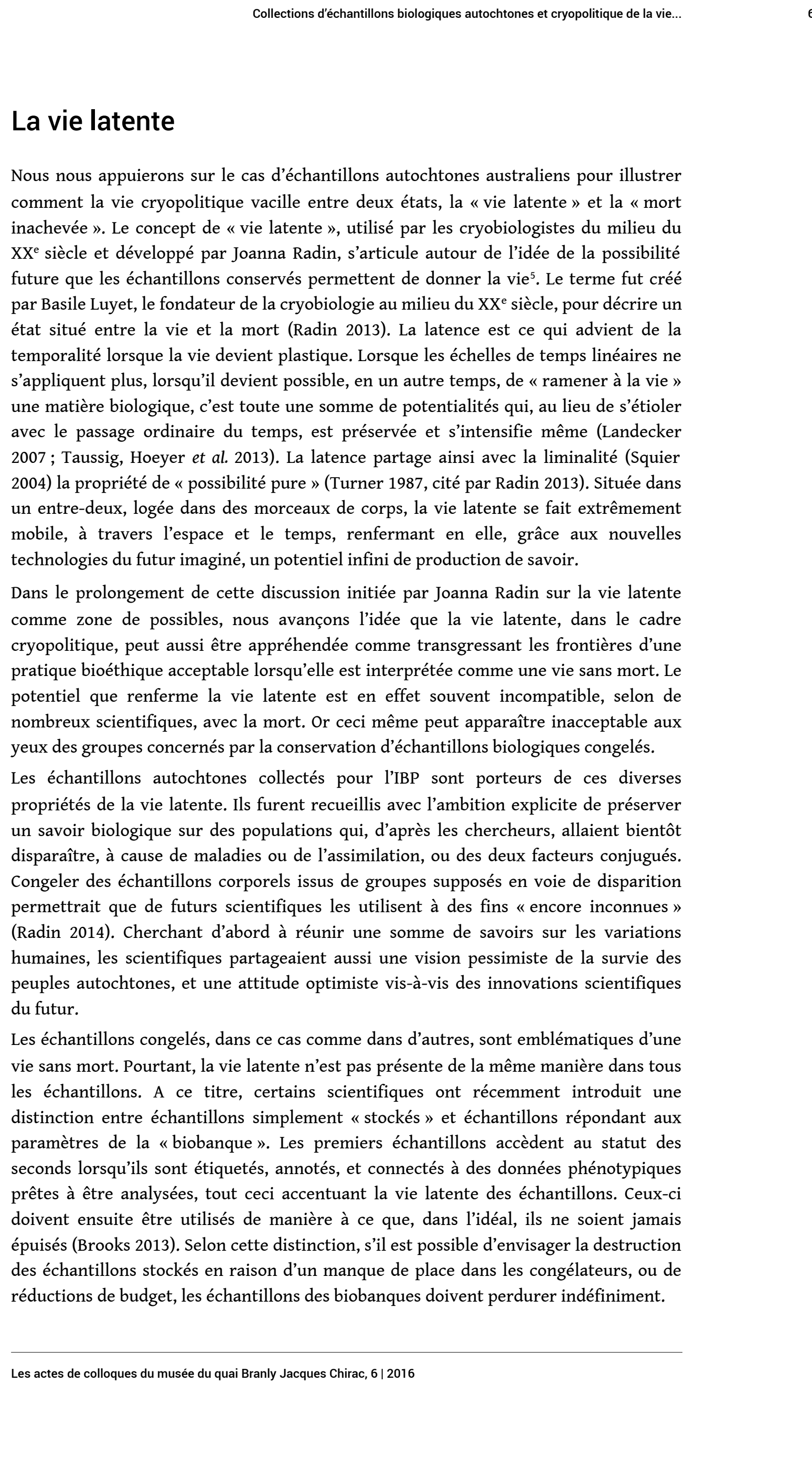

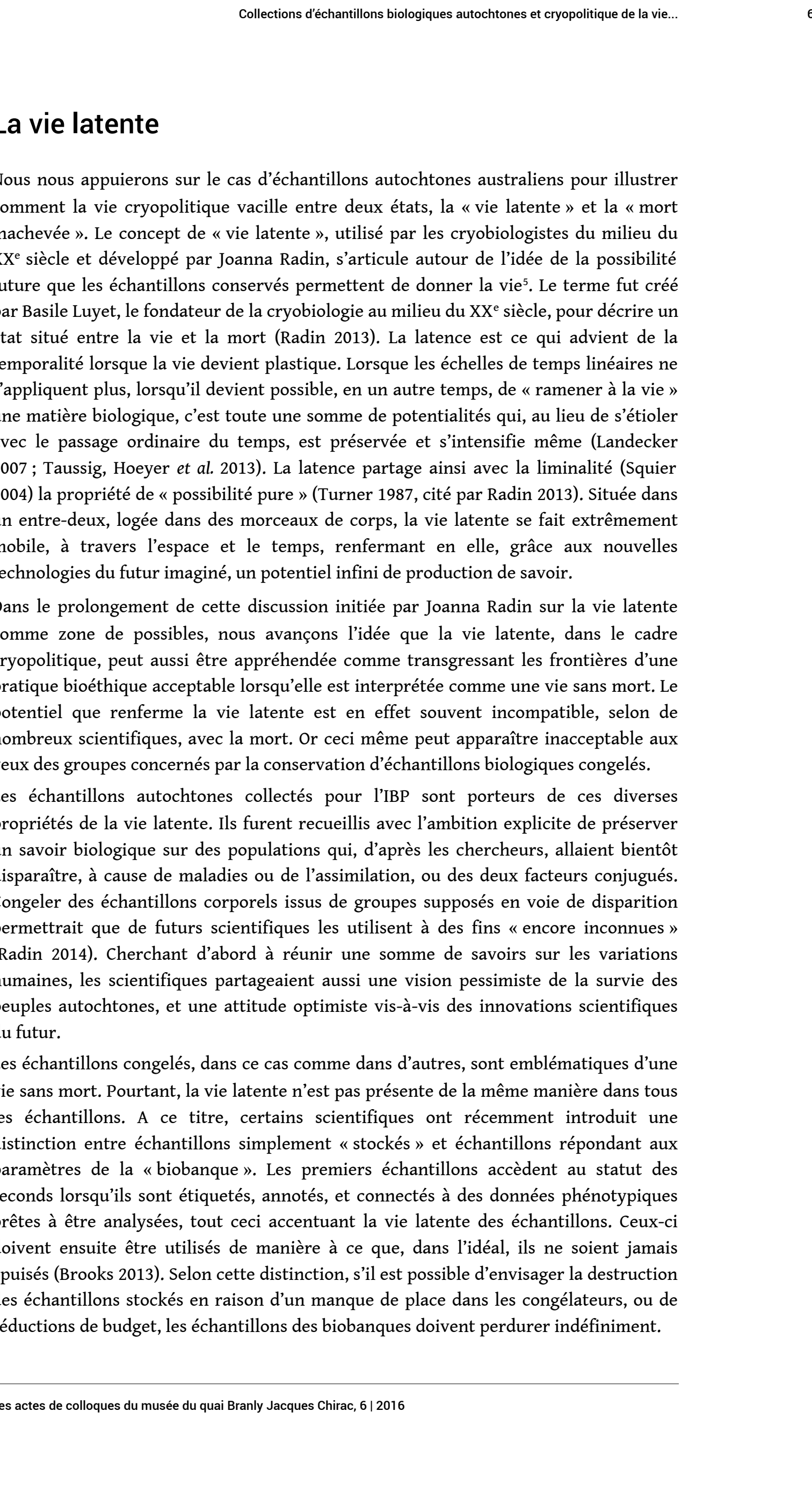

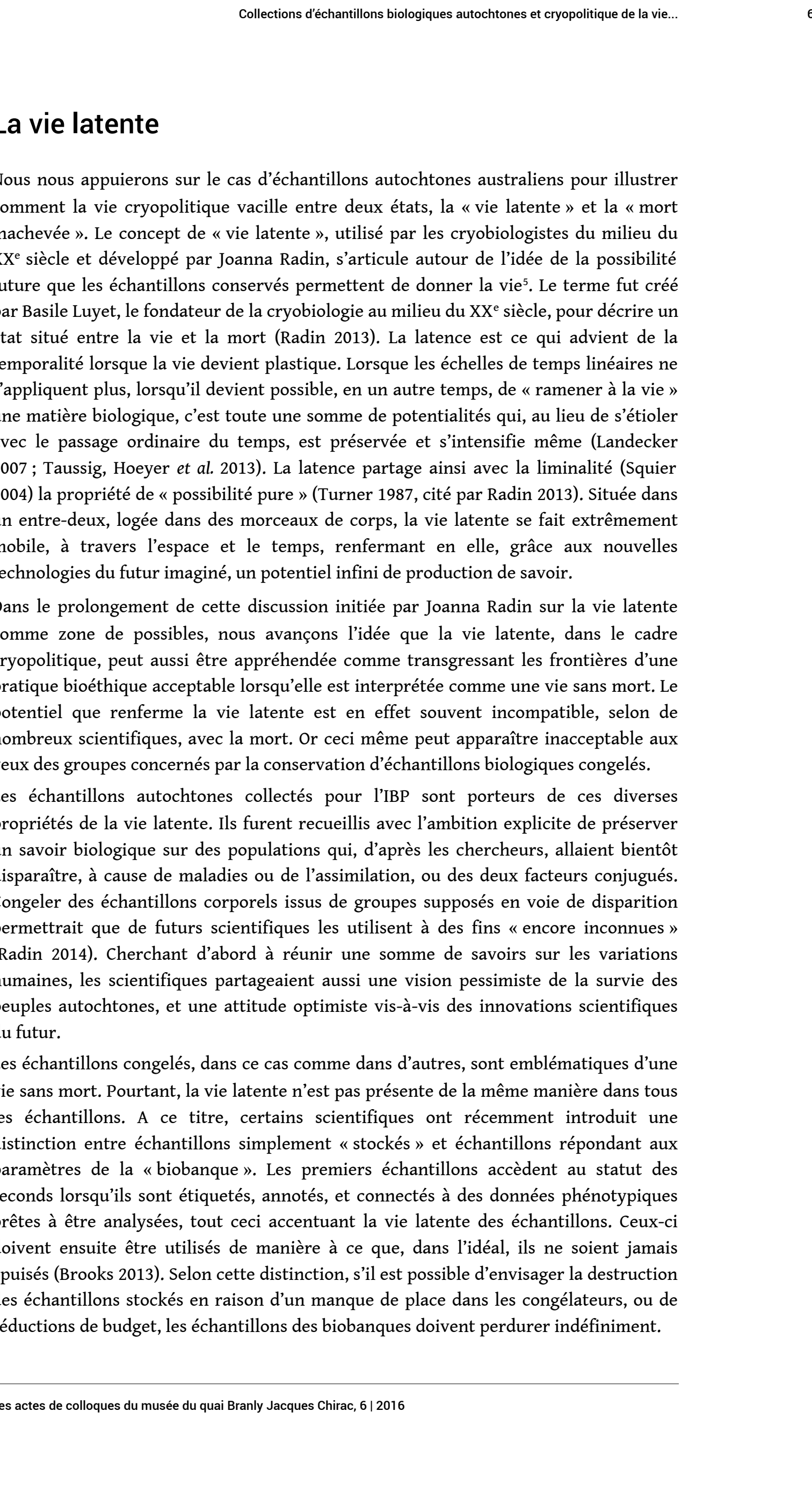

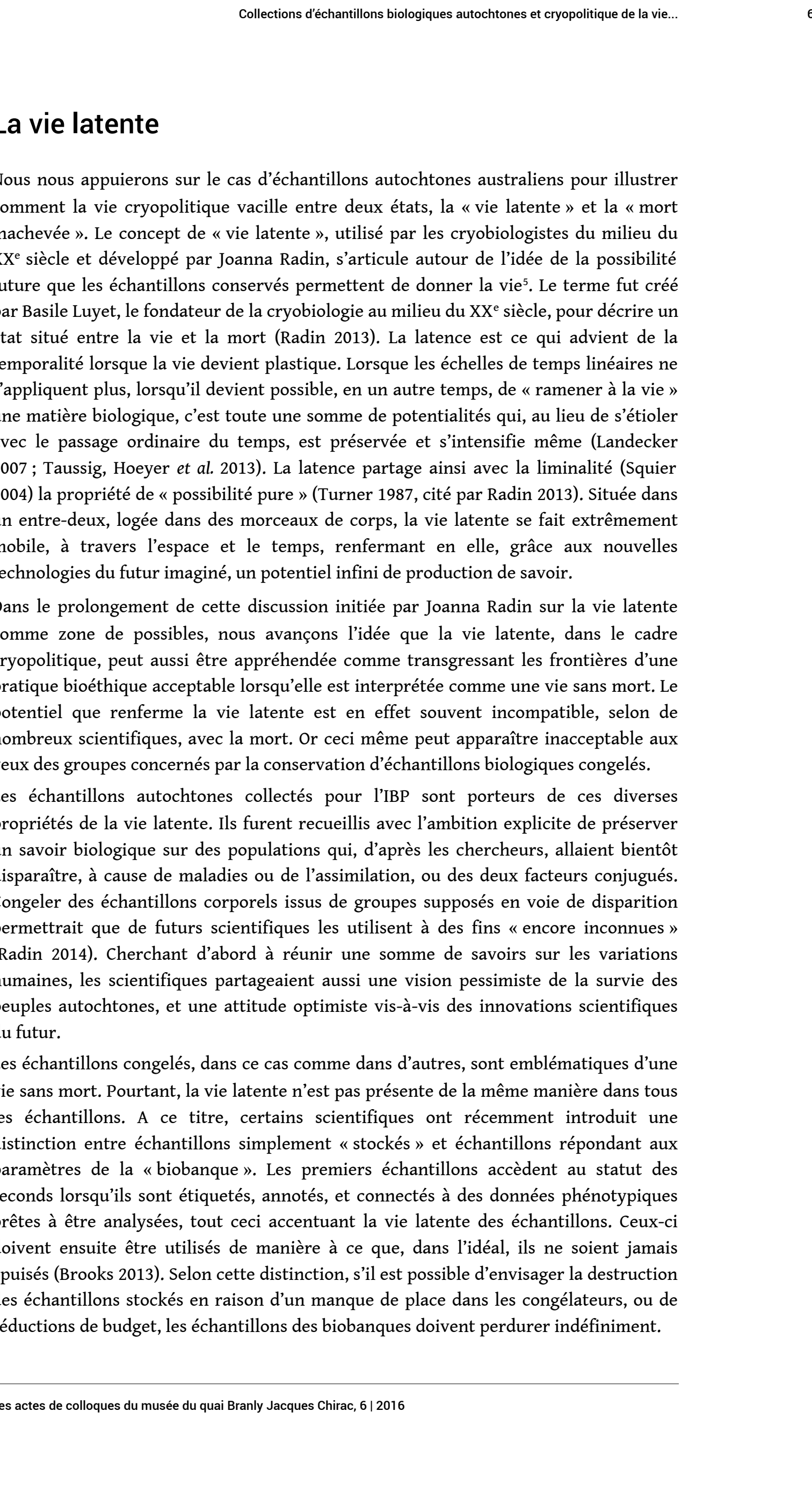

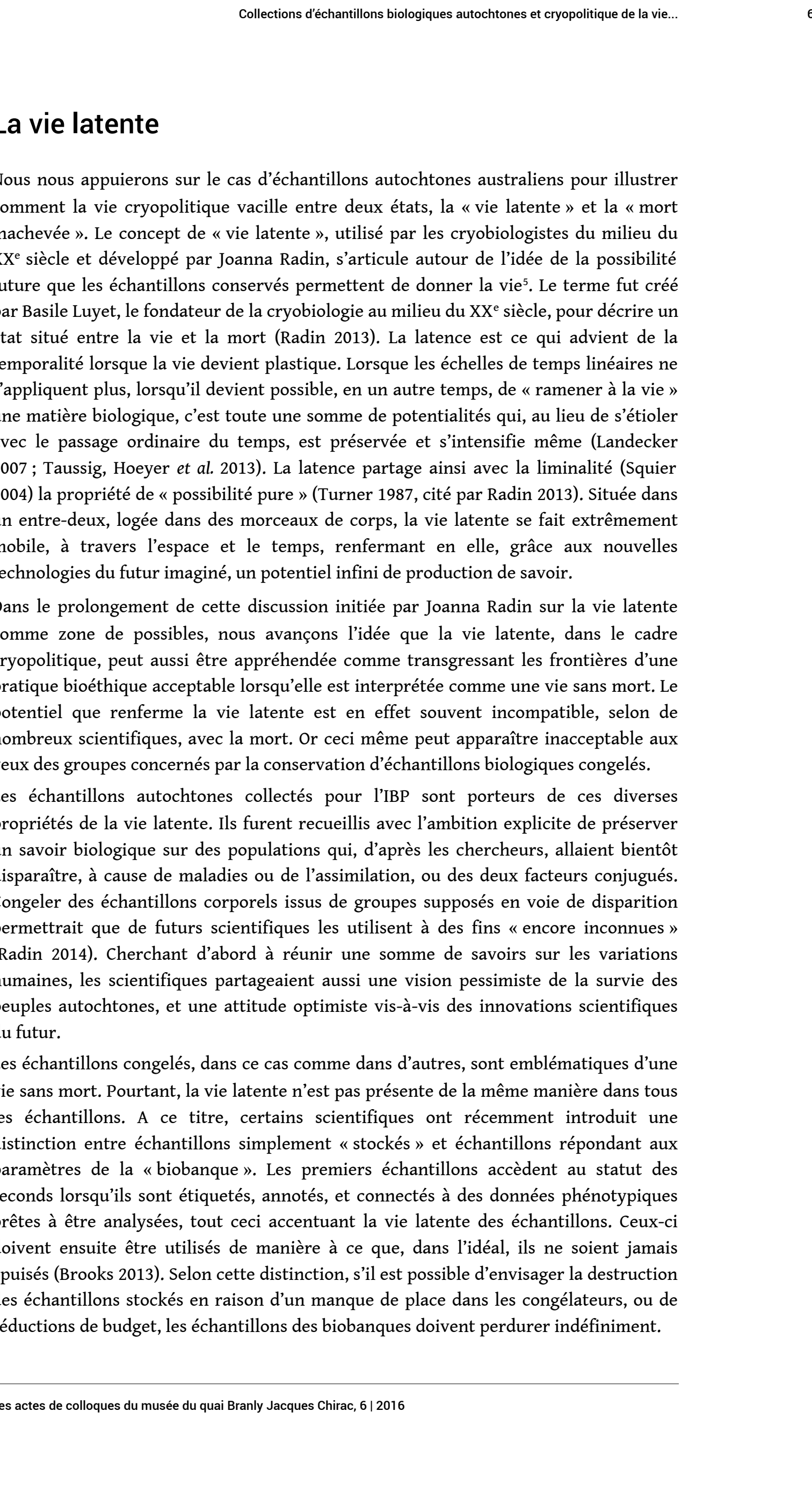

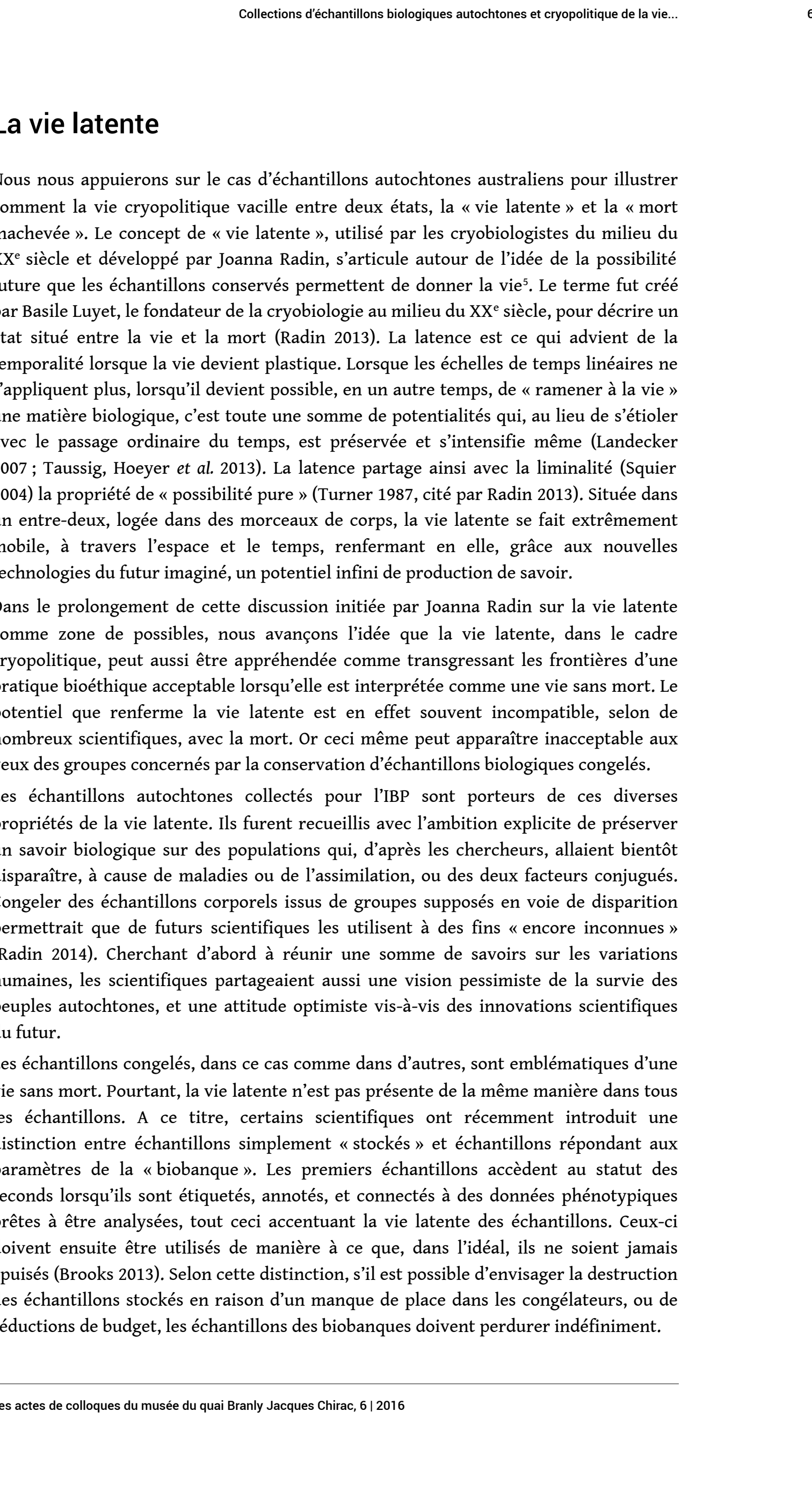

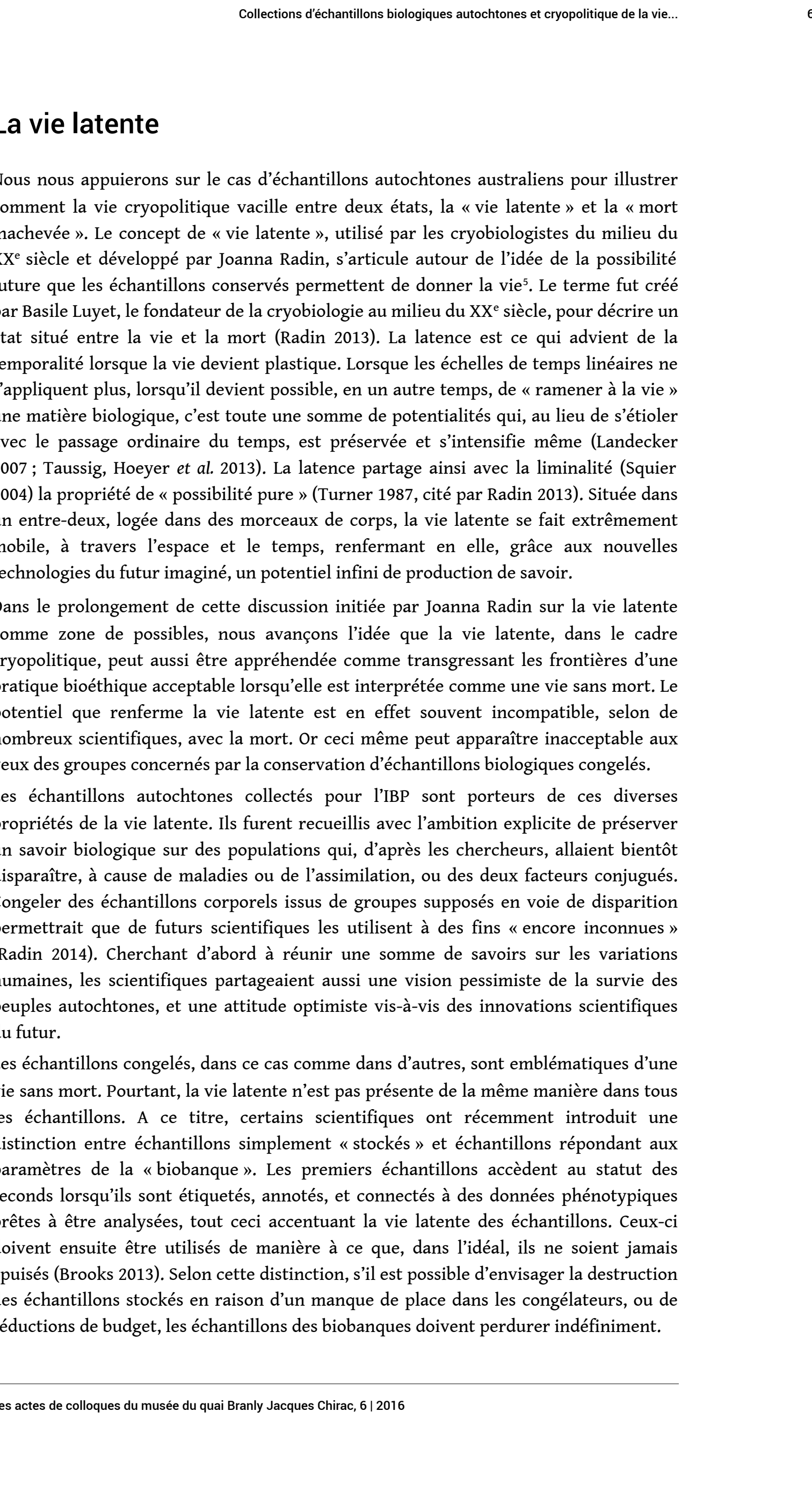
sont étiquetés, 


\section{La mort inachevée} biophysique de la vie latente, dans ce qu'il évoque de possibilités futures, renferme aussi un double perceptuel : l'état de «mort inachevée ». Nous nous appuyons ici sur le concept, développé par Deborah Rose, de « zone de l'inachevé » (Rose, non daté), terme inspiré par la croyance chrétienne en l'idée que les humains défunts sont dans un état «suspendu, en attente de la résurrection ». Rose développe son propos à partir d'une autre itération de la cryopolitique: l'usage de la cryoconservation pour sauver des espèces non-humaines menacées d'extinction. Dans la sphère des non-humains, les biologistes emploient un éventail de tactiques pour assurer la préservation des espèces menacées, allant de programmes de reproduction en captivité, entre plusieurs zoos et réserves naturelles, au moyen de gamètes congelées pour s'assurer d'une diversité génétique suffisante, à des «zoos congelés » où du sang, des gamètes ou des animaux entiers sont congelés pour garantir la possibilité que, dans le futur, des espèces menacées ou disparues puissent être ramenées à la vie ("réanimées ») grâce à la manipulation génétique animale (Friese 2013).

Rose souligne le fait que si ces diverses initiatives de " dé-extinction " prétendent faire reculer la mort, elles suspendent en réalité la vie autant que la mort. Des espèces maintenues en vie par des programmes de reproduction en captivité, par exemple, peuvent perdre les comportements sociaux essentiels à leur survie (van Dooren 2014). Les zoos ont longtemps été perçus comme créateurs d'une forme amoindrie de vie animale, détournant par la même occasion l'attention des habitats animaux menacés. Les projets de zoos congelés en constituent une version extrême, où les animaux vivants sont remplacés par des échantillons congelés de leur corps. Matthew Chrulew remarque que lorsqu'une espèce est davantage menacée, la vie animale n'en devient que plus abstraite, les scientifiques donnant la priorité « aux espèces sur les individus, au code génétique sur la vie, aux gènes sur le corps » (Chrulew 2011). Si une telle forme de vie apparaît ainsi appauvrie, Rose souligne que la «zone de l'inachevé » constitue aussi une forme de mort appauvrie (Rose, non daté). Les efforts de préservation de la vie et de barrage à la mort par congélation peuvent provoquer la suspension de la vie et de la mort simultanément, effaçant les possibles que la mort a à offrir.

La distinction entre vie latente et mort inachevée est mise en évidence par les manières contraires selon lesquelles différents acteurs perçoivent les échantillons biologiques autochtones dont il est question dans cette présentation. Le fait de considérer ces échantillons de sang sous l'angle de la vie latente oriente l'attention vers leur potentiel futur. Si l'on considère ces mêmes échantillons sous l'angle de la mort inachevée, le regard est en revanche dirigé vers un ensemble de relations au passé, que la persistance des échantillons dans l'état congelé ne permet pas de s'établir. Ainsi, beaucoup des groupes autochtones concernés ne reconnaissent pas, ou rejettent explicitement, le potentiel latent des échantillons à créer le savoir auquel les scientifiques accordent de la valeur. Leur regard n'est pas orienté vers des promesses futures, mais relie les échantillons au passé, les considérant comme un prolongement des corps des parents décédés (Reardon et TallBear 2012) ${ }^{6}$. Les restes humains conservés dans les musées (par le biais de la congélation ou par d'autres moyens) sont l'exemple par excellence de la «mort inachevée »: le rapatriement de matériaux tels que des ossements a été

Les actes de colloques du musée du quai Branly Jacques Chirac, 6 | 2016 
considéré comme justifié lorsqu'il permettait de rétablir leur trajectoire interrompue vers la mort. La matière biologique humaine extraite de corps vivants, lorsque ceux-ci sont marqués comme autochtones, peut devenir de même "rapatriable». Le congélateur apparaît alors comme une machine à voyager dans le temps (Radin 2012) et comme une machine de vie, qui fait vivre les choses et fait sans cesse obstacle à la mort.

Dans ce qui suit, nous souhaiterions mettre en avant l'utilité d'un cadre de réflexion cryopolitique. La vie latente et la mort inachevée sont étroitement liées : le fait de préserver sur la durée un potentiel de vie conjure nécessairement la mort. Mais si toutes deux sont des états cryopolitiques, le déplacement de l'attention de la vie latente vers la mort inachevée signale une toute autre relation humaine à la matière biologique, avec des implications décisives pour les échantillons ${ }^{7}$. Considérés comme relevant de la vie latente, les échantillons ne peuvent être détruits; sous l'angle de la mort inachevée, leur destruction est au contraire impérative.

\section{De la vie latente à la mort inachevée}

L'architecture futuriste de l'Institut John Curtin en recherche médicale, dont la construction fut achevée en 2012, vient masquer la vue sur le bâtiment original des années 1960, progressivement démoli pour faire place neuve. De même, les congélateurs situés dans les sous-sols du nouveau bâtiment dissimulent l'héritage crucial d'une autre ère de la recherche biologique. Parmi les millions d'échantillons que les nombreux congélateurs de l'Institut maintiennent à diverses températures, se trouvent 100000 échantillons, collectés par Bob Kirk dans le monde entier, dont un ensemble d'environ 7000 échantillons recueillis auprès de communautés autochtones.

Ces échantillons furent pratiquement abandonnés par Kirk après son départ à la retraite en 1987. Lorsque ses anciens collègues lui posaient des questions sur la collection, il ne leur donnait que de vagues réponses ou évitait tout simplement leurs questions. La plus grande partie des échantillons ne furent pas physiquement collectés par Kirk lui-même, mais par des agents du gouvernement, des personnels médicaux, des médecins de l'hôpital et des chercheurs extérieurs à l'université. Kirk était le seul à les avoir rencontrés et à savoir comment les contacter. Sa réticence à répondre aux questions, ou à mettre en relation le personnel actuel avec celui qui avait directement recueilli les échantillons, posa un certain nombre de problèmes jusque dans les années 1990. Bien que les échantillons aient continué à être utilisés par les chercheurs après le départ à la retraite de Kirk, et que de l'ADN ait été extrait de plusieurs centaines d'entre eux, il devint de plus en plus difficile en son absence de pouvoir se porter garant des échantillons et de la manière dont ils avaient été recueillis. Après son décès en 2010, le problème est devenu définitif.

Ce fut une période difficile pour le responsable actuel de la collection (à ce poste depuis le départ à la retraite de Kirk). Les doctorants travaillant sur la collection furent contraints d'abandonner leurs projets en cours, et des mémoires de recherche prometteurs demeurèrent non publiés. Dans les termes cryopolitiques que nous proposons, on peut dire que la perception du statut des échantillons se modifia alors irrévocablement, passant d'une vie latente pleine de promesses à un état de mort inachevée, qui était problématique pour les scientifiques. technicien en chef du laboratoire, recruté par Kirk au début des années 1970. Depuis ses 
débuts au laboratoire après la fin de ses études universitaires, jusqu'à son départ à la retraite trente-cinq ans plus tard, il fut responsable de la gestion de la collection. Il se souvient des émotions ambivalentes qu'il éprouva lorsque la collection fut fermée à l'étude. "Je ne savais pas ce que je devais faire», nous dit-il. "Dois-je la sortir discrètement et l'autoclaver complètement [la détruire par vaporisation] ? Est-ce que des gens veulent la récupérer? » L'identité « autochtone » des échantillons devint tout à coup importante, et source d'inquiétude pour le personnel du laboratoire. "D'un point de vue strictement gestionnaire, l'identité [des échantillons] est bien dissimulée », dit-il, « le terme aborigène n'est pratiquement jamais mentionné [sur la liste des échantillons]. Mais tous les noms... ", ajouta-t-il en laissant sa phrase en suspens, faisant référence aux listes détaillées de noms et autres informations sur les donneurs (que les scientifiques qualifient de «listes ensanglantées») archivées en d'autres lieux du bâtiment. La liste des noms, des noms de parents et noms de langue qui indiquaient la provenance des échantillons les marquaient aussi irrévocablement en tant qu' « autochtones ", quand bien même leur présence matérielle (dans des boîtes remplies de tubes de verre aux bouchons d'aluminium, et plus récemment de tubes cryogéniques en plastique) ne laissait rien deviner de leur particularité au milieu des milliers d'autres tubes semblables conservés dans le laboratoire.

31 Les échantillons n'avaient alors encore jamais fait l'objet de revendications autochtones. Mais les évolutions politiques de l'époque, sur les droits autochtones et le statut des restes humains conservés dans les musées (question évoquée en ouverture de cette présentation), eurent des répercussions sur le statut d'autres types de matériaux biologiques, dont des échantillons congelés, provoquant certaines inquiétudes auprès de ceux qui pouvaient être amenés à les manipuler. La collection n'était plus simplement un matériau brut, de valeur scientifique, mais pouvait aussi désormais faire l'objet de revendications de la part de divers acteurs extérieurs au laboratoire. Les scientifiques associés à la collection ne pouvaient clairement expliquer ce qui lui était arrivé, mais ils avaient décidé d'un commun accord qu'elle devait continuer à être conservée, sans plus servir à des études scientifiques.

La réaction consistant à détruire les échantillons (les "autoclaver complètement») aurait constitué une réponse logique à cette incertitude. Mettre fin à leur présence matérielle aurait résolu les problèmes qu'ils posaient. Mais pour un autre scientifique associé à la collection, un tel acte était inadmissible, synonyme de "vandalisme scientifique ». La vie latente des collections cryoconservées, elles-mêmes souvent comparées à des archives d'une valeur inestimable, interdit leur destruction et nécessite que la mort soit sans cesse repoussée. Mais la décision de les détruire aurait aussi pu refléter, de la part du technicien en chef du laboratoire, l'intuition que le statut des échantillons risquait d'être passé du domaine de la vie latente à celui de la mort inachevée. L'évolution que perçurent les scientifiques à la fin des années 1990 les empêchait désormais d'accéder à la vie latente de la collection, faisant progresser celleci vers l'état de mort inachevée (Kowal, Radin et al. 2013). Aujourd'hui, la conservation de la collection continue d'être problématique et son avenir reste incertain pour l'Institut. 


\section{Fin(s) de la cryopolitique}

33 La perspective cryopolitique présentée ici que la tension existant entre le potentiel propre à la vie latente et l'anxiété générée par la mort inachevée doit être libérée, et ce, de deux façons possibles. Soit la vie latente des échantillons peut être utilisée pour produire un savoir profitable à ceux dont la matière biologique est dérivée, soit les échantillons doivent être conduits vers une mort satisfaisante.

Cette seconde possibilité s'accorde avec l'exemple des Yanomami, qui ont demandé le rapatriement des échantillons les concernant de manière à ce qu'ils puissent faire l'objet de rites funéraires. Les communautés ou les familles autochtones d'Australie pourraient également vouloir que les échantillons de sang congelé recueillis auprès d'un parent défunt leur soient retournés pour que le processus de leur mort, interrompu par la vie cryopolitique des échantillons, puisse être mené à son terme. Si de tels désirs et convictions sont exprimés par les communautés autochtones, il est possible que les échantillons leur soient retournés. En dehors du congélateur, l'état des échantillons se dégraderait rapidement, et ils seraient sans doute enterrés ou détruits.

Il est intéressant de noter que le rapatriement des échantillons d'une part, et leur autoclave par les scientifiques d'autre part ont le même résultat matériel: la dégradation ou la destruction des échantillons. La destruction des échantillons, que ce soit par les familles autochtones ou par les scientifiques, contrevient à l'impératif scientifique selon lequel la continuité des échantillons contenus dans les biobanques doit être assurée. Cependant, les deux modes de destruction prennent pour point de départ des états cryopolitiques très différents. Le fait de détruire les échantillons s'apparenterait, de la part des scientifiques, à une réaction défensive vis-à-vis de la limitation de leurs capacités d'accès à la vie latente, et une manière de faire face à la confusion et l'anxiété que cela engendre. Pour les communautés autochtones, la destruction des échantillons permettrait de mettre un terme à leur mort inachevée.

Une autre alternative émerge de la perspective cryopolitique que nous proposons: la vie latente des échantillons pourrait être réarticulée de manière à ce qu'elle soit perçue par les acteurs autochtones comme porteuse de possibilités avantageuses. Des intellectuels autochtones ont récemment manifesté leur intérêt pour les contributions potentielles de la génétique à la santé des populations autochtones. L'épigénétique suscite un intérêt particulier : elle montre comment les expériences de vie éprouvantes peuvent affecter l'expression des gènes sur le cours d'une vie et de plusieurs générations, et offre potentiellement à ce titre une base solide de démonstration en termes biologiques des traumatismes transgénérationnels (Bombay, Matheson et al. 2009 ; Hopkins 2011 ; Brockie, Heinzelmann et al. 2013) ${ }^{8}$. Les tenants de cette approche promeuvent l'idée d'utiliser les échantillons collectés au milieu du $\mathrm{XX}^{\mathrm{e}}$ siècle comme bases d'une recherche comparative sur les effets biologiques du traumatisme colonial à travers le temps et l'espace.

Ceci ferait à nouveau basculer les échantillons de la mort inachevée à la vie latente, mais une forme de vie latente radicalement reconfigurée. La vie latente des échantillons collectés au milieu du $\mathrm{XX}^{\mathrm{e}}$ siècle et conservés dans des congélateurs se fondait sur la possibilité qu'ils génèrent, dans un futur indéterminé, un savoir scientifique "encore inconnu", au service de conceptions occidentales de la vie humaine. Cette autre forme de vie latente correspondrait en revanche, du moins suivant le cadre d'analyse proposé, à une forme de vie distinctivement " autochtone ", 
tournée vers un avenir placé sous contrôle autochtone, lors duquel le potentiel des échantillons pourrait être utilisé pour examiner les effets des blessures du passé et leurs ramifications (Clifford 2013). Il est trop tôt pour savoir comment se dessinera cet avenir, et si les peuples autochtones se prononceront en faveur d'une mise à leur profit du potentiel des échantillons, ou en faveur de l'achèvement du processus de mort interrompu par la vie latente, ou bien encore s'ils pousseront la science à prendre en compte de nouvelles formes de vie.

Cette présentation donnée en anglais a été traduite par Lise Garond.

\section{BIBLIOGRAPHIE}

American Anthropological Association

2002 «El Dorado task force papers », Vol II.

Anderson, Warwick

2008 The collectors of lost souls : turning kuru scientists into whitemen. Baltimore, Johns Hopkins University Press.

Bombay Amy, Kim Matheson et al.

2009 «Intergenerational trauma : convergence of multiple processes among first nations peoples in Canada ", Journal of Aboriginal Health : 1-47.

Borofsky, Robert

2005 Yanomami : the fierce controversy and what we might learn from it. Berkeley, University of California Press.

Brockie, Teresa N., Morgan Heinzelmann et al.

2013 « A framework to examine the role of epigenetics in health disparities among Native Americans ", Nursing Research and Practice :1-9.

Brooks, Andrew

2013 « Optimizing bioprocessing and sample management strategies to achieve successful translational research and drug development ", ISBER Annual Meeting and Exhibits, Sydney Convention and Exhibition Centre (SCEC), Sydney, Australia, 2013.

Chrulew, Matthew

2011 « Managing love and death at the zoo : the biopolitics of endangered species preservation », Australian Humanities Review 50.

Clifford, James

2013 Returns : becoming indigenous in the twenty-first century. Cambridge, Harvard University Press.

Collins, K. J. et J. S. Weiner

1977 Human adaptability : a history and compendium of research in the international biological programme. Londres, Taylor \& Francis.

Coupaye, Ludovic

2016 « Yams as vernacular methodology? Approaching vital process through technical processes ", in Perig Pitrou, Ludovic Coupaye et Fabien Provost (éds.), Actes du colloque « Des êtres 
vivants et des artefacts : l'imbrication des processus vitaux et des processus techniques ", 9 et 10 avril 2014, musée du quai Branly, Paris. [https://actesbranly.revues.org/673].

Couzin-Frankel, Jennifer

2010 « Researchers to return blood samples to the Yanomamo », Science 328 (5983) : 1218.

Fforde, Cressida, Jane Hubert et P. Turnbull.

2002 The dead and their possessions : repatriation in principle, policy and practice. Londres, Routledge.

Fischer, Michael M.J.

2003 Emergent forms of life and the anthropological voice. Durham, Duke University Press.

Fortun, Mike

2008 Promising genomics : Iceland and deCODE Genetics in a world of speculation. Berkeley, University of California Press.

Foucault, Michel

Society must be defended : lectures at the Collège De France 1975-1976. New York, Picador.

Fox Keller, Evelyn

2000 The century of the gene. Cambridge, Harvard University Press.

Franklin Sarah et Margaret Lock (éds.),

2003 Remaking life and death : toward an anthropology of the biosciences. Santa Fe, School of American Research Press.

Friese, Carrie

2013 Cloning wild life : zoos, captivity, and the future of endangered animals. New York, NYU Press.

Harmon, Amy

2010 « Indian tribe wins fight to limit research of its DNA », New York Times April 22, 2010 : A1.

Helmreich, Stephan,

2009 Alien ocean : anthropological voyages in microbial seas. Durham, Duke University Press.

Helmreich, Stefan et Sylvia Roosth

2010 « Life forms : a keyword entry », Representations 112 (1) : 27-53.

Helmreich, Stefan

2011 « What was life ? Answers from three limit biologies », Critical Inquiry 37 (4) : 671-696.

Hopkins, Ruth

2011 « Epigenetics : scientific evidence of intergenerational trauma », Indian Country Today Media Network [http://indiancountrytodaymedianetwork.com/2011/11/26/epigenetics-scientificevidence-intergenerational-trauma]

Kakaliouras, Ann

2012 « An anthropology of repatriation », Current Anthropology 53 (S5) : S210-S221.

Kakaliouras, Ann et Joanna Radin

2014 « Archiving anthropos : tracking the ethics of collections across history and anthropology », Curator 57 (2) : 147-51.

Kay, Lily

2000 Who wrote the book of life? A history of the genetic code. Stanford, Stanford University Press.

Kowal, Emma, Joanna Radin et al.

2013 « Indigenous body parts, mutating temporalities, and the half-lives of postcolonial technoscience ", Social Studies of Science 43 (4) : 465-483. 
Landecker, Hannah

2005 « Living differently in time : plasticity, temporality and cellular biotechnologies », Culture

Machine vol. 7.

Landecker, Hannah

2007 Culturing life. Cambridge, Harvard University Press.

Nelkin, Dorothy et Susan Lindee

2004 The DNA mystique : the gene as a cultural icon. Ann Arbor, University of Michigan Press.

Parry, Bronwyn

2004 « Technologies of immortality : the brain on ice ", Studies in History and Philosophy of Biological and Biomedical Sciences 35 (2) : 391-413.

Pitrou, Perig

2016 « Êtres vivants/artefacts, processus vitaux/processus techniques : remarques à propos d'un cadran analytique ", in Perig Pitrou, Ludovic Coupaye et Fabien Provost (éds.), Actes du colloque "Des êtres vivants et des artefacts : l'imbrication des processus vitaux et des processus techniques ", 9 et 10 avril 2014, musée du quai Branly, Paris. [https://actesbranly.revues.org/653].

Radin, Joanna

2012 Life on ice : frozen blood and human biological variation in a genomic age, 1950-2010, thèse de doctorat, Université de Pennsylvanie.

Radin, Joanna

2013 « Latent life : concepts and practices of human tissue preservation in the international biological program », Social Studies of Science 43 (4) : 484-508.

Radin, Joanna

2014 « Unfolding epidemiological stories : how the WHO made frozen blood into a flexible resource for the future ", Studies in History and Philosophy of Biological and Biomedical Sciences 47 : 62-73.

Reardon, Jenny et Kim TallBear

2012 «'Your DNA is our history'«, Current Anthropology 53 (5) : s233-s245.

Rose, Deborah Bird

Non daté " Reflections on the zone of the incomplete ».

Rose, Nikolas

2001 " The politics of life itself », Theory, Culture and Society 18 (6) :1-30.

Rose, Nikolas

2007 « Molecular biopolitcs, somatic ethics and the spirit of biocapital », Social Theory and Health $5: 3-29$.

Smith, Linda Tuhiwai

2012 Decolonizing methodologies, research and Indigenous peoples. Londres et New York, Zed Books Ltd.

Squier, Susan Merrill

2004 Liminal lives : imagining the human at the frontiers of biomedicine. Durham, Duke University

Press.

Taussig, Karen-Sue, Klaus Hoeyer et al.

2013 « The anthropology of potentiality in biomedicine », Current Anthropology 54 (S7) : S3-S14. 
Tierney, Patrick

2001 Darkness in El Dorado : how scientists and journalists devastated the Amazon. New York, W. W. Norton \& Company.

van Dooren, Thom

2014 Flight ways : life and loss at the edge of extinction. New York, Columbia University Press.

Waldby, Cathy et Susan Merrill Squier

2003 « Ontogeny, ontology, and phylogeny : embryonic life and stem cell technologies »,

Configurations 11(1) : 27-46.

Worthington, Edgar Barton (éd.)

1975 The evolution of IBP.Cambridge, Cambridge University Press.

\section{NOTES}

1. Aborigènes et Insulaires du détroit de Torres sont les termes actuellement en usage pour désigner les peuples autochtones de ce qui est aujourd'hui la nation australienne. Ces termes sont dans cette présentation remplacés de façon interchangeable par l'autre terme couramment accepté de peuple « autochtone » [NdT : en anglais, «Indigenous». Les auteures soulignent que ce terme est en anglais marqué d'une majuscule, comme il est de rigueur dans cette langue pour les noms de peuple ayant valeur d'adjectifs; le mot est utilisé sans majuscule lorsqu'il désigne les peuples autochtones de manière plus générale, à l'échelle internationale].

2. Les consultations prennent place sous les auspices du Centre national pour la Génomique Autochtone (National Centre for Indigenous Genomics).

3. La question du rapatriement et de son impact sur les collections de musées a fait l'objet d'un numéro spécial de la revue Curator (Voir Kakaliouras et Radin 2014).

4. Le cas des Havasupai est un autre cas d'intérêt que nous ne pouvons pas évoquer ici par manque de place (Voir Harmon 2010).

5. La vie latente est un aspect d'un discours plus large sur la science comme source de potentialités futures. Voir notamment l'idée de Helmreich et Roosth (2010) selon laquelle les «formes vivantes » sont soumises à présent à une forme de raisonnement abductif. Dans la même veine, se référer au concept de génomique promissoire (Fortun 2008), et aux réflexions de Hoeyer, Taussig et Helmreich sur la potentialité (Karen-Sue Taussig, Klaus Hoeyer et al. 2013).

6. Comme l'a remarqué Anderson, les scientifiques pourraient être tout autant troublés par l'inaliénabilité inflexible des échantillons conservant des traces de la personne du donneur (Anderson 2008).

7. Nous ne concevons pas la vie latente et la mort inachevée comme deux états ontologiques strictement séparés, entre lesquels les échantillons évoluent, mais comme des "formes de vie » ainsi que nous l'avons précédemment expliqué. Les mêmes échantillons peuvent être simultanément considérés comme relevant de la vie latente par une personne ou un groupe, et comme relevant de la mort inachevée par d'autres.

8. L'une de nous-deux (EK) a entendu des leaders autochtones des États-Unis, du Canada, de Nouvelle-Zélande et d'Australie discuter des promesses de l'épigénétique lors de rencontres publiques, mais il n'existe encore que très peu de publications faisant état de cette idée. 


\section{RÉSUMÉS}

In the mid-twentieth century, scientists began to collect and freeze blood samples for a range of purposes. This article considers the broader implications of scientific freezing for time and life by drawing on interviews with scientists associated with a large collection of samples collected from Indigenous Australians in the 1960s. We first review some key critiques of cryopreservation posed by Indigenous scholars and by science and technology studies. We then propose "cryopolitics" as a concept to express the various political, ethical and temporal conundrums presented by the practice of freezing. We frame cryopolitics as a mode of Michel Foucault's biopolitics. If biopolitical assemblages make live and let die, cryopolitical ones reveal the dramatic consequences of mundane efforts to make live and not let die. In our case study, we argue that frozen blood vacillates between two cryopolitical states, "latent life" and "incomplete death". Samples seen as latent life contain infinite potential and cannot be destroyed; samples understood as incomplete death demand destruction.

\section{AUTEURS}

\section{EMMA KOWAL}

Emma Kowal is a Professor in the Faculty of Arts and Education, Deakin University. She is a cultural anthropologist who has previously worked as a medical doctor and public health researcher in Indigenous health settings. Her research interests include Indigenous-state relations, whiteness and anti-racism, race and science. Since 2007 she has been researching the use of genetics in Indigenous Australian communities. Her current project, supported by the Australian Research Council is an anthropological and historical study of Indigenous biospecimen collections. She is an editor of Postcolonial Studies journal and Convenor of the Asia-Pacific Science, Technology and Society Network. She is the author of Trapped in the gap: doing good in Indigenous Australia (Berghahn, 2015).

[emma.kowal [@] deakin.edu.au]

\section{JOANNA RADIN}

Joanna Radin received her PhD in History and Sociology of Science from the University of Pennsylvania. Her research examines the social and technical conditions of possibility for the systems of biomedicine and biotechnology that we live with today. She has particular interests in the history of biomedical technology, scientific collections, anthropology, public health, humanism, and research ethics. She is currently working on a book manuscript, tentatively titled Life on Ice: Frozen Blood and Biological Variation in a Genomic Age which tracks the rise of human tissue as a resource for remaking anthropology and population genetics after World War II. [joanna.radin [@] yale.edu] 